\title{
ANÁlise dA SEGURANÇA NO PROJETO DE ESTRUTURAS: MÉTODO DOS ESTADOS LIMITES
}

\author{
LEILA APARECIDA DE CASTRO
}

Dissertação apresentada à Escola de Engenharia de São Carlos, da Universidade de São Paulo, como parte dos requisitos para a obtenção do Título de Mestre em Engenharia de Estruturas.

ORIENTADOR: Prof. Dr. Maximiliano Malite

São Carlos

1997 
Class. TESE

Area : rongenhar a de Estruturas.

cutt. 1278

Tombo $T 130 / 97$

st 0934247

Ficha catalográfica preparada pela Seção de Tratamento

da Informação do Serviço de Biblioteca - EESC-USP

Castro, Leila Aparecida de
C355a Análise dà segurança no projeto de estruturas:

método dos estados limites / Leila Aparecida de

Castro. -- São Carlos, 1997.

Dissertação (Mestrado) -- Escola de Engenharia

de São Carlos-Universidade de São Paulo, 1997.

Área: Engenharia de Estruturas

Orientador: Prof. Dr. Maximiliano Malite.

1. Estruturas. 2. Estruturas de aço.

3. Segurança. 4. Confiabilidade. 5. Estados

limites. I. Título 
Aos meus pais, meus primeiros e grandes professores. 


\section{AGRADECIMENTOS}

Ao professor Maximiliano Malite pela orientação fornecida durante a elaboração deste trabalho.

À professora Maria Cecília M. Barreto do Laboratório de Estatística Aplicada do Departamento de Estatística da UFSCar ${ }^{1}$, pelo auxílio nos estudos estatísticos.

Aos meus irmãos Maria Helena, Cesar e Antonio Carlos pelo incentivo e apoio.

Ao meu noivo Flávio pelo constante apoio e compreensão.

Ao $\mathrm{CNPQ}^{2}$, pela concessão da bolsa de pesquisa no período de março de 1995 a março de 1996.

À $\mathrm{FAPESP}^{3}$, pela concessão da bolsa de pesquisa no período de abril de 1996 a fevereiro de 1997.

Às Amigas Cristina e Patrícia , amigos Daniel e Rivelli, pelo apoio e principalmente amizade.

A todos os colegas, professores e funcionários do Departamento de Engenharia de Estruturas da EESC/USP ${ }^{4}$ pelo companheirismo.

E principalmente a Deus que sempre me amparou e iluminou durante cada etapa da realização deste trabalho.

\footnotetext{
${ }^{1}$ Universidade Federal de São Carlos

${ }^{2}$ Conselho Nacional de Desenvolvimento Científico e Tecnológico

${ }^{3}$ Fundação de Amparo à pesquisa do Estado de São Paulo

${ }^{4}$ Escola de Engenharia de São Carlos da Universidade de São Paulo
} 


\section{SUMÁRIO}

LISTA DE FIGURAS ........................................................... i

LISTA DE TABELAS E QUADROS ............................................... iii

LISTA DE ABREVIATURAS E SIGLAS ................................... v

LISTA DE SÍMBOLOS.......................................................... vi

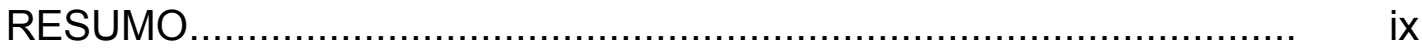

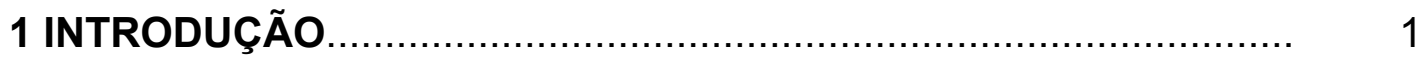

1.1 Avanços na engenharia estrutural.................................... 1

1.2 Segurança estrutural................................................... 4

1.3 A evolução das normas de cálculo................................... 7

1.4 A emergência de cálculo em estados limites......................... 10

1.5 Normas de cálculo em estados limites baseadas em probabilidade........................................................... 14

1.6 As normas em estados limites.......................................... 18

1.7 Perspectivas para o futuro em normas de cálculo estrutural...... 22

2 CONFIABILIDADE DE SISTEMAS DE ENGENHARIA ................. 26

2.1 Introdução................................................................ 26

2.2 Análise e verificação de confiabilidade..................................... 27

3 CRITÉRIO DE CÁLCULO BASEADO EM PROBABILIDADE......... 58

3.1 Critério de cálculo.......................................................... 58

3.2 Métodos de segundo momento....................................... 61

4 COEFICIENTES DE CÁLCULO PARA AS NORMAS EM ESTADOS LIMITES............................................................ 65

4.1 Introdução.................................................................. 65

4.2 Análise dos níveis de confiabilidade do cálculo em tensões 


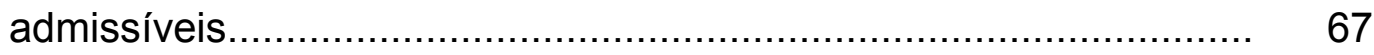

4.3 Calibração dos coeficientes de cálculo dos estados limites........ 76

5 EXEMPLOS

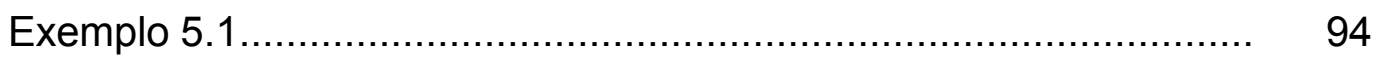

Exemplo 5.2

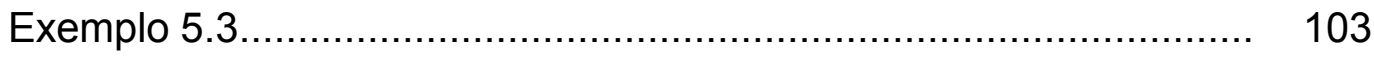

6 CONCLUSÕES E COMENTÁRIOS FINAIS ................................... 107

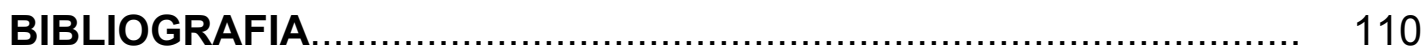




\section{LISTA DE FIGURAS}

Figura 1.1 - Funções de distribuição das solicitações e resistência.......... 6

Figura 1.2 - Evolução do peso de uma estrutura ao longo do tempo........ 8

Figura 2.1 - Funções densidade de probabilidade $f_{\mathrm{X}}(\mathrm{x})$ e $f_{\mathrm{Y}}(\mathrm{Y}) \ldots \ldots \ldots \ldots . \quad 30$

Figura 2.2a - Efeito da posição relativa entre $f_{\mathrm{X}}(\mathrm{x})$ e $f_{\mathrm{Y}}(\mathrm{Y})$ em $\mathrm{p}_{\mathrm{F}} \ldots \ldots \ldots . . . .31$

Figura 2.2b - Efeito das dispersões de $f_{\mathrm{X}}(\mathrm{x})$ e $f_{\mathrm{Y}}(\mathrm{Y})$ em $\mathrm{p}_{\mathrm{F}} \ldots \ldots \ldots \ldots \ldots \ldots . . . . . . .32$

Figura 2.3 - Função densidade de probabilidade da margem de

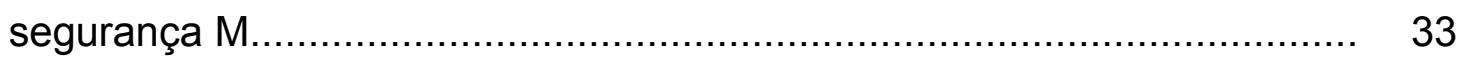

Figura 2.4 - Função densidade de probabilidade do fator de segurança $\Theta$....... 36

Figura 2.5 - Espaço das variáveis reduzidas $X^{\prime}$ e $Y^{\prime}$............................ 38

Figura 2.6-Estados de segurança e falha no espaço de variáveis reduzidas............................................................... 40

Figura 2.7 - Superfície estado limite no espaço tridimensional X' ${ }_{1}, X_{2}{ }_{2}, X^{\prime}{ }_{3} \quad 46$

Figura 2.8 - Rotação das coordenadas X' para Y.............................. 53

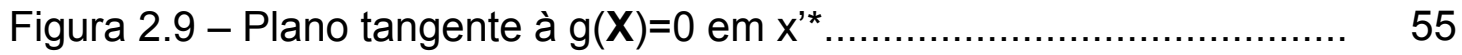

Figura 2.10 - Implicações de várias superfícies de falha...................... 57

Figura 3.1 - Projetos correspondentes a diferentes superfícies de falha... 64

Figura 4.1 - Índices de confiabilidade para vigas de aço calculadas em tensões admissíveis............................................................... 74

Figura 4.2 - Índice de confiabilidade para elementos de aço - ação gravitacional mais ação do vento....................................................... 76

Figura 4.3 - Índice de confiabilidades para elementos de aço e concreto armado - ações atuando em sentidos contrários.

Figura 4.4 - Coeficientes de ponderação das ações e resistência para vigas de aço.

Figura 4.5 - Índice de confiabilidade para vigas de aço usando ações fatorados individualmente. 
Figura 4.6-Valores de $\phi$ para valores alvos dos índices de confiabilidade...

Figura 4.7 - Gamas de valores $\beta$ para $\phi=0,9 .$. 


\section{LISTA DE TABELAS E QUADROS}

Tabela 1.1 - Fatores básicos de segurança em cem anos de evolução em cálculo de estruturas de aço

Tabela 1.2 - Tensões de escoamento do aço carbono mais utilizado em cem anos de evolução da construção metálica.

Tabela 1.3 - Número de páginas da especificação do AISC.

Tabela 1.4 - Economia em projeto de aço - 1923 - 1986.

Tabela 1.5 - Valores alvos para os índices de confiabilidade da norma A58.1 ANSI

Tabela 2.1 - Relação quantitativa entre probabilidade de falha e índice de confiabilidade.

Tabela 2.2 - Comparação de probabilidades de falha calculadas.

Tabela 4.1 - Resumo dos dados estatísticos de resistência (GALAMBOS, 1982).

Tabela 4.2 - Resumo de dados estatísticos das ações (GALAMBOS, 1982)

Tabela 4.3 - Resumo de confiabilidades associadas às antigas normas de cálculo. 75

Tabela 4.4 - Casos analisados por ROSOWSKY, 1994.

Tabela 4.5 - Confiabilidades de vigas de aço em tensões admissíveis.

Tabela 4.6 - Coeficientes de ponderação das ações requeridos - uma ação atuando.

Tabela 4.7 - Pesos para combinações das ações $(D+L)$ e (D+S)

Tabela 4.8 - Valores ótimos para os coeficientes de ponderação das ações e de resistência para ações gravitacionais.

Tabela 4.9 - Coeficientes de ponderação das ações e de resistência para as ações gravitacionais atuando com ação do vento.

Tabela 4.10 - Variações de $\beta$ para valores típicos de $\phi$ $\left(\bar{R} / R_{n}=1,10 ; V_{R}=0,15\right)$ 
Tabela 4.11 - Índices de confiabilidade $\beta$ de vigas de aço para vários valores de $\phi$

Tabela 5.1 - Resultados das iterações necessárias para o cálculo de $\beta$ 102 Tabela 5.2 - Resultados das iterações para o cálculo dos coeficientes de cálculo. 108

Quadro 1.1 - Condições de segurança das primeiras normas de cálculo em estados limites. 


\title{
LISTA DE ABREVIATURAS E SIGLAS
}

\author{
AASHTO - American Association of State Highway and Transportation \\ Officials \\ $\mathrm{ACl} \quad-$ American Concrete Institute \\ AISC - American Institute of Steel Construction \\ AISI - American Iron and Steel Institute \\ ASCE - American Society of Civil Engineers \\ CEB - Comite Euro-International Du Beton \\ COV - Coeficiente de Variação \\ CSA - Canadian Standards Association \\ FORM - First Order Reliability Method \\ FOSM - First Order Second Moment \\ LRFD - Load and Resistance Factor Design \\ LSD - Limit States Design \\ NBR - Norma Brasileira Registrada \\ SORM - Second Order Reliability Method
}




\section{LISTA DE SÍMBOLOS}

\begin{tabular}{|c|c|}
\hline $\mathrm{A}_{\mathrm{T}}$ & Área de influência de um elemento submetido a ação variável \\
\hline$[\mathrm{C}]$ & Matriz covariância \\
\hline $\operatorname{Cov}\left(X_{i}, X_{j}\right)$ & Covariância entre os pares de variáveis $X_{i}$ e $X_{j}$ \\
\hline $\mathrm{D}$ & $\begin{array}{l}\text { Distância de um ponto } X^{\prime}=\left(X_{1}^{\prime}, X_{2}^{\prime}, \ldots, X_{n}^{\prime}\right) \text { na superfície de } \\
\text { falha } g(X)=0 \text { à origem de } X^{\prime}\end{array}$ \\
\hline$\overline{\mathrm{D}}$ & Valor médio da ação permanente \\
\hline d & Distância da linha de falha à origem 0 \\
\hline $\mathrm{D}_{\mathrm{n}}$ & Valor nominal da ação permanente \\
\hline$f_{K}$ & Resistência característica do material \\
\hline$f_{m}$ & Resistência média do material \\
\hline FS & Fator de segurança \\
\hline$f_{\mathrm{X}}(\mathrm{X})$ & Função densidade de probabilidade da variável $x$ \\
\hline$f_{\mathrm{X}, \mathrm{Y}}(\mathrm{X}, \mathrm{Y})$ & Função densidade de probabilidade conjunta das variáveis $\mathrm{x}$ e y \\
\hline$F_{X}(X)$ & Função de distribuição de probabilidade da variável x \\
\hline G & Vetor gradiente \\
\hline$g(X)$ & Função de desempenho ou função estado \\
\hline $\mathrm{L}$ & Ação variável de ocupação ou sobrecarga \\
\hline $\mathrm{L}_{0}$ & Sobrecarga sem redução especificada pelo ANSI A58.1, 1972 \\
\hline$\overline{\mathrm{L}}$ & Valor médio da sobrecarga \\
\hline$L_{n}$ & Valor nominal da sobrecarga \\
\hline$p_{F}$ & Probabilidade de falha \\
\hline$p_{S}$ & Probabilidade de sucesso \\
\hline$Q_{n}$ & Ação ou efeito nominal \\
\hline Q & Ação em geral ou efeito desta ação \\
\hline $\mathrm{R}$ & Resistência da estrutura ou elemento estrutural \\
\hline $\mathrm{R}_{\mathrm{K}}$ & Resistência característica do material \\
\hline $\bar{R}$ & Valor médio da resistência \\
\hline
\end{tabular}




\begin{tabular}{|c|c|}
\hline $\mathrm{R}_{\mathrm{n}}$ & Valor nominal da resistência \\
\hline S & Ação ou solicitação em uma estrutura ou elemento estrutural \\
\hline$S_{m}$ & Solicitação média \\
\hline $\mathrm{S}_{\mathrm{K}}$ & Solicitação característica \\
\hline$\overline{\mathrm{S}}$ & Valor médio da ação da neve \\
\hline$S_{n}$ & Valor nominal da ação da neve \\
\hline $\mathbf{T}$ & Matriz de transformação ortogonal \\
\hline u & Parâmetro da distribuição extremo tipo I \\
\hline$v_{x}$ & Coeficiente de variação da variável $X$ \\
\hline W & Ação do vento \\
\hline$\overline{\mathrm{W}}$ & Valor médio da ação do vento \\
\hline $\mathrm{W}_{\mathrm{n}}$ & Valor nominal da ação do vento \\
\hline $\mathbf{x}$ & Vetor de variáveis básicas de cálculo do problema \\
\hline$X^{\prime}$ & Vetor de variáveis reduzidas \\
\hline$X^{\prime *}$ & Ponto de falha mais provável \\
\hline$X^{\prime}$ & Variável reduzida \\
\hline$\Phi(\mathrm{X})$ & $\begin{array}{l}\text { Função de distribuição de probabilidade para variáveis normais } \\
\text { reduzidas }\end{array}$ \\
\hline$\alpha$ & Parâmetro da distribuição extremo tipo I \\
\hline$\alpha_{1}^{*}$ & Co-seno diretor do ponto de falha $x_{i}^{*}$ \\
\hline$\beta$ & Índice de confiabilidade \\
\hline$\delta x$ & Coeficiente de variação da variável $x$ \\
\hline$\phi$ & Coeficiente de resistência \\
\hline$\gamma_{s}$ & Coeficiente de segurança aplicado às ações ou solicitações \\
\hline$\gamma_{f}$ & Coeficiente de ponderação das ações \\
\hline$\gamma_{\mathrm{m}}$ & Coeficiente do material \\
\hline$\lambda$ & Média de $\ln (\mathrm{x})$, sendo $\mathrm{x}$ uma variável log-normal \\
\hline$\mu_{\mathrm{x}}^{\mathrm{N}}$ & Valor médio da distribuição normal equivalente para a variável x \\
\hline$\mu_{\mathrm{x}}$ & Média da variável $\mathrm{x}$ \\
\hline$\rho x_{i}, X_{j}$ & Coeficiente de correlação entre o par de variáveis $X_{i}$ e $X_{j}$ \\
\hline . & Relação entre o valor nominal e o valor médio de uma variável \\
\hline
\end{tabular}


$\sigma_{\mathrm{x}} \quad$ Desvio padrão da variável $\mathrm{x}$

$\sigma_{x}^{N} \quad$ Desvio padrão da distribuição normal equivalente da variável $x$

$\psi \quad$ Fator de combinação das ações ou fator probabilidade

$\zeta \quad$ Desvio padrão de $\ln (\mathrm{x})$, sendo $\mathrm{x}$ uma variável log-normal

$\Theta \quad$ Coeficiente de segurança 


\title{
RESUMO
}

\section{ANÁLISE DA SEGURANÇA NO PROJETO DE ESTRUTURAS: MÉTODO DOS ESTADOS LIMITES}

\begin{abstract}
Este trabalho aborda a introdução da segurança baseada em métodos probabilísticos, aplicados nos cálculos em estados limites, apresentando informações com o objetivo de esclarecer o meio técnico em geral a respeito dos fundamentos teóricos e das vantagens que tal método apresenta frente ao tradicional método das tensões admissíveis. Apresentase ainda alguns exemplos de cálculo, mostrando a determinação do índice de confiabilidade e dos coeficientes adotados no método dos estados limites, os quais são calibrados em relação aos tradicionais coeficientes de segurança do método das tensões admissíveis.
\end{abstract}

Palavras-chave: estruturas, estruturas de aço, segurança, confiabilidade, estados limites 


\section{ABSTRACT}

\section{SAFETY IN THE STRUCTURAL DESIGN: LIMIT STATES DESIGN}

This work is about structural safety based in the probabilistic methods, applied in the structural design at limit states. Informations about theoretical background and advantages that this method shows related to traditional allowable stress design method are presented. In addition, some examples are presented, showing the determination of the reliability index and limit states factors, which are adjusted to original safety factors of the allowable stress design method.

Keywords: structures, steel structures, structural safety, reliability, limit states. 


\section{CAPÍTULO 1 - INTRODUÇÃo}

\section{1) Avanços na engenharia estrutural}

A década de 90 do século dezenove foi um período de progressos na construção de edifícios de aço, com o amadurecimento de muitos sistemas estruturais, métodos de cálculo e tecnologia, por exemplo, tecnologia de solda, construção composta aço-concreto, cálculo de estruturas sismo-resistentes, pontes estaiadas, edifícios altos, estruturas de concreto de alta resistência, e muito mais. Estes avanços na construção de edifícios, é claro, não ocorrem isoladamente.

Desenvolvimentos paralelos na ciência dos materiais, mecânica aplicada, metalurgia, matemática, ciências da computação, química, física, e em muitos outros campos fizeram do século vinte talvez o mais excitante para todos os cientistas e engenheiros.

As forças estimulantes destas mudanças são muitas, e seria presunçoso tentar enumerá-las neste trabalho. No entanto, é importante destacar que o aparecimento e evolução das normas técnicas direcionaram a construção civil, estabelecendo "regras" a serem cumpridas pelos projetistas e construtores. 
O período de 1950-1990 foi um tempo de alimentação e realização da engenharia estrutural. Pode-se considerar quatro causas que interagiram para produzir o grande avanço em construção de edifícios durante tal período: idéias, pesquisa, regulamentação e prática.

Por trás de todo progresso há idéias seminais que fazem os avanços possíveis. Entre as teorias que amadureceram neste período podem-se mencionar as seguintes:

- teoria da plasticidade (William Prager);

- teoria da confiabilidade (Alfred Freudenthal);

- análise em elementos finitos (Raymond Clough);

- teoria da elasticidade (F. R. Shanley);

- análise dinâmica (Nathan Newmark);

Os nomes entre parênteses são os que melhor representam cada idéia. Suas idéias precederam e fizeram possíveis os grandes desenvolvimentos de pesquisas em engenharia estrutural durante este período, estando estas pesquisas concentradas naturalmente, não exclusiva, mas predominantemente, nos maiores laboratórios de pesquisa em engenharia estrutural do mundo. Os avanços foram incentivados pelos desenvolvimentos de equipamentos de ensaio, de aquisição de dados e tecnologia computacional e, os resultados das pesquisas foram muitos.

Buscou-se entender bem a resistência última das estruturas sob carregamentos estáticos e dinâmicos. Este entendimento foi então aplicado na prática de uma forma direta para um projeto específico ou em normas de cálculo.

O crescimento da pesquisa em comportamento não linear de estruturas, em análise computacional, projeto ótimo (otimização), análise e cálculo probabilístico também se mostrou intenso. Em particular, a pesquisa na aplicação de métodos estocásticos tem representado, neste tema, um dos mais proveitosos esforços de pesquisa dos últimos quarenta anos. Esta foi, certamente, uma época de ouro da pesquisa em projeto e construção de edifícios. 
A terceira componente de progresso durante este século foi a emergência de normas que regulamentam o cálculo e a construção de edifícios e outras estruturas. No século passado, a construção era feita de acordo com a experiência e a perícia do construtor. Com a proliferação de estruturas, depois do avanço da tecnologia do concreto e do aço, por volta da metade do século, ficou evidente que deveria existir controle para que falhas causadas pelo mal funcionamento estrutural fossem minimizadas. Como resultado, códigos e normas começaram a ser desenvolvidos sendo que, por volta da virada do século até 1920 , um conjunto destas normas estava disponível para a maioria dos tipos de construção.

Os grandes avanços em normas durante os últimos 40 anos foram:

- a ênfase no controle e garantia de qualidade no escritório de cálculo, na fábrica e na obra;

- a emergência de métodos de introdução da segurança baseados em probabilidade;

- a mudança do método de introdução da segurança, de tensões admissíveis para estados limites;

- a progressiva internacionalização do processo de elaboração de normas, como por exemplo, os códigos europeus (EUROCODE).

A componente final de progresso está, naturalmente, na prática da construção de edifícios e outras estruturas. Freqüentemente o desenvolvimento de normas e pesquisas são precedidos por desenvolvimentos práticos. Um caso em destaque é o uso de construção composta aço-concreto antes que se tivesse uma avaliação mais precisa da resistência última de tais sistemas.

O papel das normas de cálculo é garantir a segurança de todas as estruturas construídas sob sua jurisdição. A função do calculista é então criar uma estrutura que atenda às exigências mínimas das normas para a segurança e que seja ao mesmo tempo prática e econômica. É necessário que a norma dê atenção à praticidade e à economia, mas sua principal função é a garantia da segurança. 
A segurança estrutural pode ser definida pelas duas declarações seguintes:

- não haver colapso ou outra má função estrutural durante a construção;

- não haver danos sérios à estrutura ou seus componentes, nem provocar qualquer trauma físico ou psicológico para seus ocupantes durante a vida útil da estrutura, como um resultado de eventos extraordinários que podem ser esperados para ocorrer em intervalos raros;

Calculistas estruturais, guiados pelas normas de cálculo e por sua perícia e experiência, são cobrados pela sociedade para assegurar tais condições de segurança.

\section{2) Segurança estrutural}

Projetos sempre foram realizados sob condições de incertezas quanto às ações e resistência e, as estruturas sempre foram projetadas para resistir a ações maiores do que as realmente esperadas. Historicamente havia dois métodos básicos de se impor esta condição de resistência maior do que as solicitações:

(1) Projeto em ações últimas, em que a ação total é majorada por um coeficiente de segurança e o projetista demonstra que a estrutura ou elemento estrutural considerado pode suportar esta ação majorada. Simbolicamente, isto pode ser expresso por:

$$
\gamma_{S} S \leq R
$$

onde:

$\gamma_{S}$ é um coeficiente de segurança aplicado ao carregamento $S$ é o carregamento (ações ou solicitações) na estrutura 
$R$ é a resistência da estrutura

(2) Projeto em tensões admissíveis, em que a tensão do material é limitada por alguma fração de sua tensão de falha e o projetista demonstra que, sob o carregamento esperado ou especificado, a tensão alcançada não excede o valor admissível. Isto tem sido expresso simbolicamente por:

$$
\mathrm{S} \leq \mathrm{R} / \gamma_{\mathrm{m}}
$$

onde:

$\gamma_{m}$ é um coeficiente de segurança aplicado à tensão última do material

A equação 1.1 poderia tratar com diferentes níveis de incerteza das várias ações atuantes na estrutura, aplicando-se coeficientes distintos a cada uma destas ações. Analogamente a equação 1.2 pode representar também o caso onde dois ou mais materiais diferentes são utilizados, como por exemplo o concreto armado, aplicando coeficientes diferentes nas tensões últimas do aço e concreto, de acordo com o grau de incerteza associado a cada resistência respectivamente.

Do argumento anterior percebe-se um passo óbvio para combinar estas duas aproximações para introdução da segurança nas estruturas, que seria a introdução de coeficientes de segurança separados em cada tipo de ação e em cada material usado, sendo esta a aproximação adotada pelo novo método de introdução da segurança que surgiria, o cálculo em estados limites.

Além disto, já se havia percebido também a possibilidade de se quantificar probabilisticamente algumas das incertezas associadas a um projeto estrutural. Vale comentar que o conceito de que uma aproximação probabilística poderia fornecer uma forma razoável para definir os coeficientes de segurança não era novo quando o método dos coeficientes parciais de segurança foi criado e, foi somente natural que a possibilidade de definir estes coeficientes por meios estatísticos deveria ser considerada. 
É importante ressaltar ainda que o método dos coeficientes parciais é a ferramenta utilizada para a aplicação do princípio dos estados limites, ou seja, os estados limites de cada projeto específico são verificados com a aplicação de coeficientes de cálculo individuais a cada variável do problema (coeficientes parciais).

As duas maiores causas de mau funcionamento estrutural são aquelas quantificáveis por teoria probabilística racional e aquelas devidas a causas irracionais.

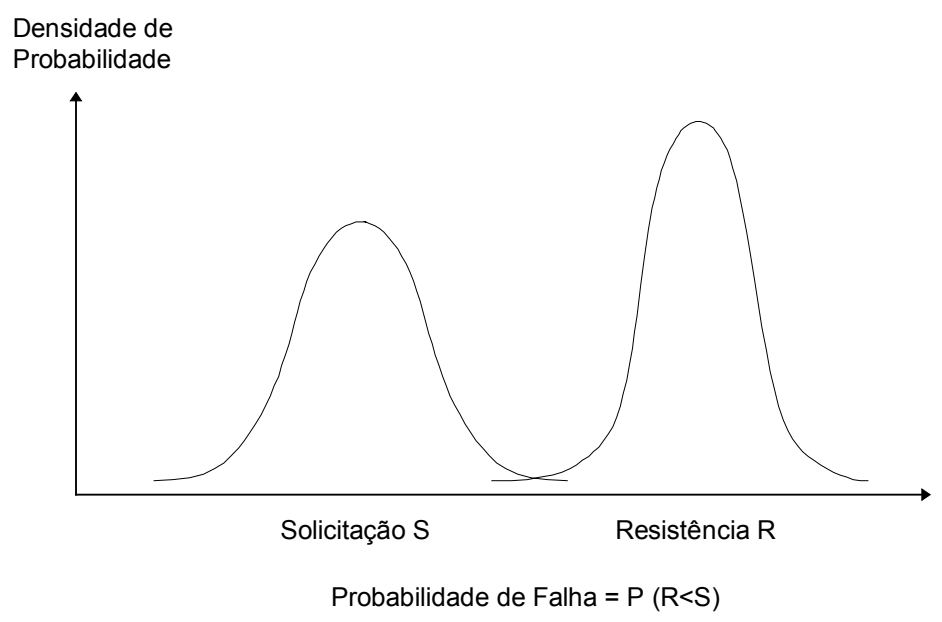

Figura 1.1: Funções de distribuição das solicitações e resistência.

As causas quantificáveis são as coincidências de resistência excepcionalmente baixa e ações excepcionalmente altas (figura 1.1). Estes são os domínios de normas de cálculo estrutural, e eles afetam os valores dos coeficientes que fornecem as margens de segurança, por exemplo fatores de segurança, coeficientes de ponderação das ações, coeficientes de resistência, etc.

As causas irracionais de falha são relacionadas a erro humano. Embora tenha havido vários esforços para quantificar alguns aspectos do erro humano, as principais formas de evitar tal erro são: controle de qualidade no escritório de cálculo e local de construção, educação, desincentivos aos erros (leis e punições), e apontamento de honestidade e 
integridade de todos os participantes do processo. A maioria das falhas de estruturas são causadas por erro humano e a fuga de tais erros é uma importante atividade dentro do processo de construção.

\section{3) A evolução das normas de cálculo}

Espera-se que as normas de cálculo forneçam as exigências mínimas para estruturas seguras.

A evolução esquemática das normas de cálculo é ilustrada na figura 1.2, onde o peso da estrutura, refletindo um aspecto do custo da construção, é plotado versus o tempo. Quando uma certa estrutura é usada pela primeira vez, ela em geral resulta pesada, pois há falta de experiência e confiança. Se experiências bem sucedidas são conseguidas, os calculistas ficam mais confiantes e o peso tende a cair. Esta tendência às vezes continua até ocorrer uma falha, em reação, as exigências de peso aumentam novamente, muitas vezes mais do que o necessário. O peso eventualmente decresce gradualmente até que um nível de cálculo satisfatório, testado com o tempo, seja alcançado.

Pode-se apontar muitos exemplos deste processo evolutivo. Um deles é a evolução do enrijecimento da estrutura das pontes pênseis e estaiadas, onde a tendência para sistemas mais e mais leves foi dramaticamente parada pelo famoso desastre da Ponte Tacoma Narrows. Outro exemplo mais recente é a série de falhas de construção de pontes de vigas caixão de aço de paredes delgadas, de 1969 a 1970, apontadas pela necessidade de incluir alguns parâmetros negligenciados anteriormente, a saber, o empenamento inicial de chapas no cálculo de tais pontes.

O processo descrito pelo esquema da figura 1.2 é lento, caro e algumas vezes até mesmo trágico. Muitas das pesquisas em cálculo 
probabilístico têm-se focalizado no alívio destas demoras e no desenvolvimento de esquemas de calibração de normas que permitam evolução mais rápida de otimização.

O processo de evolução de normas em cálculo estrutural de aço é ilustrado nos dados apresentados nas tabelas 1.1 a 1.4 . A tabela 1.1 lista os fatores básicos de segurança utilizados pela prática de cálculo de aço nos Estados Unidos. O fator de segurança recomendado há 100 anos foi 2,0, proposto pelo professor Dubois da Universidade de Harvard em seu livro de 1890 sobre cálculo de estruturas de aço. Em 1918 o manual "Ketchum" reduziu o fator para 1,72. Na primeira edição da especificação para o cálculo, fabricação e montagem de estruturas de aço para edifícios, do AISC, em 1923, o fator foi 1,83. Contudo, pela metade de 1930 o fator fica igual a 1,65 e, a partir da metade do século passado permaneceu essencialmente naquele nível. Meio século de evolução produziu assim um nível aceitável de confiabilidade com relação aos tipos de estruturas calculadas pela especificação AISC (GALAMBOS, 1990).

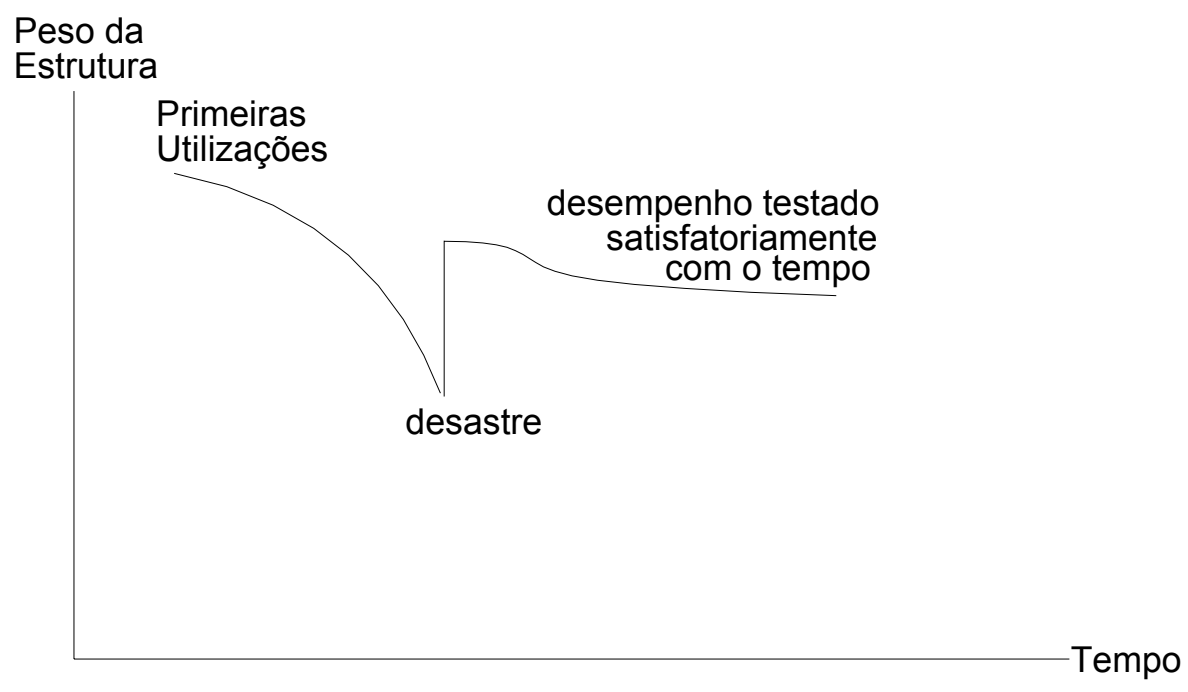

Figura 1.2: Evolução do peso de uma estrutura ao longo do tempo

A tabela 1.2 ilustra a flutuação da tensão de escoamento do aço carbono mais utilizado nas respectivas épocas. O limite de escoamento 
convencional deste parâmetro do material subiu cerca de $30 \%$ no período de 1890-1990.

Tabela 1.1: Fatores básicos de segurança em cem anos de evolução em cálculo de estruturas de aço

\begin{tabular}{|l|r|}
\hline Dubois, 1890 & 2,00 \\
\hline Ketchum, 1918 & 1,72 \\
\hline AISC, $1923-1936$ & 1,83 \\
\hline AISC, $1936-1963$ & 1,65 \\
\hline AISC, 1963 em diante & $5 / 3 \cong 1,67$ \\
\hline
\end{tabular}

Tabela 1.2: Tensões de escoamento do aço carbono mais utilizado em cem anos de evolução da construção metálica

\begin{tabular}{|l|l|}
\hline Dubois, 1890 & $197 \mathrm{MPa}$ \\
\hline Ketchum, 1918 & $190 \mathrm{MPa}$ \\
\hline AISC, 1923-1963 & $228 \mathrm{MPa}$ \\
\hline AISC, 1963 em diante & $248 \mathrm{MPa}$ \\
\hline
\end{tabular}

Além das mudanças no fator de segurança e nas propriedades dos materiais, há também uma grande mudança na "sofisticação" dos processos de cálculo. A tabela 1.3 ilustra isto mostrando o aumento drástico do número de páginas na especificação AISC através dos anos. A primeira edição foi um mero livro de bolso com 15 páginas, ao passo que a edição de 1986 possui 219 páginas (GALAMBOS, 1990).

Tabela 1.3: Número de páginas da especificação do AISC

\begin{tabular}{|c|c|c|c|c|}
\hline Ano & Especificação & Apêndices & Comentários & Total \\
\hline 1923 & 15 & 0 & 0 & 15 \\
\hline 1928 & 16 & 0 & 0 & 16 \\
\hline 1936 & 19 & 0 & 0 & 19 \\
\hline 1949 & 30 & 0 & 0 & 30 \\
\hline 1963 & 55 & 42 & 37 & 134 \\
\hline 1969 & 62 & 51 & 45 & 158 \\
\hline 1978 & 65 & 34 & 63 & 162 \\
\hline 1986 & 86 & 50 & 83 & 219 \\
\hline
\end{tabular}


A tabela 1.4 mostra que as estruturas em 1986 são muito mais leves (neste exemplo particular, 40\%) do que em 1923. Tem-se assim sentido um decréscimo no fator de segurança e um aumento na resistência dos materiais, resultando em maior economia.

À partir de 1960 duas correntes poderosas de mudança no cálculo estrutural começaram a se fazer sentir: a emergência de cálculo em estados limites e a idéia de que os parâmetros de cálculo podem ser racionalmente quantificados através da teoria de probabilidade.

Tabela 1.4: Economia em projeto de aço - 1923-1986

$\mathrm{p}($ permanente $)=\mathrm{p}($ variável $)=21,9 \mathrm{kN} / \mathrm{m}$

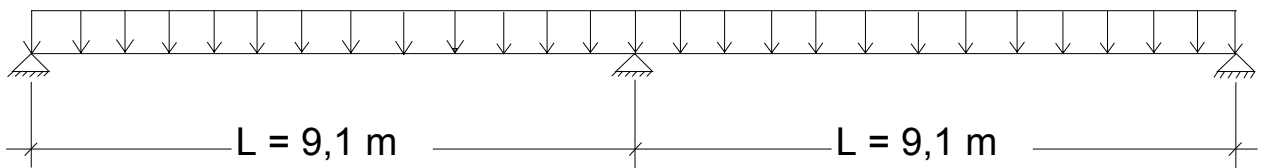

Aço Carbono, perfil compacto

\begin{tabular}{|c|c|}
\hline Ano & Perfil \\
\hline 1923 & W $27 \times 94$ \\
\hline 1936 & W $27 \times 94$ \\
\hline 1948 & W $24 \times 76$ \\
\hline 1963 & W $21 \times 62$ \\
\hline 1969 & W $24 \times 55$ \\
\hline 1978 & W $24 \times 55$ \\
\hline 1986 & W $24 \times 55$ \\
\hline
\end{tabular}

\section{4) A emergência de cálculo em estados limites}

O método de cálculo estrutural tradicional que dominou a maioria do século vinte foi o método de cálculo em tensões admissíveis. Ele teve origem na metade do século anterior quando os princípios de métodos 
viáveis de análise linear elástica foram formulados, o que levou convenientemente ao cálculo de tensões.

No método das tensões admissíveis a estrutura é investigada sob ações de trabalho (nominais), impondo-se que uma tensão admissível não seja excedida. As ações de trabalho são as máximas ações esperadas para o tempo de vida útil da estrutura. As tensões resultantes são calculadas admitindo comportamento elástico e linear. A tensão admissível é uma fração de alguma tensão limitante, tal como a tensão de escoamento ou a tensão crítica de flambagem. A relação da tensão limitante para a tensão admissível é denominada fator de segurança (ver tabela 1.1). Este fator prevê a possibilidade de ocorrência de valores desfavoráveis das ações e propriedades dos materiais, assim como as incertezas do modelo teórico. Os valores dos fatores de segurança representam o juízo e experiência coletiva da atividade do cálculo estrutural.

O cálculo em tensões admissíveis é um método de cálculo muito atrativo, é fácil de usar do ponto de vista computacional e é de fácil compreensão. O calculista verifica que a estrutura é segura sob ações que são fixadas em valores altos, usando uma tensão admissível substancialmente abaixo de um valor limitante. O método assegura que sob condições extremas de carregamento, que podem ser verificadas facilmente, a estrutura responde elasticamente. Não há problemas com a presença de múltiplas ações, podendo haver a superposição de efeitos. Assegurando a não superação de uma tensão admissível elástica, a maioria dos problemas de utilização são também levados em conta automaticamente.

Se tem-se um método tão prático, por que a mudança? Inicialmente, o método de cálculo em tensões admissíveis dá pouca informação sobre a capacidade real da estrutura. Para diferentes tipos de estruturas, a relação da ação limite baseada em tensões admissíveis para a resistência última é até certo ponto variável. Isto é especialmente verdade para estruturas indeterminadas estaticamente. Para muitas estruturas (por exemplo estruturas de concreto armado), a suposição de linearidade entre tensões e 
deformações, esforços e ações, não é muito realista até mesmo sob níveis de ação de trabalho. No começo deste século, ficou também evidente para muitos engenheiros, que o método de tensões admissíveis não foi uma ferramenta de cálculo muito econômica. Isto levou ao desenvolvimento de métodos de cálculo plástico para estruturas de aço no período de 1940 a 1950. Outros pesquisadores começaram a perceber a possibilidade de quantificar os juízos e incertezas que são a base dos fatores de segurança, usando teoria de probabilidade.

Fora destas várias raízes tais como, teoria de probabilidade, de plasticidade e pesquisa extensa do comportamento de resistência última de vários tipos de estruturas e conexões, surgiu a primeira geração de normas de cálculo baseadas na capacidade última e, eventualmente, conhecidas como normas de cálculo em estados limites.

As primeiras normas de cálculo em estados limites aprovadas nos Estados Unidos foram a Strength Design Code do American Concrete Institute $(\mathrm{ACl})$ e as prescrições para o cálculo plástico da especificação do AISC. Ambas apareceram nos primeiros anos da década de 60. Os desenvolvimentos em cálculo e as evoluções de normas em outras partes do mundo são semelhantes, exceto para os detalhes peculiares à situação dada e para o tempo de elaboração destas normas. Assim, em cálculo de estruturas de aço nos Estados Unidos, a primeira norma em estados limites foi a especificação do AISC para cálculo plástico, que foi emitida sob uma forma preliminar em 1959, relançada em 1961 e, tornou-se uma parte da especificação oficial do AISC em 1963. Ela não foi aprovada como uma especificação única, mas foi anexada como Parte 2 de uma norma de aço geral, que teve como sua primeira parte uma especificação de cálculo em tensões admissíveis. O calculista assim tinha escolha para usar o cálculo plástico onde este fosse apropriado, ou usar o cálculo em tensões admissíveis se este fosse o indicado. 
No entanto, a Parte 1 da especificação AISC 1963 não foi realmente um verdadeiro método de cálculo em tensões admissíveis. A especificação AISC 1963 foi um documento inteiramente novo, tendo pouca semelhança com a anterior (1949). Ela incorporou muitos dos resultados da pesquisa em aço realizada na Universidade de Lehigh nos anos 50, por exemplo, uma nova curva de flambagem para coluna, regras de esbeltez, resistência pósflambagem de vigas esbeltas, novos critérios para conexão, etc. $\mathrm{Na}$ realidade, então, ambas as partes desta especificação tinham critérios de estados limites. Uma parte teve o formato de cálculo em estados limites explícito e a outra mascarou-se na forma de cálculo em tensões admissíveis. A parte 1 teve como estados limites a formação da primeira rótula plástica (incluindo alguma redistribuição de força), instabilidades locais ou globais dos elementos e da estrutura como um todo. A obtenção de um mecanismo plástico foi o limite de utilização para a Parte 2. Dois coeficientes de ponderação das ações foram usados em ambas as partes, e estes foram essencialmente idênticos: 1,67 (ou 1,7) para ações gravitacionais e 1,33 (ou 1,3) para ações gravitacionais combinadas com vento ou terremoto. $O$ primeiro número é o fator de segurança para a Parte 1 e o número entre parênteses para a Parte 2.

A especificação AISC 1963 foi, para todos os propósitos práticos, uma norma de cálculo em estados limites exceto por conservar os coeficientes de ponderação das ações anteriores testados na época. Nem coeficientes de ponderação das ações múltiplos, nem coeficientes de resistência foram usados. Na realidade, então, a norma foi inteiramente moderna em determinar a resistência estrutural (ou capacidade última), apesar de não mudar os fatores de segurança que tinham sido usados para os 25 anos anteriores. Por meados dos anos 60 , os institutos AISC para aço e $\mathrm{ACl}$ para concreto, preocupados com o cálculo de edifícios nos Estados Unidos, desenvolveram as normas baseadas nos princípios de cálculo em estados limites. A principal diferença entre as duas normas foi que a norma $\mathrm{ACl}$ tinha um conjunto de coeficientes de resistência e ações mais avançado e versátil. 
Seguindo o sucesso destes dois modelos, foi iniciada, em 1965, a pesquisa para desenvolvimento de uma norma de cálculo em estados limites para pontes. Esta norma usou coeficientes múltiplos de ponderação das ações e essencialmente os mesmos estados limites que a especificação AISC. Escolhendo coeficientes de ponderação das ações diferentes para ação permanente $(1,3)$ e ação variável $(2,17)$, economias consideráveis foram alcançadas para pontes maiores, onde a ação permanente é predominante. A nova norma de cálculo em estados limites e a norma de cálculo em tensões admissíveis proporcionaram o mesmo consumo de aço para uma ponte de $12 \mathrm{~m}$ de vão. Isto forneceu o ponto de calibração entre o cálculo em tensões admissíveis e a nova norma de cálculo em estados limites. A nova norma foi oficialmente adotada pela American Association of State Highway and Transportation Officials em 1976. O quadro 1 apresenta as expressões das três normas.

Quadro 1.1: Condições de segurança das primeiras normas de cálculo em estados limites:

Cálculo Plástico AISC, 1978:

$$
\begin{aligned}
& R_{n} \geq 1,7 Q_{D}+1,7 Q_{L} \\
& R_{n} \geq 1,3 Q_{D}+1,7 Q_{w}
\end{aligned}
$$

Norma ACl:

$$
\begin{aligned}
& \phi R_{\mathrm{n}} \geq \psi\left(1,4 Q_{\mathrm{D}}+1,7 \mathrm{Q}_{\mathrm{L}}+1,7 \mathrm{Q}_{\mathrm{S}}+1,7 \mathrm{Q}_{\mathrm{W} / \mathrm{E}}\right) \\
& \psi=1,0 \text { para } \mathrm{D}, \mathrm{L}, \mathrm{S} \\
& \psi=0,75 \text { para } \mathrm{D}, \mathrm{L}, \mathrm{S}, \mathrm{W} / \mathrm{E}
\end{aligned}
$$

Especificação AASHTO:

$$
R_{n} \geq 1,3 Q_{D}+2,17 Q_{(L+1)}
$$

D- permanente; L- variável; S- neve; W- vento; E- terremoto; I- força de impacto 


\section{5) Normas de cálculo em estados limites baseadas em probabilidade}

No início dos anos 60 , haviam duas normas de cálculo em estados limites nos Estados Unidos. Em outros países, especialmente no leste da Europa, normas semelhantes estavam em uso cerca de 10 a 15 anos antes. Mais normas surgiram nos anos posteriores, e estas normas formaram a primeira geração de normas de cálculo em estados limites, e foram colocadas em uso por volta de 1990 na maioria dos países. As linhas comuns entre todas elas são: (1) modelos teóricos para avaliação da capacidade de elementos estruturais baseados em pesquisas recentes; (2) os fatores que consideram as incertezas das variáveis ação e resistência são determinados por juízo (opinião) e calibração com as normas correspondentes em tensões admissíveis.

A idéia de que as variáveis ação e resistência são quantidades aleatórias tem sido sempre aceita pelos engenheiros estruturais, e é a base para a aceitação filosófica do conceito de fatores de segurança. Como foi difícil usar os preceitos probabilísticos explicitamente, estes foram aplicados implicitamente através do juízo coletivo dos engenheiros construtores e calculistas quando escolheram os fatores de segurança aplicáveis. Quanto maior a incerteza suposta da ação ou resistência, maior o fator de segurança. Os fatores de segurança flutuam acima ou abaixo, dependendo da experiência de insucesso ou sucesso. Dado o tempo suficiente, experiência e juízo produzirão estruturas aceitáveis que são, em média ou na maioria das vezes, seguras e econômicas. De alguma forma nos tempos modernos este processo empírico é julgado não totalmente satisfatório: ele leva muito tempo para adquirir a experiência para os esquemas estruturais novos. 
Para fazer a verificação da segurança de maneira mais científica, métodos estatísticos e conceitos probabilísticos são mais convenientes. A idéia de que esta aproximação forneceria ferramentas de cálculo práticas foi adiantada nos anos de 1920 a 1930. Bolotin referiu-se a um livro alemão de 1926 por M. Maier, e a uma série de publicações russas, que afirmavam que a teoria de probabilidade poderia ser usada em cálculo estrutural. Murzewiki afirmou que W. Wierzbicki (Polônia, 1936) e N. S. Streleckij (URSS, 1935) foram os propositores dos conceitos probabilísticos de segurança. Pouco depois do fim da segunda guerra mundial em 1945, os métodos de cálculo em estados limites com fatores múltiplos de ação, que eram baseados em teoria de probabilidade, começaram a aparecer na URSS e no leste europeu.

No oeste, os dois maiores defensores (proponentes) da aproximação probabilística na era imediata pós-guerra foram Pugsley e Freudenthal. Ambos tiveram experiência em cálculo de aeronaves, e ambos foram membros de comitês profissionais em segurança estrutural. $\mathrm{O}$ comitê de Pugsley apresentou à Instituição Britânica de Engenheiros Estruturais, em 1955, recomendações que incluíam uma série de coeficientes de ponderação das ações e combinações de ação que foram obtidos por consenso (opinião) de um conjunto de peritos. $O$ uso de probabilidade foi feito somente de maneira indireta e subjetiva. $O$ trabalho de Pugsley foi o precursor da primeira geração de normas de cálculo em estados limites.

Uma vez que o comitê de Pugsley completou seu trabalho em quatro anos e deu um conjunto de recomendações claras, o comitê da Sociedade Americana de Engenheiros Civis, sob a presidência de Julian e com Freudenthal como membro principal (este último foi apontado presidente depois que venceu o período de Julian), enfrentou sessões turbulentas e concluiu, depois de mais de dez anos, com dois artigos finais. Mesmo não havendo claras orientações para o cálculo, exceto pelas repreensões um tanto pessimistas; "ficou evidente que este trabalho será de pequena utilidade até que engenheiros estruturais tenham adquirido a necessária competência no cálculo de probabilidade" e "embora o comitê não tenha sido 
bem sucedido em seus esforços para resolver a questão fator de segurança, a opinião do presidente e alguns de seus membros é que a aproximação de probabilidade merece consideravelmente mais estudo do que tem recebido", o impacto do comitê ASCE, e especialmente do artigo de Freudenthal, foi profundo. Freudenthal apontou o caminho em que a pesquisa subsequente continuou: além da opinião e experiência (probabilidade subjetiva), as normas modernas de cálculo em estados limites são baseadas em cálculos probabilísticos explícitos.

A estrutura prática de criar tais normas baseadas em probabilidade foi desenvolvida nos anos 60 com os "Métodos de Confiabilidade de Primeira Ordem" (FORM) por E. Basler, Benjamin, Cornell, Lind, Ang e outros. Elaborações do método conhecido como o "Método de Confiabilidade de Segunda Ordem" (SORM), começaram a ficar disponíveis no início dos anos 70.

Em 1964 o Comitê Europeu do Concreto (CEB) adotou a aproximação dos coeficientes parciais, mas um fato adicional do método proposto pelo CEB foi a introdução de resistência e ações características, definidas respectivamente por:

$f_{K}=f_{m}-K \sigma_{m} \quad$ e $\quad S_{K}=S_{m}-K \sigma_{S}$

onde:

$f_{K}$ e $S_{K}$ são a resistência característica do material e as ações ou solicitações características, respectivamente.

$\mathrm{f}_{\mathrm{m}}$ e $\mathrm{S}_{\mathrm{m}}$ são a resistência e solicitações médias

K é uma constante

$\sigma_{\mathrm{m}}$ e $\sigma_{\mathrm{S}}$ são os desvios padrão da resistência do material e das solicitações respectivamente 
O CEB descreve este conceito estatístico como aproximação "semiprobabilista". Simbolicamente este método pode ser colocado como:

$$
R_{K} / \gamma_{m} \geq \gamma_{s} S_{K}
$$

em que $R_{K}$ é a resistência característica do material

Neste modelo, a estatística foi usada somente para definir os valores característicos e não para determinar os coeficientes parciais de cálculo. Mesmo na segunda versão das recomendações do CEB, publicada em 1970, é deixado claro que os coeficientes adotados para modificar os valores característicos são destinados a considerar aqueles aspectos ainda não avaliados por tratamento estatístico.

As normas brasileiras, NBR 6118, 1978 e o projeto de revisão da antiga NB11-51 ainda incorporam este modelo de valores característicos para as resistências, especificando valores característicos inferiores, com $5 \%$ de probabilidade de atingirem valores menores.

Mas no começo dos anos 70, ferramentas estavam disponíveis para desenvolver realmente uma norma de cálculo baseada em probabilidade e, a aproximação básica adotada era considerar as propriedades estatísticas das variáveis envolvidas. Duas linhas de trabalho probabilístico podem ser identificadas:

(a) desenvolvimento de métodos de cálculo completamente probabilístico;

(b) calibração de coeficientes parciais por meios probabilísticos.

Esta última é a linha de maior interesse deste trabalho e é também a linha com maior aplicação para as normas técnicas de cálculo.

Desenvolvimentos posteriores têm comprovado que estava errada a previsão pessimista de Freudenthal: o estudo de confiabilidade em engenharia estrutural tem sido um dos mais ativos e proveitosos esforços de pesquisa de nossa profissão no último quarto de século. O tempo foi de 
amadurecimento então, em 1970, para a emergência da segunda geração de normas de cálculo em estados limites.

\section{6) As normas em estados limites}

Em 1969 o AISC começou o patrocínio de pesquisa que resultou na adoção da especificação AISC-LRFD em 1986. Por volta do mesmo tempo, o trabalho foi iniciado na Norma Nacional do Canadá S16.1 que trata, como a norma AISC, do cálculo de estruturas de edifícios de aço conformado a quente (perfis laminados e soldados). A norma canadense foi adotada em 1974. A longa demora de 17 anos da especificação AISC teve muitas causas, mas a principal razão para o longo período de gestação foi que a diversidade e o número de participantes no processo de decisão nos Estados Unidos não acomodou uma mudança rápida.

Estão listados a seguir os conceitos fundamentais, suposições e metodologias básicas das normas de cálculo em estados limites de segunda geração:

(1) O formato do critério de cálculo é mostrado na equação 1.5: ele usa a capacidade última $R_{n}$, que é reduzida pelo coeficiente de resistência $\phi$, e as ações especificadas em normas, que são ampliadas pelos coeficientes de ponderação $\gamma$. O coeficiente de resistência $\phi$ geralmente modifica a expressão toda para $R_{n}$, mas em algumas normas de cálculo em estados limites estes coeficientes podem atuar nos componentes individuais da expressão para $R_{n}$.

(2) As especificações em estados limites reconhecem que as ações, os efeitos das ações e as resistências são todas quantidades aleatórias cujos valores reais são conhecidos somente através da distribuição de probabilidade das 
quantidades aleatórias individuais que constituem suas partes componentes. É feito o uso de métodos de confiabilidade de primeira ordem ou métodos de confiabilidade de segunda ordem onde estes forem apropriados, para desenvolver os coeficientes de resistência $\phi$, dando confiabilidades aproximadamente uniformes em todo o domínio de cálculo.

(3) Os índices de confiabilidade são calibrados para resultar aproximadamente iguais àqueles das especificações anteriores, ou seja, por volta de 3,0, dependendo da relação entre ação variável e ação permanente.

(4) Para evitar excessivas complicações no cálculo, o número de coeficientes de resistência diferentes é conservado relativamente pequeno.

(5) Os coeficientes de ponderação das ações, as ações propriamente ditas e combinações destas devem ser indicadas em normas de ações e segurança para serem utilizadas nos cálculos com as novas normas em estados limites.

(6) Os critérios de cálculo são baseados nos estados limites alcançados pelos elementos estruturais (uma viga, pilar, solda individual, parafuso, metal base ou ligação) ou pela estrutura como um todo (plastificação, por exemplo). Ligações (parafusos ou soldas) geralmente têm um maior índice de confiabilidade do que as barras, para forçar a falha na barra e não na ligação.

(7) Não é feita distinção quanto às conseqüências de falha. Não há qualquer consideração explícita dada à estrutura como um sistema composto de barras e ligações.

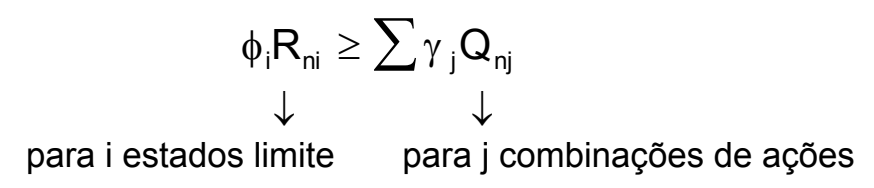

onde:

$\phi$ é o coeficiente de resistência 


$$
\begin{aligned}
& R_{n} \text { é a resistência nominal } \\
& \gamma \text { é o coeficiente de ponderação das ações } \\
& Q_{n} \text { é o efeito da ação nominal }
\end{aligned}
$$

Fez-se necessário também o desenvolvimento de um conjunto de coeficientes de ponderação das ações mais consistentes com o novo método de cálculo e que pudessem dar à nova geração de normas de cálculo uma base mais ampla, sendo estes coeficientes aplicáveis em estruturas de edifícios feitas de todos os materiais, por exemplo, aço, aço conformado a frio, alumínio, concreto armado e protendido, madeira, alvenaria, etc. As premissas básicas deste trabalho, que resultaria nas normas de ações e segurança, foram as seguintes:

(1) Os coeficientes de ponderação das ações foram desenvolvidos usando FORM ou SORM por calibração para casos padrões de estruturas determinadas estaticamente, calculadas pelas então correntes especificações estruturais para aço, concreto armado e protendido, madeira, alumínio e estruturas de alvenaria, buscando um produto final com aproximadamente a mesma confiabilidade.

(2) Os coeficientes de cálculo foram desenvolvidos para um tempo de vida útil de 50 anos.

(3) As combinações de ações obedecem à regra que quando mais de uma ação variável, isto é, sobrecarga de utilização, ações do vento, neve, água ou terremoto, atuam na estrutura, então somente uma destas toma o seu valor máximo e as outras assumem seus valores reduzidos. Estas ações variáveis são então alternadas para fornecer a combinação crítica para o calculista. O esquema é ilustrado pela equação 1.6.

$$
\gamma_{D} Q_{D}+\gamma_{i} Q_{n i}+\sum \gamma_{j} Q_{n j}
$$

onde: 
$\gamma_{\mathrm{i}}$ é o coeficiente de ponderação das ações para o máximo valor previsto da ação durante a vida útil da estrutura.

$\gamma_{j}$ é o coeficiente de ponderação das ações para a ação variável arbitrada em um certo tempo.

A tabela 1.5 mostra os valores alvos dos índices de confiabilidade utilizados para o desenvolvimento da norma de ações A58.1 ANSI (ANSI A58) publicada em 1982 nos Estados Unidos (GALAMBOS, 1990).

Em resumo, os aspectos de confiabilidade das normas mais recentes podem ser declarados como segue: são especificações de cálculo em estados limites em conteúdo e formato; seus estados limites aplicam-se aos elementos ou estrutura como um todo; os coeficientes de ponderação das ações e os coeficientes de resistência são calibrados para dar aproximadamente as mesmas confiabilidades inerentes às especificações anteriores, testadas na época para elementos estruturais padrões; e métodos probabilísticos (FORM, SORM) e juízos foram usados em seu desenvolvimento.

Tabela 1.5: Valores alvos para os índices de confiabilidade da norma A58.1 ANSI

\begin{tabular}{|l|l|}
\hline $\begin{array}{l}\text { permanente + ação variável } \\
\text { permanente + ação de neve }\end{array}$ & $\beta=3,0$ \\
\hline permanente + ação variável + efeito do vento & $\beta=2,5$ \\
\hline permanente + ação variável + efeito de terremoto & $\beta=1,5$ \\
\hline $\begin{array}{l}\text { permanente - efeito do vento } \\
\text { permanente - efeito de terremoto }\end{array}$ & $\beta=2,0$ \\
\hline
\end{tabular}

\section{7) Perspectivas para o futuro em normas de cálculo estrutural}

A especificação AISC-LRFD, a família de normas canadenses para aço, concreto armado e estruturas de ponte (por exemplo o Ontario Bridge Code), a Nordic Code dos países escandinavos e os Eurocodes, são normas 
típicas de cálculo em estados limites, pertencentes à segunda geração. 0 período da última década do vigésimo século vive o uso quase universal de tais normas de cálculo.

Desenvolvimentos e mudanças em normas de cálculo são lentas e graduais. Maiores mudanças na filosofia da norma, tal como mudar de tensões admissíveis para estados limites, não são bem aceitas. No entanto, a experiência canadense com cerca de 16 anos da norma de aço, indica que a transição pode ser alcançada com um mínimo de perturbação. No Canadá a norma de cálculo em tensões admissíveis usada anteriormente foi retirada por etapas em um período de poucos anos, e desde então, por volta de 1980, restou somente uma especificação aprovada: a nova norma de cálculo em estados limites. Nos primeiros 4 anos da especificação AISC-LRFD, ela não foi usada extensivamente em escritórios de cálculo, mas a partir de 1990 começaram a surgir algumas mudanças definitivas: (a) livros textos disponíveis para esclarecer o assunto e (b) escritórios de cálculo começaram a usar o método e a perceber que o LRFD reduzia o custo da estrutura em muitos projetos (GALAMBOS, 1990).

As razões para uma aceitação tão lenta são as seguintes:

(1) As novas especificações não introduziram somente uma nova maneira de calcular, mas todas as suas cláusulas e sua estruturação foram renovadas;

(2) A prática de escritórios de cálculo não fornece tempo para estudar novos métodos, quando os antigos são tidos como "perfeitamente bons";

(3) Tempo excessivo para desenvolvimento de novos programas para computador utilizando os novos métodos de cálculo;

(4) Não havia livros textos em cálculos com ações e resistências fatoradas quando estas normas começaram a entrar em vigor. 
Pode-se considerar algumas falhas, felizmente não comprometedoras, nas atuais normas em estados limites:

(1) A forma associada às múltiplas combinações de ações é confusa e pode levar a erros. Não há realmente nada a ser feito sobre este problema, exceto tomar cuidado na análise estrutural;

(2) A base do controle da resistência é a verificação da resistência de elementos e subestruturas. Acréscimos terão que ser feitos para considerar as confiabilidades de sistemas. Atualmente, estruturas paralelas (redundantes) e estruturas em séries (não redundantes) são tratadas da mesma forma. A consideração de sistemas aqui referida consiste em levar em conta a disposição dos elementos estruturais no cálculo da segurança, ou seja, existe diferença na confiabilidade de uma estrutura formada por elementos dispostos em série, da confiabilidade de um sistema de elementos dispostos paralelamente. O colapso de um elemento deste último sistema não implicará no colapso do sistema como um todo, enquanto que, para uma estrutura formada por elementos dispostos em série, a ruptura de um deles causará a falha de toda a estrutura.

(3) Um dos objetivos anunciados do cálculo probabilístico tem sido a igualdade da confiabilidade de todas as estruturas e elementos. Este objetivo não tem sido completamente alcançado ainda. Tem sido mostrado que o índice de confiabilidade de elementos fletidos pode variar de 2,5 a 3,5, que é uma ordem de magnitude de variação na probabilidade de exceder um estado limite. A razão para esta variação é que um único valor do coeficiente de resistência (por exemplo $\phi=0,9$ para a maioria das normas) é usado para todos os elementos sob flexão, independente do tipo de estado limite. Este problema pode, e deverá, ser resolvido pela introdução de um número maior de coeficientes $\phi$ em edições futuras das novas normas de cálculo em estados limites; 
(4) Alguns modelos não são os mais modernos, por exemplo, não são usadas curvas múltiplas para colunas (elementos comprimidos) na especificação AISC-LRFD, e há modelos de cálculo disponíveis para vigas esbeltas muito mais precisos do que os usados atualmente pelas normas (GALAMBOS, 1990).

Várias mudanças e correções destas imperfeições ainda existentes estão surgindo com as novas e modernas normas:

(1) Muitas novas normas baseadas em probabilidade foram completadas ou estão em estágios avançados de pesquisa e desenvolvimento. Entre estas estão as novas especificações norte-americanas LRFD elaboradas para estruturas de aço conformado a frio e estruturas de aço inoxidável, os vários Eurocodes e normas em muitos outros países, a norma de cálculo de madeira nos Estados Unidos e a norma de cálculo de pontes do American Association of State Highway and Transportation Officials (AASHTO), a Ontario Bridge Code revisada, o Projeto de estruturas de madeira (NBR 7190), etc.

(2) Pesquisa intensiva tem sido conduzida por uns 15 anos no assunto de confiabilidade de sistemas estruturais e sobre uma forma de se implementar métodos desta confiabilidade nas normas de cálculo. O suficiente é conhecido sobre este assunto para alguns dos resultados aparecer brevemente nas normas de cálculo em estados limites de forma implícita (incentivos para sistemas redundantes) ou explícita (uma análise de confiabilidade de sistema);

“A partir de 1990 tem havido uma vasta quantidade de pesquisas, com grande impacto na forma em que as estruturas são calculadas e avaliadas. Além disso, há até uma maior quantidade de dados de pesquisa revisando e complementando trabalhos passados. Infelizmente muito pouco destas informações entram nas normas de cálculo, e tão pouco elas são usadas em escritórios de cálculo. 
A única solução para este problema é através da educação, isto deveria ser iniciado na graduação, com o objetivo de tornar futuros engenheiros de cálculo estrutural hábeis a fazer uma análise de confiabilidade baseada em probabilidade com a mesma facilidade com que estes agora fazem a análise de esforços em uma estrutura.

A ampla disseminação dos métodos de análise de confiabilidade resultará no aumento do uso de tais análises para projetos e surgirá a necessidade de normas que padronizem a interpretação de resultados." (GALAMBOS, 1990). 


\section{CAPÍTULO 2 - CONFIABILIDADE DE}

SISTEMAS DE ENGENHARIA

\section{1) Introdução}

Um dos principais objetivos do cálculo estrutural na engenharia é assegurar o desempenho satisfatório das estruturas com o máximo de economia possível. Certamente a garantia de desempenho, incluindo a segurança, é primeiramente (se não unicamente) responsabilidade de engenheiros. Atingir este objetivo, entretanto, geralmente não é um problema simples, particularmente pelo grande número de sistemas estruturais existentes. Sistemas estruturais podem falhar ao desempenhar suas funções para as quais foram projetados, pois o risco está geralmente implícito nestes sistemas.

A maioria dos projetos e cálculos dos sistemas de engenharia estrutural podem ser bem sucedidos sem o conhecimento completo das informações; consequentemente, a garantia de desempenho raramente é perfeita. Além disso, muitas decisões requeridas durante o processo de projeto e cálculo são tomadas, invariavelmente, sob condições de incertezas. Portanto, há sempre alguma probabilidade de falha ou mau desempenho associado às suas conseqüências adversas; assim o risco será 
sempre inevitável. Sob tais condições, não é viável (prática ou economicamente) garantir segurança total ou desempenho absoluto das estruturas de engenharia (FREUDENTHAL, 1947).

No caso de uma estrutura, sua segurança é, claramente, uma função da máxima ação (ou combinação de ações) que lhe pode ser imposta durante seu tempo de vida útil e dependerá também da resistência ou capacidade desta estrutura ou seus componentes, de suportar estas ações. Como a máxima ação da vida útil de uma estrutura e sua capacidade real são difíceis de serem previstas exatamente, e qualquer previsão está sujeita a incertezas, a garantia absoluta da segurança de uma estrutura é impossível. Na realidade, segurança (ou desempenho) podem ser garantidos somente em termos da probabilidade de que a resistência disponível (ou capacidade estrutural) será suficiente para resistir à máxima ação ou combinação de ações que poderá ocorrer durante a vida útil da estrutura.

\section{2) Análise e verificação de Confiabilidade}

\subsection{1) PROBLEMA BÁSICO}

Problemas de confiabilidade em engenharia podem ser definidos como a determinação da capacidade de um sistema que atenda a determinadas condições (exigências). $\mathrm{Na}$ consideração da segurança de uma estrutura, a preocupação é assegurar que a resistência da estrutura seja suficiente para suportar a atuação da máxima ação ou combinação de ações durante a sua vida útil.

Tradicionalmente, a confiabilidade de sistemas estruturais é alcançada através da utilização de coeficientes ou margens de segurança e adoção de suposições conservadoras nos métodos de cálculo, visando assegurar uma mínima condição de resistência para suportar a atuação de 
uma ação máxima. Freqüentemente, esta confiabilidade é definida em bases de juízos subjetivos e, a suficiência ou insuficiência das "margens" aplicadas podem ser avaliadas ou calibradas somente em termos de experiências passadas com sistemas semelhantes. É difícil quantificar a eficiência da aproximação tradicional e há carência de bases lógicas para o estudo das incertezas, consequentemente, os níveis de segurança e confiabilidade não podem ser calculados quantitativamente. Além disso, para novos sistemas em que não há bases anteriores para calibração, o problema de assegurar o bom desempenho estrutural se torna extremamente difícil.

Na realidade, a determinação da resistência disponível bem como da máxima solicitação da estrutura não são problemas simples. Estimativas e previsões são sempre necessárias para estes tipos de problemas, incertezas são inevitáveis pela simples razão de que as informações relativas aos problemas de engenharia são invariavelmente incompletas. Diante de tais incertezas, a resistência disponível e a solicitação real não podem ser determinadas precisamente, elas podem ser descritas como pertencentes a determinados intervalos, podendo ser modeladas como variáveis aleatórias. Nestes termos, portanto, a confiabilidade de um sistema pode ser mais realisticamente medida em termos de probabilidade. Para esta proposta, definem-se as seguintes variáveis aleatórias:

$$
\begin{aligned}
& X=\text { resistência } \\
& Y=\text { solicitação }
\end{aligned}
$$

O objetivo da análise de confiabilidade é assegurar o evento $(\mathrm{X}>\mathrm{Y})$ durante toda a vida útil da estrutura. Esta garantia é possível somente em termos da probabilidade $\mathrm{P}(\mathrm{X}>\mathrm{Y})$. Esta probabilidade, portanto, representa a medida realista da confiabilidade do sistema (da estrutura); a probabilidade do evento complementar $(\mathrm{X}<\mathrm{Y})$ é a correspondente medida da não confiabilidade. 
Assumindo no momento, que as distribuições de probabilidade necessárias de $\mathrm{X}$ e $\mathrm{Y}$ são disponíveis, isto é, $\mathrm{F}_{\mathrm{X}}(\mathrm{x})$ ou $f_{\mathrm{X}}(\mathrm{x})$ e $\mathrm{F}_{\mathrm{Y}}(\mathrm{y})$ ou $f_{\mathrm{Y}}(\mathrm{y})$ são conhecidas. Se as variáveis $\mathrm{X}$ e $\mathrm{Y}$ são contínuas e não correlacionadas, as probabilidades desejadas podem então ser formuladas como segue (FREUDENTHAL, GARRELT, SHINOZUKA, 1966):

$$
\mathrm{p}_{\mathrm{F}}=\int_{0}^{\infty} \mathrm{F}_{\mathrm{X}}(\mathrm{y}) f_{Y}(\mathrm{y}) \mathrm{dy}
$$

A equação 2.1 é a integração em relação a "y" e pode ser explicada pela figura 2.1 como segue: se $Y=y$, a probabilidade condicional de falha seria $F_{\mathrm{X}}(\mathrm{y})$, mas desde que $\mathrm{Y}=\mathrm{y}$ (ou mais precisamente $\mathrm{y}<\mathrm{Y} \leq \mathrm{y}+$ dy) esteja associada com a probabilidade $f_{\mathrm{Y}}(\mathrm{y}) \mathrm{dy}$, a integração sobre todos os valores de $\mathrm{Y}$ resulta na equação 2.1. A confiabilidade pode também ser formulada pela integração em relação a "x", ficando:

$$
\mathrm{p}_{\mathrm{F}}=\int_{0}^{\infty}\left[1-\mathrm{F}_{\mathrm{Y}}(\mathrm{x})\right] f_{X}(\mathrm{x}) \mathrm{dx}
$$

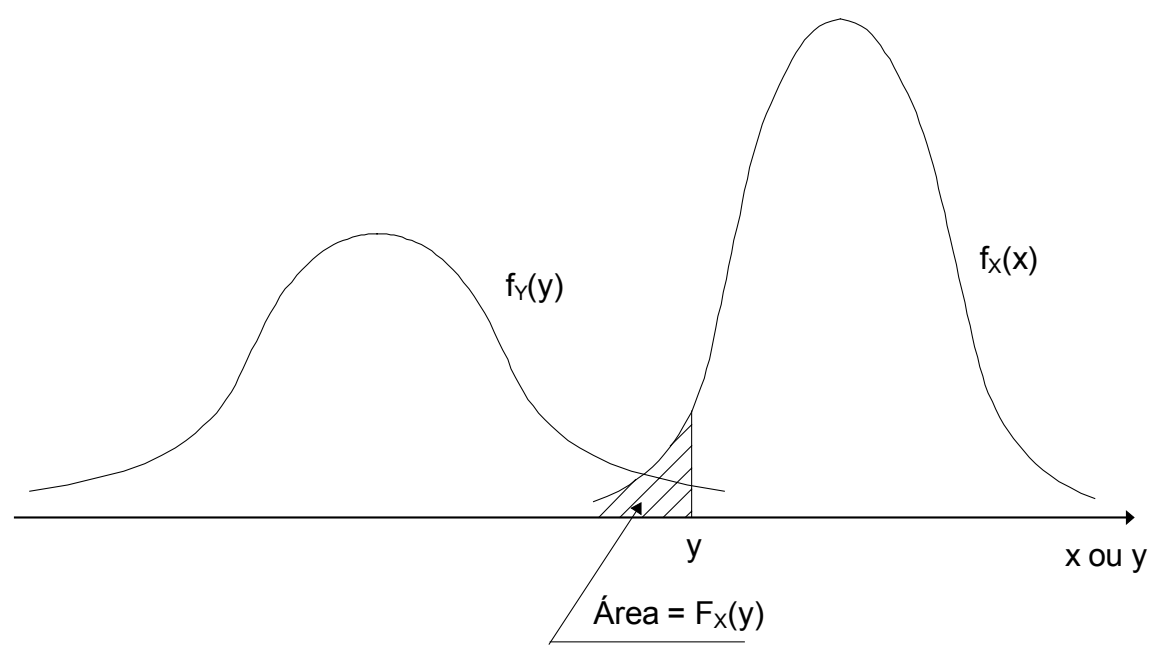

Figura 2.1: Funções densidade de probabilidade $f_{\mathrm{X}}(\mathrm{x})$ e $f_{\mathrm{Y}}(\mathrm{y})$. 


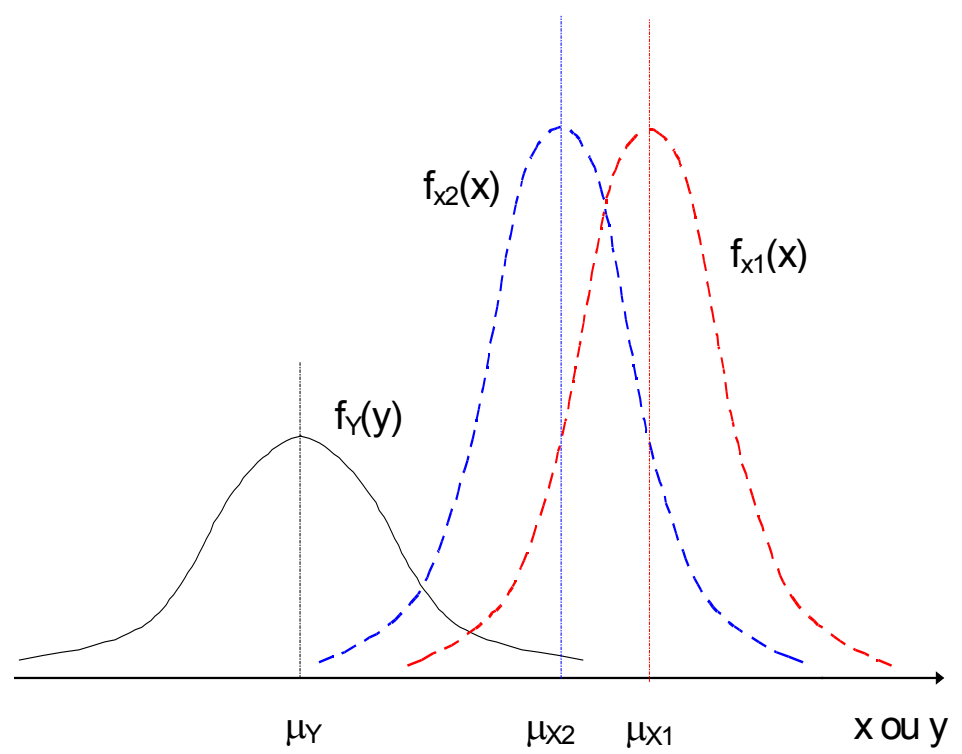

Figura 2.2a: Efeito da posição relativa entre $f_{\mathrm{X}}(\mathrm{x})$ e $f_{\mathrm{Y}}(\mathrm{y})$ em $\mathrm{p}_{\mathrm{F}}$.

A correspondente probabilidade de bom desempenho, portanto, é:

$$
p_{S}=1-p_{F}
$$

Como interpretado graficamente na figura 2.1, a sobreposição das curvas $f_{\mathrm{X}}(\mathrm{x})$ e $f_{\mathrm{Y}}(\mathrm{y})$ representa uma medida da probabilidade de falha $\mathrm{p}_{\mathrm{F}}$. Com isto, observa-se o seguinte:

(1) A região sobreposta depende das posições relativas de $f_{\mathrm{X}}(\mathbf{x})$ e $f_{\mathrm{Y}}(\mathrm{y})$, como pode ser visto na figura 2.2a; quando as duas curvas ficam mais afastadas, $p_{F}$ diminui, ao passo que $p_{F}$ aumenta quando as curvas $f_{\mathrm{X}}(\mathrm{x})$ e $f_{\mathrm{Y}}(\mathrm{y})$ ficam mais próximas. A posição relativa entre $f_{\mathrm{X}}(\mathrm{x})$ e $f_{\mathrm{Y}}(\mathrm{y})$ pode ser medida pela relação $\mu_{X} / \mu_{Y}$, que pode ser chamada de "fator de segurança central" ou pela diferença $\left(\mu_{X}-\mu_{Y}\right)$ que é a "margem de segurança" média.

(2) A região sobreposta também depende do grau de dispersão de $f_{\mathrm{X}}(\mathrm{x})$ e $f_{\mathrm{Y}}(\mathrm{y})$, como mostra a figura $2.2 \mathrm{~b}$, comparando a sobreposição das curvas de linhas pretas com a das curvas de 
linhas coloridas. Estas dispersões podem ser expressas em termos dos coeficientes de variação $\delta_{x}$ e $\delta_{Y}$.

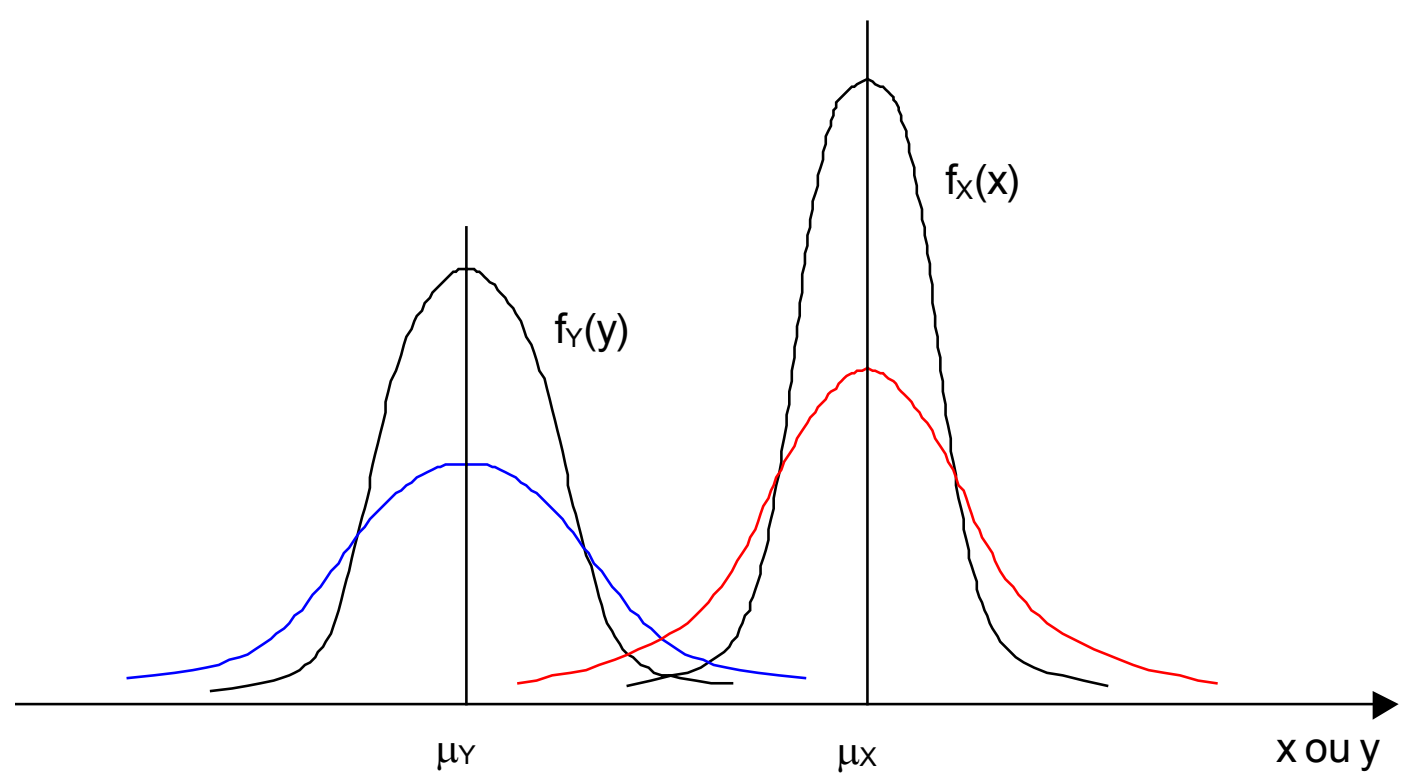

Figura 2.2b: Efeito das dispersões de $f_{\mathrm{X}}(\mathrm{x})$ e $f_{\mathrm{Y}}(\mathrm{y})$ em $\mathrm{p}_{\mathrm{F}}$.

Em resumo:

$$
\mathrm{p}_{\mathrm{F}} \cong \mathrm{g}\left(\mu_{\mathrm{X}} / \mu_{\mathrm{Y}} ; \delta_{X}, \delta_{\mathrm{Y}}\right)
$$

Portanto, qualquer medida de segurança confiável deve ser uma função da posição relativa de $f_{\mathrm{X}}(\mathrm{x})$ e $f_{\mathrm{Y}}(\mathrm{y})$, bem como do grau de dispersão destas curvas.

Teoricamente, a probabilidade de falha $\mathrm{p}_{\mathrm{F}}$ dependerá também da forma de $f_{\mathrm{X}}(\mathrm{x})$ e $f_{\mathrm{Y}}(\mathrm{y})$. Na prática entretanto, informações sobre as variáveis que se estuda são limitadas, as informações disponíveis podem ser suficientes somente para calcular os principais parâmetros estatísticos (ou primeiros momentos) de $\mathrm{X}$ e $\mathrm{Y}$, tais como os valores médios $\mu_{\mathrm{X}}$ e $\mu_{\mathrm{Y}}$ e os correspondentes coeficientes de variação (c.o.v.'s) $\delta_{x}$ e $\delta_{Y}$. $\quad$ desenvolvimento quantitativo da verdadeira probabilidade de falha freqüentemente esbarra em maiores problemas, por exemplo, a determinação das formas corretas de $f_{\mathrm{X}}(\mathrm{x})$ e $f_{\mathrm{Y}}(\mathrm{y})$, que não é uma tarefa simples. 
Nas equações. 2.2 e 2.3 é assumido que $X$ e $Y$ são variáveis aleatórias estatisticamente independentes. Em geral, entretanto, estas variáveis podem ser correlacionadas e, para tais casos, a probabilidade de falha pode ser expressa em termos da função densidade de probabilidade conjunta como segue:

$$
\mathrm{p}_{\mathrm{F}}=\int_{0}^{\infty}\left[\int_{0}^{\mathrm{y}} f_{\mathrm{X}, \mathrm{Y}}(\mathrm{x}, \mathrm{y}) \mathrm{d} \mathrm{x}\right] \mathrm{dy}
$$

ao passo que a confiabilidade correspondente é:

$$
\mathrm{p}_{\mathrm{S}}=\int_{0}^{\infty}\left[\int_{0}^{\mathrm{x}} f_{\mathrm{X}, \mathrm{Y}}(\mathrm{x}, \mathrm{y}) \mathrm{dy}\right] \mathrm{dx}
$$

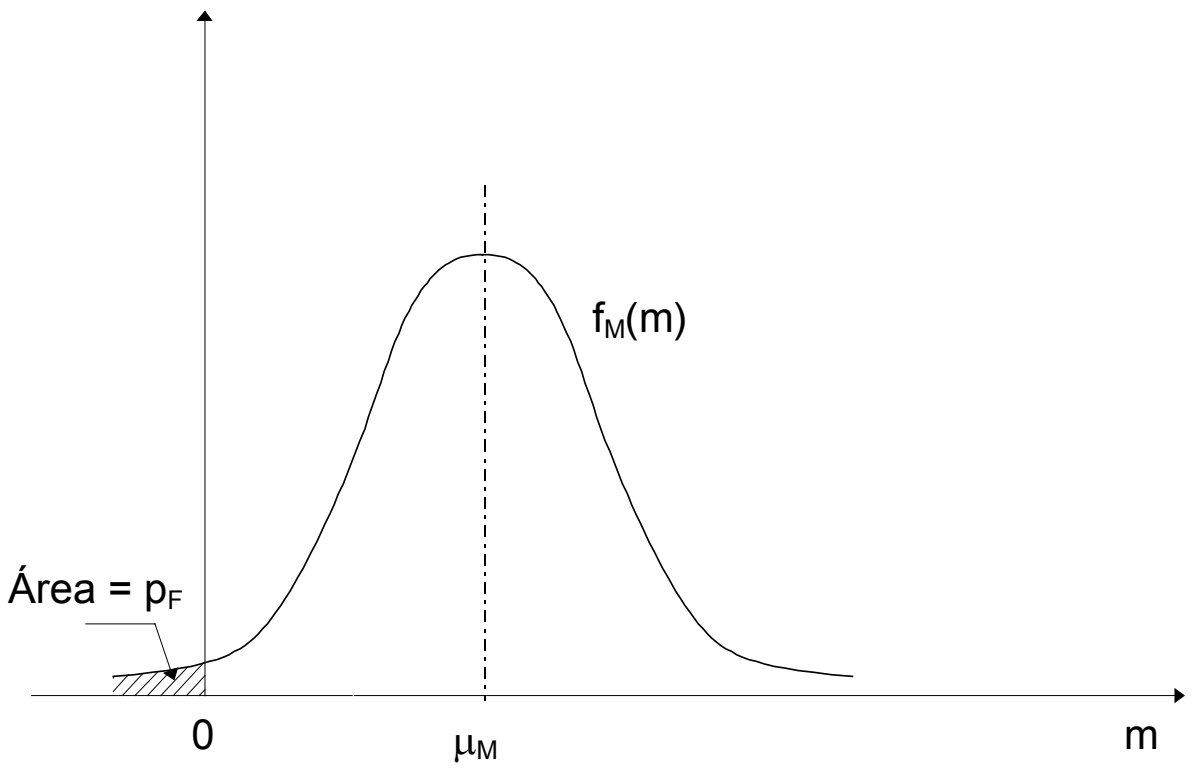

Figura 2.3: Função densidade de probabilidade da margem de segurança $M$.

Margem de segurança: o problema resistência-solicitação anterior pode ser formulado em termos de margem de segurança, $M=X-Y$. Como $X$ e $Y$ são variáveis aleatórias, $M$ é também uma variável aleatória com a correspondente função densidade de probabilidade $f_{M}(m)$. Neste caso, a falha é obviamente o evento $(\mathrm{M}<0)$, e assim a probabilidade de falha é:

$$
\mathrm{p}_{\mathrm{F}}=\int_{-\infty}^{0} f_{\mathrm{M}}(\mathrm{m}) \mathrm{dm}=\mathrm{F}_{\mathrm{M}}(0)
$$


Graficamente, isto é representado pela área sob $f_{M}(m)$ e m menor que 0 , como mostrado na figura 2.3.

Considerando uma estrutura cuja resistência $R$ e solicitações $S$ sejam variáveis aleatórias normais, $\mathrm{N}\left(\mu_{R}, \sigma_{R}\right)$ e $\mathrm{N}\left(\mu_{S}, \sigma_{S}\right)$, a distribuição de probabilidade da margem de segurança $M=R-S$ é também normal $N\left(\mu_{M}\right.$, $\left.\sigma_{M}\right)$, em que:

$$
\mu_{\mathrm{M}}=\mu_{\mathrm{R}}-\mu_{\mathrm{S}}
$$

e, para R e S estatisticamente independentes

$$
\sigma_{M}^{2}=\sigma_{R}^{2}+\sigma_{S}^{2}
$$

onde $\sigma_{M}, \sigma_{R}$ e $\sigma_{S}$ são os desvios padrão da margem de segurança, resistência e solicitações, respectivamente.

Além disso, $\left(\mathrm{M}-\mu_{M}\right) / \sigma_{M}$ é $\mathrm{N}(0,1)$. Então, a equação 2.5 resulta:

$$
\begin{aligned}
& \mathrm{p}_{\mathrm{F}}=\mathrm{F}_{\mathrm{M}}(0)=\Phi\left(\frac{-\mu_{\mathrm{M}}}{\sigma_{\mathrm{M}}}\right)=1-\Phi\left(\frac{\mu_{\mathrm{M}}}{\sigma_{\mathrm{M}}}\right) \\
& \mathrm{p}_{\mathrm{S}}=1-\mathrm{p}_{\mathrm{F}}=\Phi\left(\frac{\mu_{\mathrm{M}}}{\sigma_{\mathrm{M}}}\right)
\end{aligned}
$$

Pode-se observar que a confiabilidade é uma função da relação $\mu_{M} / \sigma_{M}$, que é a margem de segurança expressa em termos de $\sigma_{M}$ e pode ser chamado de índice de confiabilidade ou índice de segurança e denominado de $\beta$. Para o presente exemplo:

$$
\beta=\frac{\mu_{M}}{\sigma_{M}}=\frac{\mu_{R}-\mu_{S}}{\sqrt{\sigma_{R}^{2}+\sigma_{S}^{2}}}
$$

A probabilidade de segurança, portanto, fica;

$$
p_{\mathrm{s}}=\Phi(\beta)
$$

e a correspondente probabilidade de falha é:

$$
\mathrm{p}_{\mathrm{F}}=1-\Phi(\beta)
$$


Isto ilustra o fato que o nível de confiabilidade é uma função da posição relativa de $f_{\mathrm{R}}(\mathrm{r})$ e $f_{\mathrm{S}}(\mathrm{s})$ como medido pela margem de segurança, $\mu_{M}=\mu_{R}-\mu_{S}$, e do grau de dispersão como medido em termos do desvio padrão, $\sigma_{M}=\left(\sigma_{R}^{2}+\sigma_{S}^{2}\right)^{1 / 2}$. E, neste caso, um fator que inclui o efeito dos dois fatores é o índice de confiabilidade $\beta$, como indicado anteriormente.

No caso de $R$ e $S$ normais, a relação quantitativa entre a probabilidade $p_{F}$ e o índice de confiabilidade $\beta$ é a seguinte:

Tabela 2.1: Relação quantitativa entre probabilidade de falha e índice de confiabilidade

\begin{tabular}{|c|c|}
\hline$p_{F}$ & $\beta$ \\
\hline 0,5 & 0 \\
\hline 0,25 & 0,67 \\
\hline 0,16 & 1,00 \\
\hline 0,10 & 1,28 \\
\hline 0,05 & 1,65 \\
\hline $10^{-2}$ & 2,33 \\
\hline $10^{-3}$ & 3,10 \\
\hline $10^{-4}$ & 3,72 \\
\hline $10^{-5}$ & 4,25 \\
\hline $10^{-6}$ & 4,75 \\
\hline
\end{tabular}

Outro termo familiar em engenharia é o fator de segurança, que é definido como:

$$
\Theta=X / Y
$$


Se $X$ e/ou $Y$ são variáveis aleatórias, o fator de segurança $\Theta$ também será uma variável aleatória. Neste caso, a falha deverá ser o evento $(\Theta<1)$ e a correspondente probabilidade de falha, portanto, é:

$$
\mathrm{p}_{\mathrm{F}}=\int_{0}^{1} f_{\Theta}(\theta) \mathrm{d} \theta=\mathrm{F}_{\Theta}(1)
$$

que é a área sob $f_{\Theta}(\theta)$ entre 0 e 1, como mostra a figura 2.4.

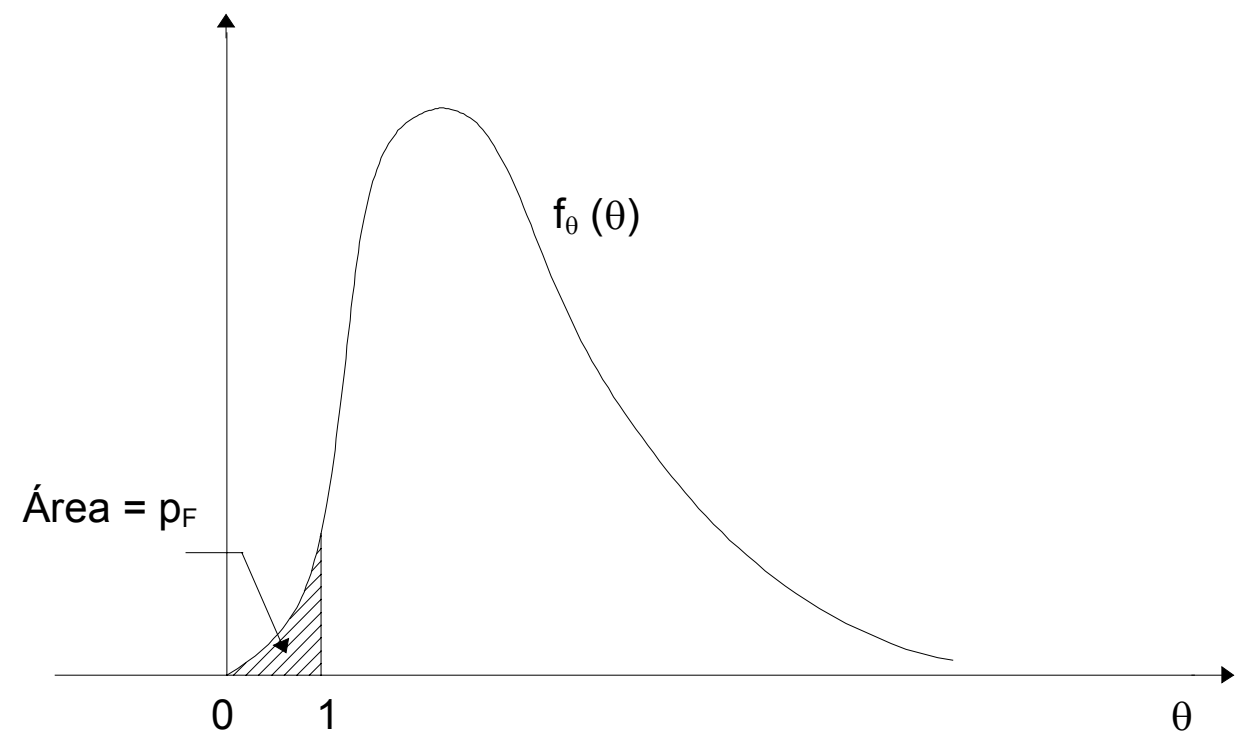

Figura 2.4: Função densidade de probabilidade do fator de segurança $\Theta$.

\subsection{2) FORMULAÇÃO DE SEGUNDO MOMENTO}

O cálculo da probabilidade de segurança ou probabilidade de falha, requer o conhecimento das distribuições $f_{\mathrm{X}}(\mathrm{x})$ e $f_{\mathrm{Y}}(\mathrm{y})$, ou da distribuição conjunta $f_{\mathrm{X}, \mathrm{Y}}(\mathrm{x}, \mathrm{y})$. Mas, mesmo quando as distribuições requeridas podem ser especificadas, o cálculo exato das probabilidades exigindo uma integração numérica das equações. 2.1 a 2.5 pode ser impraticável. Como uma alternativa prática, pode-se recorrer a aproximações para as distribuições normais equivalentes.

Freqüentemente as informações ou dados disponíveis podem ser suficientes apenas para estimar os primeiros e segundos momentos; isto é, os valores médios e as variâncias das respectivas variáveis aleatórias e, 
talvez as covariâncias entre pares de variáveis. Medidas práticas de segurança e confiabilidade, portanto, devem ser limitadas a funções destes primeiros momentos. Sob esta condição, a implementação de conceitos de confiabilidade deve, necessariamente, ser limitada à formulação baseada nos primeiros e segundos momentos das variáveis aleatórias, ou seja, restrita à formulação de segundo momento (CORNELL, 1969; ANG; CORNELL, 1974). Pode ser enfatizado que a aproximação de segundo momento é consistente também com a representação normal equivalente de distribuições não normais.

Com a aproximação de segundo momento, a confiabilidade pode ser inteiramente medida com uma função dos primeiros e segundos momentos das variáveis de cálculo, isto é, o índice de confiabilidade, $\beta$, quando não houver informações das distribuições de probabilidade.

Com relação à margem de segurança $\mathrm{M}=\mathrm{X}-\mathrm{Y}$, o "estado seguro" de um sistema pode ser definido como $(M>0)$, e o "estado de falha" como $(\mathrm{M}<0)$. O contorno que separa o estado seguro do estado de falha é o estado limite definido pela equação $M=0$.

Introduzindo as variáveis reduzidas:

$$
\begin{aligned}
& X^{\prime}=\frac{X-\mu_{X}}{\sigma_{X}} \\
& Y^{\prime}=\frac{Y-\mu_{Y}}{\sigma_{Y}}
\end{aligned}
$$

No espaço destas variáveis reduzidas o estado seguro e o estado de falha podem ser representados como mostrado na figura 2.5. Também, em termos das variáveis reduzidas, o estado limite $M=0$, fica:

$$
\sigma_{X} X^{\prime}-\sigma_{Y} Y^{\prime}+\mu_{X}-\mu_{Y}=0
$$

que é uma linha reta como mostrado na figura 2.5. A distância da linha de falha (linear) à origem, 0 , é por si própria uma medida do índice de confiabilidade, esta distância, d, é dada na geometria analítica como: 


$$
d=\frac{\mu_{X}-\mu_{Y}}{\sqrt{\sigma_{X}^{2}+\sigma_{Y}^{2}}}
$$

de acordo com o resultado obtido na equação 2.7 pode ser observado que para $\mathrm{X}$ e $\mathrm{Y}$ normais, esta distância $\mathrm{d}$ é também o índice de confiabilidade $\beta$, ou seja $d=\beta$ e assim a confiabilidade é $p_{s}=\Phi(d)$.

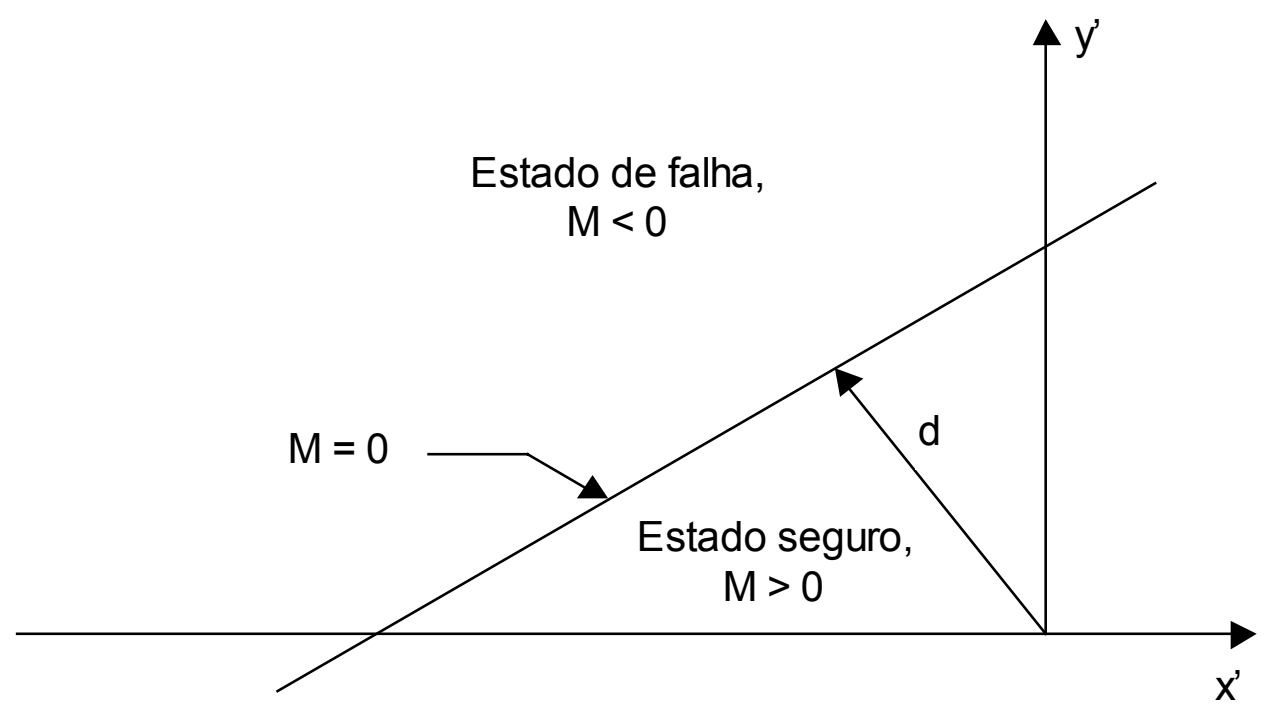

Figura 2.5: Espaço das variáveis reduzidas $X^{\prime}$ e $Y^{\prime}$.

\subsubsection{1) Generalização}

A confiabilidade de um sistema de engenharia pode envolver variáveis múltiplas. Em particular, a resistência e a solicitação podem, respectivamente, ser funções de várias outras variáveis. Para tais casos, o problema resistência-solicitação do item 2.2.1 pode ser generalizado. Esta generalização é freqüentemente necessária em engenharia, particularmente quando o problema deve ser formulado em termos das variáveis básicas de cálculo.

Num sentido mais amplo, a confiabilidade de um sistema de engenharia pode ser definida como a probabilidade que o mesmo apresenta de desempenhar suas funções ou missões pretendidas. O nível de desempenho de um sistema, obviamente dependerá das propriedades deste 
sistema. Neste contexto e para a proposta de uma formulação geral, definese uma função desempenho ou função estado:

$$
g(X)=g\left(X_{1}, X_{2}, \ldots, X_{n}\right)
$$

onde $\mathbf{X}=\left(\mathrm{X}_{1}, \mathrm{X}_{2}, \ldots, \mathrm{X}_{\mathrm{n}}\right)$ é um vetor de variáveis de cálculo básicas do sistema. A exigência de desempenho limitante pode ser definida como $g(\mathbf{X})=0$, que é o chamado estado limite do sistema.

Segue, portanto, que:

$$
[g(\mathbf{X})>0]=\text { "estado seguro" }
$$

e

$$
[\mathrm{g}(\mathbf{X})<0]=\text { "estado de falha" }
$$

Geometricamente, a equação estado limite, $g(\mathbf{X})=0$, é uma superfície $n$ dimensional que pode ser chamada de "superfície de falha". De um lado da superfície de falha está o estado seguro, $g(\mathbf{X})>0$, ao passo que do outro lado está o estado de falha, $\mathrm{g}(\mathbf{X})<0$.

Sendo assim, se a função de distribuição de probabilidade conjunta das variáveis de cálculo $\mathrm{X}_{1}, \mathrm{X}_{2}, \ldots, \mathrm{X}_{\mathrm{n}}$ é $f_{\mathrm{X}_{1}, \ldots, \mathrm{X}_{\mathrm{n}}}\left(\mathrm{X}_{1}, \ldots, \mathrm{X}_{\mathrm{n}}\right)$, a probabilidade do estado seguro é:

$$
\int \ldots \int_{g(\mathbf{X})>0} f_{\mathrm{X}_{1}, \ldots, \mathrm{x}_{\mathrm{n}}}\left(\mathrm{x}_{1}, \ldots, \mathrm{x}_{\mathrm{n}}\right) \mathrm{dx} \mathrm{x}_{1} \ldots \mathrm{d} \mathrm{x}_{\mathrm{n}}
$$

que pode ser escrita abreviadamente como:

$$
p_{S}=\int_{g(\mathbf{X})>0} f_{\mathbf{x}}(\mathbf{x}) \mathrm{d} \mathbf{x}
$$

A equação $2.14 a$ é simplesmente a integral no volume de $f_{\mathbf{X}}(\mathbf{x})$ sobre a região segura $g(\mathbf{X})>0$. $E$ a probabilidade do estado de falha, ou probabilidade de falha, será a correspondente integral no volume sobre a região de falha:

$$
\mathrm{p}_{\mathrm{F}}=\int_{g(\mathrm{X})<0} f_{\mathbf{x}}(\mathbf{x}) \mathrm{d} \mathbf{x}
$$


O cálculo da probabilidade $p_{S}$ ou $p_{F}$ através da equação $2.14 a$ ou $2.14 b$, entretanto, é geralmente uma tarefa impraticável.

Para propósitos práticos, métodos alternativos para o cálculo de $\mathrm{p}_{\mathrm{s}}$ ou $\mathrm{p}_{\mathrm{F}}$ (ou seus equivalentes) são necessários.

\subsubsection{2) Variáveis não correlacionadas}

Introduzindo-se o conjunto de variáveis reduzidas não correlacionadas (FREUDENTHAL, 1956):

$$
X_{i}^{\prime}=\frac{X_{i}-\mu_{X_{i}}}{\sigma_{X_{i}}} ; \quad i=1,2, \ldots, n
$$

obviamente, o estado seguro e o estado de falha podem também ser interpretados no espaço reduzido das variáveis acima, separados pela equação estado limite apropriada. No caso de duas variáveis, esta deverá ser como mostrado na figura 2.6. Em termos das variáveis reduzidas, $X_{i}^{\prime}$, a equação estado limite será:

$$
g\left(\sigma_{X_{1}} X^{\prime}{ }_{1}+\mu_{X_{i}}, \ldots, \sigma_{X_{n}} X_{n}^{\prime}+\mu_{X_{n}}\right)=0
$$

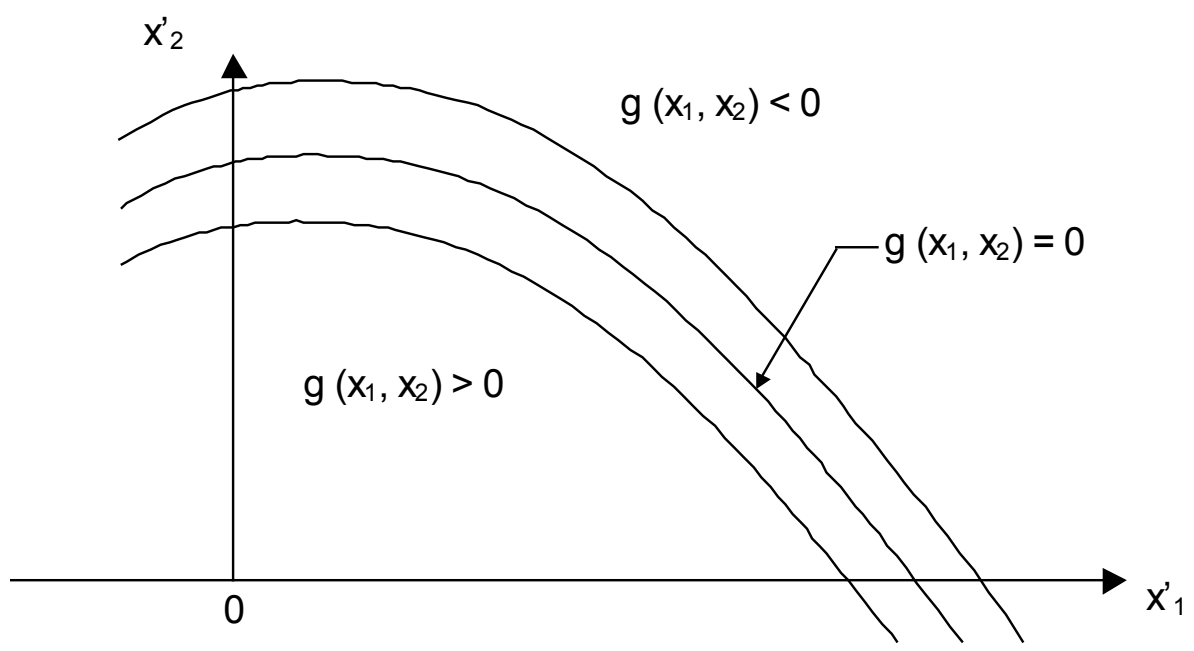

Figura 2.6: Estados de segurança e de falha no espaço de variáveis reduzidas. 
Pode-se observar na figura 2.6 que quando a superfície estado limite (ou superfície de falha), $g(\mathbf{X})=0$, se afasta ou se aproxima da origem, a região segura, $g(\mathbf{X})>0$, aumenta ou diminui. Portanto, a posição da superfície de falha em relação à origem das variáveis reduzidas, determinará a segurança ou a confiabilidade do sistema. A posição da superfície de falha pode ser representada pela distância mínima da superfície $g(\mathbf{X})=0$ à origem das variáveis reduzidas (HASOFER; LIND, 1974; DITLEVSEN, 1979); de fato, SHINOZUKA (1983) mostrou que o ponto na superfície de falha com mínima distância da origem é o ponto mais provável de falha. Assim, com algum sentido aproximado, esta distância mínima pode ser usada como uma medida de confiabilidade.

Seguindo SHINOZUKA (1983), a distância mínima requerida pode ser determinada como segue. A distância de um ponto $\mathbf{X}^{\prime}=\left(X^{\prime}{ }_{1}, X^{\prime}{ }_{2}, \ldots, X_{n}^{\prime}\right)$ na superfície de falha $g(\mathbf{X})=0$ à origem de $\mathbf{X}$ ' é:

$$
\mathrm{D}=\sqrt{\mathrm{X}_{1}^{\prime 2}+\ldots+\mathrm{X}_{\mathrm{n}}^{\prime 2}}=\left(\mathbf{X}^{\mathbf{\prime}^{\mathrm{t}}} \mathbf{X}^{\prime}\right)^{1 / 2}
$$

o ponto na superfície de falha, $\left(\mathrm{X}_{1}^{\prime^{*}}, \mathrm{X}_{2}^{\prime^{*}}, \ldots, \mathrm{X}_{\mathrm{n}}^{\prime^{*}}\right)$, tendo a mínima distância da origem pode ser determinado pela minimização da função $D$, sujeita à limitação $g(\mathbf{X})=0$ :

Minimize D

sujeito à $\mathrm{g}(\mathbf{X})=0$.

Para esta proposta, o método de multiplicadores de Lagrange pode ser usado. Seja:

$$
L=D+\lambda g(\mathbf{X})
$$

ou

$$
L=\left(\mathbf{X}^{\mathrm{t}} \mathbf{X}^{\prime}\right)^{1 / 2}+\lambda g(\mathbf{X})
$$

Em notação escalar:

$$
L=\sqrt{X_{1}^{\prime 2}+X_{2}^{\prime 2}+\ldots+X_{n}^{\prime 2}}+\lambda g\left(X_{1}, X_{2}, \ldots, X_{n}\right)
$$


em que, $X_{i}=\sigma_{X_{i}} X_{i}^{\prime}+\mu_{X_{i}}$.

Minimizando $L$, obtém-se o seguinte conjunto de $n+1$ equações com $n+1$ incógnitas:

$$
\frac{\partial \mathrm{L}}{\partial \mathbf{X}_{\mathrm{i}}^{\prime}}=\frac{\mathrm{X}_{\mathrm{i}}^{\prime}}{\sqrt{\mathbf{X}_{1}^{\prime 2}+\mathbf{X}_{2}^{\prime 2}+\ldots+\mathbf{X}_{\mathrm{n}}^{\prime 2}}}+\lambda \frac{\partial \mathrm{g}}{\partial \mathbf{X}_{i}^{\prime}}=0 ; \quad \mathrm{i}=1,2, \ldots, \mathrm{n}
$$

e

$$
\frac{\partial L}{\partial \lambda}=g\left(X_{1}, X_{2}, \ldots, X_{n}\right)=0
$$

A solução do conjunto de equações anteriores dá o ponto de falha mais provável $\left(\mathrm{X}_{1}^{\prime^{*}}, \mathbf{X}_{2}^{\prime \prime^{*}}, \ldots, \mathbf{X}_{\mathrm{n}}^{\prime^{*}}\right)$.

Introduzindo o vetor gradiente:

$$
\mathbf{G}=\left(\frac{\partial g}{\partial \mathbf{X}_{1}^{\prime}}, \frac{\partial \mathbf{g}}{\partial \mathbf{X}_{2}^{\prime}}, \ldots, \frac{\partial \mathrm{g}}{\partial \mathbf{X}_{\mathrm{n}}^{\prime}}\right)
$$

em que:

$$
\frac{\partial g}{\partial X_{i}^{\prime}}=\frac{\partial g}{\partial X_{i}} \frac{d X_{i}}{d X_{i}^{\prime}}=\sigma_{X_{i}} \frac{\partial g}{\partial X_{i}}
$$

o conjunto de equações anteriores, a equação 2.17, pode ser escrita em notação matricial como segue:

$$
\frac{\mathbf{X}^{\prime}}{\left(\mathbf{X}^{\mathrm{t}} \mathbf{X}^{\prime}\right)^{1 / 2}}+\lambda \mathbf{G}=0
$$

donde:

$$
\mathbf{X}^{\prime}=-\lambda \mathbf{D G}
$$

portanto:

$$
\mathrm{D}=\left[\left(\lambda \mathrm{DG} \mathbf{G}^{\mathrm{t}}\right)(\lambda \mathrm{DG})\right]^{1 / 2}=\lambda \mathrm{D}\left(\mathbf{G}^{\mathrm{t}} \mathbf{G}\right)^{1 / 2}
$$

e assim:

$$
\lambda=\left(\mathbf{G}^{\mathrm{t}} \mathbf{G}\right)^{-1 / 2}
$$


Usando este último resultado na equação 2.19 fica:

$$
\mathbf{X}^{\prime}=\frac{-\mathbf{G D}}{\left(\mathbf{G}^{\mathrm{t}} \mathbf{G}\right)^{1 / 2}}
$$

Multiplicando os dois membros da equação 2.20 por $\mathbf{G}^{t}$ e arranjando os termos, temos:

$$
\mathrm{D}=\frac{-\mathbf{G}^{\mathrm{t}} \mathbf{X}^{\mathbf{1}}}{\left(\mathbf{G}^{\mathrm{t}} \mathbf{G}\right)^{1 / 2}}
$$

Substituindo a equação 2.20 na equação 2.18 resulta em uma equação simples com $D$ desconhecido, a solução da equação resultante dá a distância mínima $d_{\min }=\beta$, assim:

$$
\beta=\frac{-\mathbf{G}^{*} \mathbf{X}^{\mathbf{H}^{*}}}{\left(\mathbf{G}^{*} \mathbf{G}^{*}\right)^{1 / 2}}
$$

em que $\mathbf{G}^{*}$ é o vetor gradiente no ponto de falha mais provável $\left(x_{1}^{\prime *}, x_{2}^{*}, \ldots, x_{n}^{\prime *}\right)$. Na forma escalar, a equação 2.22a é:

$$
\beta=\frac{-\sum_{i}{\mathbf{X}_{i}^{\prime *}}^{*}\left(\frac{\partial g}{\partial \mathbf{X}_{i}^{\prime}}\right)_{*}}{\sqrt{\sum_{i}\left(\frac{\partial g}{\partial \mathbf{X}_{i}^{\prime}}\right)_{*}^{2}}}
$$

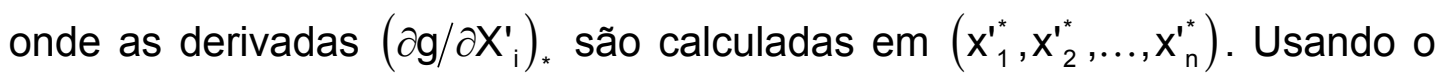
valor de $\beta$ acima na equação 2.20 , o ponto mais provável na superfície de falha fica:

$$
\mathbf{X}^{*}=\frac{-\mathbf{G}^{*} \beta}{\left(\mathbf{G}^{*} \mathbf{G}^{*}\right)^{1 / 2}}
$$

$\mathrm{Na}$ forma escalar, os componentes de $\mathbf{X}^{,{ }^{*}}$, equação $2.20 \mathrm{a}$, são:

$$
x_{i}^{\prime *}=-\alpha_{i}^{*} \beta ; \quad i=1,2, \ldots, n
$$

em que: 


$$
\alpha_{i}^{*}=\frac{\left(\frac{\partial g}{\partial X_{i}^{\prime}}\right)_{*}}{\sqrt{\sum_{i}\left(\frac{\partial g}{\partial X_{i}^{\prime}}\right)^{2}}}
$$

são os co-senos diretores ao longo do $x_{i}^{\prime}$.

\subsubsection{3) Interpretação de primeira ordem}

As equações. 2.20a e 2.22a podem ser interpretadas em bases de aproximações de primeira ordem para a função $\mathbf{g}(\mathbf{X})$ como segue.

Expandindo a função de desempenho $\mathbf{g}(\mathbf{X})$ em série de Taylor em um ponto $\mathbf{x}^{*}$, que está na superfície de falha $g\left(\mathbf{x}^{*}\right)=0$, ou seja:

$$
\begin{aligned}
g\left(X_{1}, X_{2}, \ldots, X_{n}\right)=g\left(x_{1}^{*}, x_{2}^{*}, \ldots, x_{n}^{*}\right)+\sum_{i=1}^{n}\left(X_{i}-x_{i}^{*}\right)\left(\frac{\partial g}{\partial X_{i}}\right) & \\
& +\sum_{j=1}^{n} \sum_{i=1}^{n}\left(X_{i}-x_{i}^{*}\right)\left(X_{j}-x_{j}^{*}\right) /\left(\frac{\partial^{2} g}{\partial X_{i} \partial X_{j}}\right)+\ldots
\end{aligned}
$$

onde as derivadas são calculadas em $\left(\mathrm{x}_{1}^{*}, \mathrm{x}_{2}^{*}, \ldots, \mathrm{x}_{\mathrm{n}}^{*}\right)$. Mas $\mathrm{g}\left(\mathrm{x}_{1}^{*}, \mathrm{x}_{2}^{*}, \ldots, \mathrm{x}_{\mathrm{n}}^{*}\right)=0$ na superfície de falha, portanto:

$$
g\left(X_{1}, X_{2}, \ldots, X_{n}\right)=\sum_{i=1}^{n}\left(X_{i}-X_{i}^{*}\right)\left(\frac{\partial g}{\partial X_{i}}\right)+\sum_{j=1}^{n} \sum_{i=1}^{n}\left(X_{i}-x_{i}^{*}\right)\left(X_{j}-x_{j}^{*}\right) /\left(\frac{\partial^{2} g}{\partial X_{i} \partial X_{j}}\right)+\ldots
$$

Recordando que:

$$
X_{i}-X_{i}^{*}=\left(\sigma_{X_{i}} X_{i}^{\prime}+\mu_{X_{i}}\right)-\left(\sigma_{X_{i}} X^{\prime^{*}}{ }_{i}+\mu_{X_{i}}\right)=\sigma_{X_{i}}\left(X_{i}^{\prime}-X^{X^{*}}{ }_{i}\right)
$$

e

$$
\frac{\partial g}{\partial X_{i}}=\frac{\partial g}{\partial X_{i}^{\prime}}\left(\frac{d X_{i}^{\prime}}{d X_{i}}\right)=\frac{1}{\sigma_{X_{i}}} \frac{\partial g}{\partial X_{i}^{\prime}}
$$

Então:

$$
g\left(X_{1}, X_{2}, \ldots, X_{n}\right)=\sum_{i=1}^{n}\left(X_{i}^{\prime}-X_{i}^{\prime *}\right)\left(\frac{\partial g}{\partial X_{i}^{\prime}}\right)+\ldots
$$


Em aproximação de primeira ordem, isto é, truncando a série acima no termo de primeira ordem, o valor médio da função $g(\mathbf{X})$, é (ANG; TANG, 1984):

$$
\mu_{g} \cong-\sum_{i-1}^{n}{X_{i}^{\prime *}}^{*}\left(\frac{\partial g}{\partial X_{i}^{\prime}}\right)
$$

ao passo que a correspondente variância aproximada em primeira ordem (para variáveis não correlacionadas) é:

$$
\sigma_{g}^{2} \cong \sum_{i=1}^{n} \sigma_{X_{i}^{\prime}}^{2}\left(\frac{\partial g}{\partial X_{i}^{\prime}}\right)_{*}^{2}=\sum_{i=1}^{n}\left(\frac{\partial g}{\partial X_{i}^{\prime}}\right)_{*}^{2}
$$

Das equações. 2.25 e 2.26, tem-se a relação:

$$
\frac{\mu_{g}}{\sigma_{g}} \cong \frac{-\sum_{i-1}^{n} \mathbf{X}_{i}^{\prime *}\left(\frac{\partial g}{\partial X_{i}^{\prime}}\right)_{*}}{\sqrt{\sum_{i-1}^{n}\left(\frac{\partial g}{\partial X_{i}^{\prime}}\right)_{*}^{2}}}
$$

Comparando as equações. 2.22b e 2.26, percebe-se que a relação acima é a mesma da equação $2.22 \mathrm{~b}$ e, assim $\mu_{\mathrm{g}} / \sigma_{\mathrm{g}}$ é também a distância do plano tangente à superfície de falha em $\mathbf{x}^{*}$ à origem das variáveis reduzidas. Portanto, o índice de confiabilidade é também:

$$
\beta=\mu_{g} / \sigma_{g}
$$

Deve ser enfatizado que as aproximações de primeira ordem de $\mu_{\mathrm{g}}$ e $\sigma_{\mathrm{g}}$ obtidas acima devem ser calculadas em um ponto na superfície de falha $g(\mathbf{X})=0$.

\subsection{3) FUNÇÕES LINEARES DE DESEMPENHO}

Uma função linear de desempenho pode ser representada como:

$$
g(x)=a_{0}+\sum_{i} a_{i} x_{i}
$$


onde $a_{0}$ e $a_{i}$ 's são constantes. A equação estado limite correspondente é:

$$
a_{0}+\sum_{i} a_{i} x_{i}=0
$$

Em termos das variáveis reduzidas, equação 2.15, a equação estado limite fica:

$$
\mathrm{a}_{0}+\sum_{\mathrm{i}} \mathrm{a}_{\mathrm{i}}\left(\sigma_{\mathrm{X}_{\mathrm{i}}} \mathrm{X}_{\mathrm{i}}^{\prime}+\mu_{\mathrm{X}_{\mathrm{i}}}\right)=0
$$

Em três dimensões, a equação 2.28a é:

$$
a_{0}+a_{1}\left(\sigma_{X_{1}} X^{\prime}{ }_{1}+\mu_{X_{1}}\right)+a_{2}\left(\sigma_{X_{2}} X^{\prime}{ }_{2}+\mu_{X_{2}}\right)+a_{3}\left(\sigma_{X_{3}} X^{\prime}{ }_{3}+\mu_{X_{3}}\right)=0
$$

que é uma superfície plana no espaço $x_{1}^{\prime}, x_{2}^{\prime}, x_{3}^{\prime}$ como mostrado na figura 2.7.

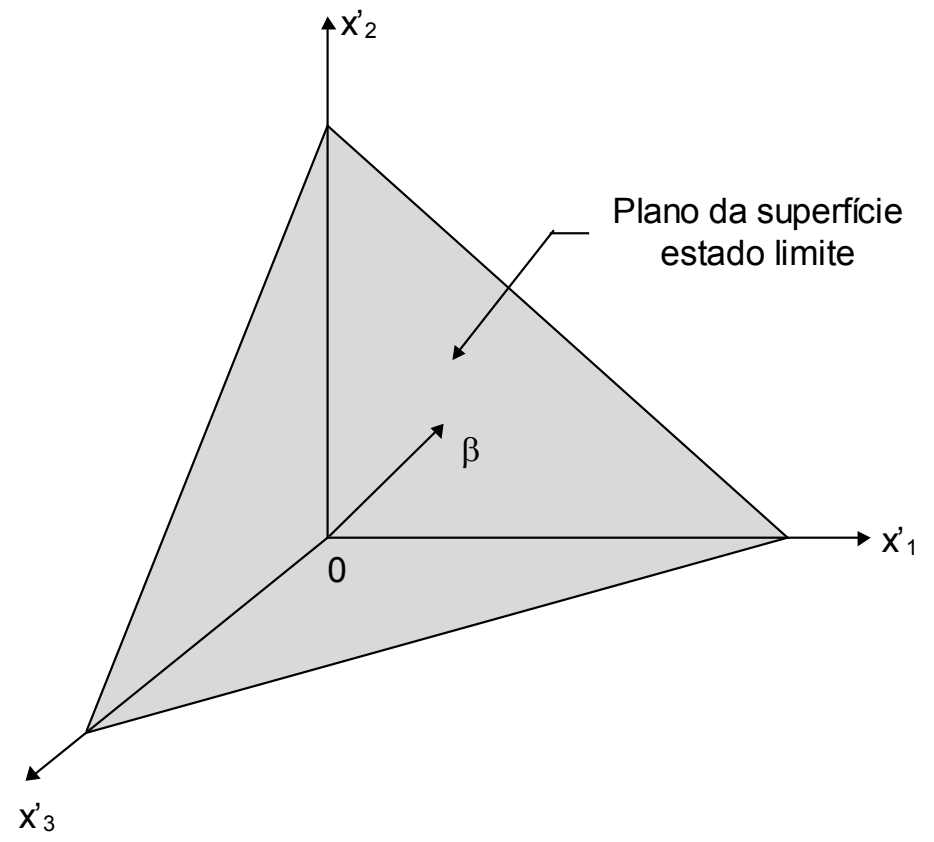

Figura 2.7: Superfície estado limite no espaço tridimensional $x_{1}^{\prime}, x_{2}{ }_{2}, x_{3}{ }_{3}$.

A distância do plano de falha, equação 2.28a, à origem das variáveis reduzidas $\mathbf{X}$ 'é: 


$$
\beta=\frac{a_{0}+\sum_{i} a_{i} \mu_{x_{i}}}{\sqrt{\sum_{i}\left(a_{i} \sigma_{x_{i}}\right)^{2}}}
$$

A equação 2.29 pode também ser obtida diretamente da equação 2.22b. No item 2.2.2 foi visto que para duas variáveis normais não correlacionadas, $\mathrm{X}$ e $\mathrm{Y}$, a probabilidade do estado seguro, $\mathrm{p}_{\mathrm{S}}$, é uma função direta da distância da linha de falha à origem das variáveis reduzidas, ou seja, a distância $\beta$. Este resultado pode ser generalizado, ou seja, se as variáveis aleatórias $X_{1}, X_{2}, \ldots, X_{n}$ são variáveis normais não correlacionadas, a probabilidade do estado seguro é, para este caso:

$$
\begin{aligned}
& p_{s}=P\left(a_{0}+\sum a_{i} x_{i}>0\right) \\
& p_{S}=1-\Phi\left[\frac{-\left(a_{0}+\sum_{i} a_{i} \mu_{x_{i}}\right)}{\sqrt{\sum_{i}\left(a_{i} \sigma_{x_{i}}\right)^{2}}}\right] \\
& p_{S}=\Phi\left[\frac{a_{0}+\sum_{i} a_{i} \mu_{x_{i}}}{\sqrt{\sum_{i}\left(a_{i} \sigma_{x_{i}}\right)^{2}}}\right]
\end{aligned}
$$

Comparando as equações. 2.29 e 2.30, percebe-se que o argumento entre colchetes da equação 2.30 é a distância $\beta$. Portanto, a probabilidade $p_{S}$ é outra vez uma função da distância do plano de falha $g(\mathbf{X})=0$ à origem das variáveis reduzidas. Portanto, no caso geral de $n$ variáveis normais não correlacionadas, a probabilidade de segurança é:

$$
\mathrm{p}_{\mathrm{s}}=\Phi(\beta)
$$




\subsubsection{1) Distribuições normais equivalentes}

Se as distribuições de probabilidade das variáveis aleatórias $\mathrm{X}_{1}, \mathrm{X}_{2}, \cdots, \mathrm{X}_{\mathrm{n}}$ não são normais, a probabilidade $\mathrm{p}_{\mathrm{S}}$ ou $\mathrm{p}_{\mathrm{F}}$ pode ser calculada através da equação 2.14 (invariavelmente, seria necessária a integração numérica), onde no caso de funções de desempenho lineares, $g(\mathbf{X})=a_{0}+\sum a_{i} X_{i}$. Entretanto, $p_{s}$ pode ser calculada também utilizando distribuições normais equivalentes (ANG; TANG, 1984).Teoricamente, tais distribuições normais equivalentes podem ser obtidas através da transformação de Rosenblatt (ANG; TANG. 1984), que não será tratada neste trabalho. Com tais distribuições normais equivalentes, o cálculo de $p_{S}$ segue o mesmo procedimento visto para as variáveis normais, isto é, através da equação 2.30 para funções lineares de desempenho.

Para uma única variável, os parâmetros normais equivalentes de uma variável não normal podem ser obtidos uma vez que, a probabilidade acumulada bem como a ordenada densidade de probabilidade da distribuição normal equivalente sejam iguais àquelas da distribuição não normal correspondente no ponto apropriado, $x_{i}^{*}$, na superfície de falha.

Igualando as probabilidades acumuladas como descrito anteriormente no ponto de falha $x_{i}^{*}$, tem-se:

$$
\Phi\left(\frac{x_{i}^{*}-\mu_{x_{i}}^{N}}{\sigma_{x_{i}}^{N}}\right)=F_{X_{i}}\left(x_{i}^{*}\right)
$$

onde:

$\mu_{X_{i}}^{N}, \sigma_{X_{i}}^{N}=$ valor médio e desvio padrão, respectivamente, da distribuição normal equivalente para $x_{i}^{*}$.

$F_{X_{i}}\left(X_{i}^{*}\right)=$ função de distribuição acumulada original de $X_{i}$ calculada em $x_{i}^{*}$. $\Phi(-)$ = função de distribuição acumulada da distribuição normal padrão. A igualdade acima então resulta: 


$$
\mu_{x_{i}}^{N}=x_{i}^{*}-\sigma_{x_{i}}^{N} \Phi^{-1}\left[F_{X_{i}}\left(x_{i}^{*}\right)\right]
$$

ao passo que igualando as ordenadas de densidade de probabilidade correspondentes em $x_{i}^{*}$ significa:

$$
\frac{1}{\sigma_{x_{i}}^{N}} \phi\left(\frac{x_{i}^{*}-\mu_{x_{i}}^{N}}{\sigma_{X_{i}}^{N}}\right)=f_{x_{i}}\left(x_{i}^{*}\right)
$$

onde $\phi(-)=$ função de distribuição de probabilidade da distribuição normal padrão. Daí resulta:

$$
\sigma_{X_{i}}^{N}=\frac{\phi\left\{\Phi^{-1}\left[\mathrm{~F}_{\mathrm{X}_{\mathrm{i}}}\left(\mathrm{x}_{\mathrm{i}}^{*}\right)\right]\right\}}{f_{\mathrm{X}_{\mathrm{i}}}\left(\mathrm{x}_{\mathrm{i}}^{*}\right)}
$$

No caso de uma função linear de desempenho, o ponto procurado na superfície de falha é dado pela equação $2.23 a$, onde os co-senos diretores, $\alpha_{i}$, equação $2.23 b$, são:

$$
\alpha_{i}=\frac{a_{i}}{\sqrt{\sum_{i} a_{i}^{2}}}
$$

e de acordo com a equação 2.29 , o índice de segurança é:

$$
\beta=\frac{a_{0}+\sum a_{i} \mu_{x_{i}}^{N}}{\sqrt{\sum_{i}\left(a_{i} \sigma_{x_{i}}^{N}\right)^{2}}}
$$

onde o sobrescrito $\mathrm{N}$ indica os parâmetros estatísticos para a distribuição normal equivalente. Portanto, o ponto de falha é:

$$
x_{i}^{*}=\sigma_{X_{i}}^{N} x_{i}^{\prime *}+\mu_{x_{i}}^{N}=-\alpha_{i} \beta \sigma_{X_{i}}^{N}+\mu_{X_{i}}^{N}
$$

Pode ser enfatizado que substituir a distribuição real pela distribuição normal equivalente exige substituir a média e o desvio padrão reais por aqueles da distribuição normal equivalente, isto é, as equações. 2.31 e 2.32. Fazendo isto na equação 2.33, obtém-se o índice de segurança $\beta$, e a correspondente probabilidade de segurança, $p_{S}$, é dada pela equação 2.30a. 


\subsubsection{2) Variáveis correlacionadas}

O procedimento descrito anteriormente para o cálculo da probabilidade de segurança ou de falha é baseado na suposição de que as variáveis aleatórias $\mathrm{X}_{1}, \mathrm{X}_{2}, \cdots, \mathrm{X}_{\mathrm{n}}$ não são correlacionadas. Para variáveis aleatórias correlacionadas, as variáveis originais podem ser transformadas em um conjunto de variáveis não correlacionadas. O procedimento descrito anteriormente, equação $2.22 \mathrm{a}$, pode então ser aplicado ao conjunto não correlacionado de variáveis transformadas.

A transformação requerida é necessariamente dependente das covariâncias ou matriz covariância das variáveis originais e pode ser obtida como segue.

Suponha a matriz covariância das variáveis aleatórias normais $\mathrm{X}_{1}, \mathrm{X}_{2}, \cdots, \mathrm{X}_{\mathrm{n}}$ :

$$
[\mathrm{C}]=\left[\begin{array}{ccccc}
\sigma_{X_{1}}^{2} & \operatorname{Cov}\left(\mathrm{X}_{1}, \mathrm{X}_{2}\right) & \operatorname{Cov}\left(\mathrm{X}_{1}, \mathrm{X}_{3}\right) & \cdots & \operatorname{Cov}\left(\mathrm{X}_{1}, \mathrm{X}_{\mathrm{n}}\right) \\
\operatorname{Cov}\left(\mathrm{X}_{2}, \mathrm{X}_{1}\right) & \sigma_{\mathrm{X}_{2}}^{2} & \operatorname{Cov}\left(\mathrm{X}_{2}, \mathrm{X}_{3}\right) & \cdots & \operatorname{Cov}\left(\mathrm{X}_{2}, \mathrm{X}_{\mathrm{n}}\right) \\
\operatorname{Cov}\left(\mathrm{X}_{3}, \mathrm{X}_{1}\right) & \operatorname{Cov}\left(\mathrm{X}_{3}, \mathrm{X}_{2}\right) & \sigma_{X_{3}}^{2} & \cdots & \operatorname{Cov}\left(\mathrm{X}_{3}, \mathrm{X}_{\mathrm{n}}\right) \\
\vdots & \vdots & \vdots & \cdots & \vdots \\
\operatorname{Cov}\left(\mathrm{X}_{\mathrm{n}}, \mathrm{X}_{1}\right) & \operatorname{Cov}\left(\mathrm{X}_{\mathrm{n}}, \mathrm{X}_{2}\right) & \operatorname{Cov}\left(\mathrm{X}_{\mathrm{n}}, \mathrm{X}_{3}\right) & \cdots & \sigma_{\mathrm{X}_{n}}^{2}
\end{array}\right]
$$

onde os elementos, $\operatorname{Cov}\left(\mathrm{X}_{\mathrm{i}}, \mathrm{X}_{\mathrm{j}}\right)$, são as respectivas covariâncias entre os pares de variáveis $X_{i}$ e $X_{j}$. A correspondente covariância entre um par de variáveis reduzidas, $X_{i}^{\prime}$ e $X_{j}^{\prime}$, é:

$$
\begin{aligned}
\operatorname{Cov}\left(X_{i}^{\prime}, X_{j}^{\prime}\right) & =E\left[\left(X_{i}^{\prime}-\mu_{X_{i}^{\prime}}\right)\left(X_{j}^{\prime}-\mu_{X_{j}^{\prime}}\right)\right] \\
& =\frac{E\left[\left(X_{i}-\mu_{X_{i}}\right)\left(X_{j}-\mu_{X_{j}}\right)\right]}{\sigma_{X_{i}} \sigma_{X_{j}}} \\
& =\frac{\operatorname{Cov}\left(X_{i}, X_{j}\right)}{\sigma_{X_{i}} \sigma_{X_{j}}} \\
& =\rho_{X_{i}, X_{j}}
\end{aligned}
$$


que significa que a covariância entre um par de variáveis reduzidas, $X_{i}^{\prime}$ e $X_{j}^{\prime}$, é igual ao coeficiente de correlação entre o correspondente par de variáveis originais $X_{i}$ e $X_{j}$. Portanto, a matriz covariância das variáveis reduzidas $\left(\mathrm{X}_{1}^{\prime}, \mathrm{X}_{2}^{\prime}, \ldots, \mathrm{X}_{\mathrm{n}}^{\prime}\right)$ é a correspondente matriz correlação das variáveis originais $\left(\mathrm{X}_{1}, \mathrm{X}_{2}, \ldots, \mathrm{X}_{\mathrm{n}}\right)$; ou seja:

$$
\left[C^{\prime}\right]=\left[\begin{array}{ccccc}
1 & \rho_{12} & \rho_{13} & \cdots & \rho_{1 \mathrm{n}} \\
\rho_{21} & 1 & \rho_{23} & \cdots & \rho_{2 \mathrm{n}} \\
\vdots & \vdots & \vdots & \cdots & \vdots \\
\rho_{\mathrm{n} 1} & \rho_{\mathrm{n} 2} & \rho_{\mathrm{n} 3} & \cdots & 1
\end{array}\right]
$$

O conjunto requerido de variáveis transformadas (não correlacionadas) pode ser obtido de $\mathbf{X}$ ' através da seguinte transformação ortogonal:

$$
\mathbf{Y}=\mathbf{T}^{\mathrm{t}} \mathbf{X}^{\mathbf{\prime}}
$$

em que:

$\mathbf{X}^{\prime}=\left\{\mathrm{X}_{1}^{\prime}, \mathrm{X}_{2}^{\prime}, \ldots, \mathrm{X}_{\mathrm{n}}^{\prime}\right\}$.

$\mathbf{Y}=\left\{Y_{1}, Y_{2}, \ldots, Y_{n}\right\} \quad$ é o conjunto de variáveis transformadas não correlacionadas procurado.

$\mathbf{T}=$ Uma matriz transformação ortogonal.

T será uma matriz ortogonal se ela é composta dos autovetores correspondentes aos autovalores da matriz correlação [C']. Especificamente, T é tal que

$$
\mathbf{T}^{\mathrm{t}}\left[\mathrm{C}^{\prime}\right] \mathbf{T}=[\lambda]
$$

em que $[\lambda]$ é uma matriz diagonal dos autovalores de [C']. Deve ser enfatizado que a matriz [C'] é real e simétrica, pois $\rho_{\mathrm{ij}}=\rho_{\mathrm{ji}}$; e assim os autovetores são mutuamente ortogonais. 
Com a transformação ortogonal da equação 2.37 , pode ser mostrado (Shinozuka, 1983) que o índice de segurança da equação 2.22a fica:

$$
\beta=\frac{-\mathbf{G}^{* t} \mathbf{X}^{\prime *}}{\left(\mathbf{G}^{{ }^{t}}\left[\mathbf{C}^{\prime}\right] \mathbf{G}^{*}\right)^{1 / 2}}
$$

As variáveis reduzidas $\mathbf{X}^{\prime}$ e as variáveis originais $\mathbf{X}$ são relacionadas com $\mathbf{Y}$ como segue. Sendo $\mathbf{T}$ ortogonal, $\mathbf{T}^{-1}=\mathbf{T}^{\mathrm{t}}$; a inversão da equação 2.37 resulta:

$$
\mathbf{X}^{\prime}=\mathbf{T Y}
$$

e

$$
\begin{aligned}
& \mathbf{X}=\left[\sigma_{\mathbf{X}}\right] \mathbf{X}^{\prime}+\mu_{\mathbf{X}} \\
& \mathbf{X}=\left[\sigma_{\mathbf{X}}\right] \mathbf{T Y}+\mu_{\mathbf{X}}
\end{aligned}
$$

em que

$$
\left[\sigma_{X}\right]=\left[\begin{array}{cccc}
\sigma_{X_{1}} & 0 & \cdots & 0 \\
0 & \sigma_{X_{2}} & \cdots & 0 \\
\vdots & \vdots & \cdots & \vdots \\
0 & 0 & \cdots & \sigma_{X_{n}}
\end{array}\right]
$$

e

$$
\mu_{X}=\left\{\begin{array}{c}
\mu_{X_{1}} \\
\mu_{X_{2}} \\
\vdots \\
\mu_{x_{n}}
\end{array}\right\}
$$

Observe que a matriz covariância de Y é:

$$
\begin{aligned}
& {\left[\mathrm{C}_{\mathbf{Y}}\right]=\mathrm{E}\left(\mathbf{Y} \mathbf{Y}^{\mathrm{t}}\right)=\mathrm{E}\left(\mathbf{T}^{\mathrm{t}} \mathbf{X}^{\prime} \mathbf{X}^{\left.\mathbf{H}^{\mathrm{t}} \mathbf{T}\right)}\right.} \\
& {\left[\mathrm{C}_{\mathbf{Y}}\right]=\mathbf{T}^{\mathrm{t}} \mathrm{E}\left(\mathbf{X}^{\prime} \mathbf{X}^{\mathrm{t}}\right) \mathbf{T}}
\end{aligned}
$$

mas

$$
E\left(X^{\prime} \mathbf{X}^{\prime t}\right)=\left[C^{\prime}\right]
$$


Assim, com a equação 2.38:

$$
\left[\mathrm{C}_{\mathrm{Y}}\right]=\mathbf{T}^{\mathrm{t}}\left[\mathrm{C}^{\prime}\right] \mathbf{T}=[\lambda]
$$

Portanto, os autovalores de [C'] são também as variâncias das respectivas variáveis $Y_{1}, Y_{2}, \ldots, Y_{n}$.

No espaço das variáveis transformadas $\mathbf{Y}$, as derivadas parciais podem ser obtidas como segue:

$$
\frac{\partial g}{\partial Y_{i}}=\sum_{j=1}^{n} \frac{\partial g}{\partial X_{j}^{\prime}} \frac{\partial X_{j}^{\prime}}{\partial Y_{i}}
$$

Além disso:

$$
\frac{\partial g}{\partial X_{j}^{\prime}}=\frac{\partial g}{\partial X_{j}} \cdot \frac{d X_{j}}{X_{j}^{\prime}}=\sigma_{X_{j}}\left(\frac{\partial g}{\partial X_{j}}\right)
$$

A transformação da equação 2.37 representa uma rotação das coordenadas de $\mathbf{X}$ ' para $\mathbf{Y}$; para o caso de duas variáveis, esta transformação é ilustrada pela figura 2.8. A origem dos eixos $Y$ permanece a mesma que a dos eixos $\mathbf{X}$.

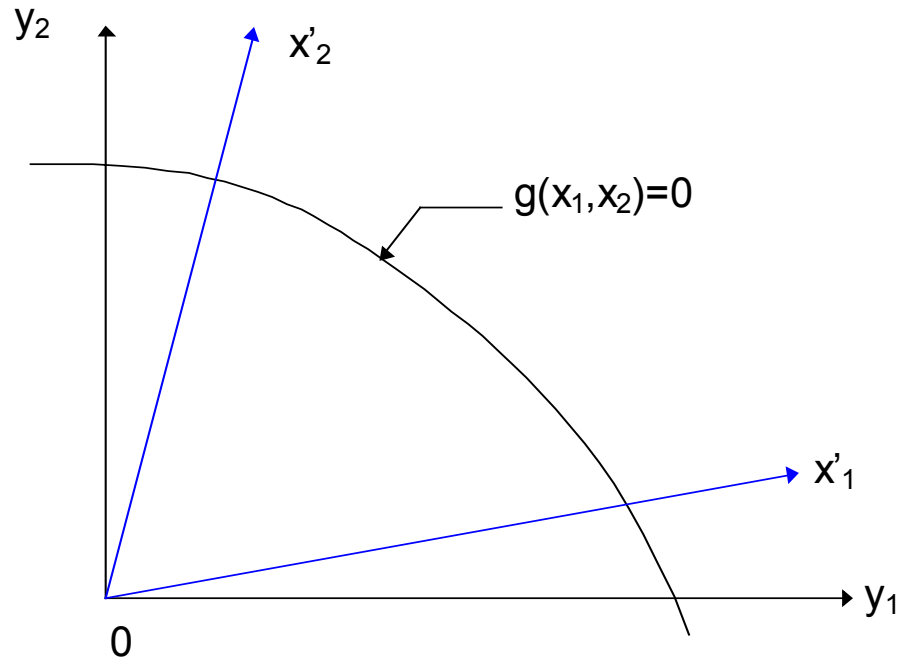

Figura 2.8: Rotação das coordenadas X' para Y.

A transformação exposta obviamente se aplica também a funções de desempenho lineares; onde neste caso, as derivadas parciais da equação 2.40 são independentes das variáveis, e assim o ponto de falha $\mathbf{y}^{*}$ e $\mathbf{x}^{*}$ 
podem ser determinados diretamente; isto é, uma iteração do algoritmo é suficiente. Alternativamente, para funções lineares de desempenho de variáveis normais correlacionadas, o índice de segurança pode também ser determinado diretamente da equação 2.22 c ou baseado na equação 2.27 , resultando:

$$
\beta=\frac{\mu_{g}}{\sigma_{g}}=\frac{a_{0}+\sum_{i=1}^{n} a_{i} \mu_{X_{i}}}{\sqrt{\sum_{i=1}^{n} \sum_{j=1}^{n} a_{i} a_{j} \rho_{i j} \sigma_{X_{i}} \sigma_{X_{j}}}}
$$

em que $\rho_{i j}$ é o coeficiente de correlação entre $X_{i}$ e $X_{j}$.

Novamente, se a distribuição das variáveis aleatórias originais não é normal, a correspondente probabilidade de segurança ou de falha pode ser calculada usando distribuições normais equivalentes, em tais casos, os valores médios e os desvios padrão das distribuições normais equivalentes, $\mu_{x_{i}}^{N}$ e $\sigma_{x_{i}}^{N}$, devem ser usados no lugar de $\mu_{x_{i}}$ e $\sigma_{x_{i}}$, na equação 2.41 .

\subsection{4) FUNÇÕES NÃO LINEARES DE DESEMPENHO}

Para funções de desempenho, $\mathbf{g}(\mathbf{X})$, que não são lineares, o cálculo da probabilidade exata de segurança ou de falha geralmente será envolvido. A equação estado limite, $g(\mathbf{X})=0$, será também não linear; ao contrário do caso linear, não há uma única distância da superfície de falha à origem das variáveis reduzidas. Como indicado no item 2.2.2, o cálculo da probabilidade exata de segurança envolve a integração da função densidade de probabilidade conjunta sobre a região não linear $\mathbf{g}(\mathbf{X})>0$, e geralmente isto exigirá quadratura numérica múltipla.

Para propósitos práticos, será necessária uma aproximação para a probabilidade de falha ou de segurança. De acordo com os resultados do item 2.2.2, o ponto $\left(\mathrm{X}_{1}^{\prime \prime^{*}}, \mathrm{X}_{2}^{\prime{ }^{*}}, \ldots, \mathrm{X}_{\mathrm{n}}^{\prime *}\right)$ na superfície de falha com mínima distância à origem das variáveis reduzidas é o ponto mais provável de falha 
(SHINOZUKA, 1983). O plano tangente à superfície de falha em $\left(\mathbf{X}_{1}^{\prime \prime^{*}}, \mathrm{X}_{2}^{\prime^{*}}, \ldots, \mathbf{X}_{\mathrm{n}}^{\prime^{*}}\right)$ pode então ser utilizado como aproximação para a superfície de falha, e o índice de confiabilidade ou a probabilidade de segurança procurada pode ser calculada como no caso linear do item 2.2.3. Se a superfície de falha não linear exata for convexa ou côncava para a origem, esta aproximação será segura ou insegura, respectivamente, como pode ser visto na figura 2.9 para o caso de duas variáveis.

$$
\begin{aligned}
& \text { O plano tangente em } \mathbf{x}^{\prime^{*}}=\left(\mathbf{X}_{1}^{\prime^{*}}, \mathbf{X}_{2}^{\mathbf{\prime}^{*}}, \ldots, \mathbf{X}_{\mathrm{n}}^{\mathbf{\prime}^{*}}\right) \text { é: } \\
& \sum_{i=1}^{n}\left(X_{i}^{\prime}-X_{i}^{\prime^{*}}\right)\left(\frac{\partial g}{\partial X_{i}^{\prime}}\right)_{*}=0
\end{aligned}
$$

onde as derivadas parciais $\left(\partial \mathrm{g} / \partial \mathbf{X}_{i}^{\prime}\right)$, são calculadas em $\left(\mathbf{X}_{1}^{\mathbf{\prime}^{*}}, \mathbf{X}_{2}^{\prime^{*}}, \ldots, \mathbf{X}_{\mathrm{n}}^{\prime^{*}}\right)$.

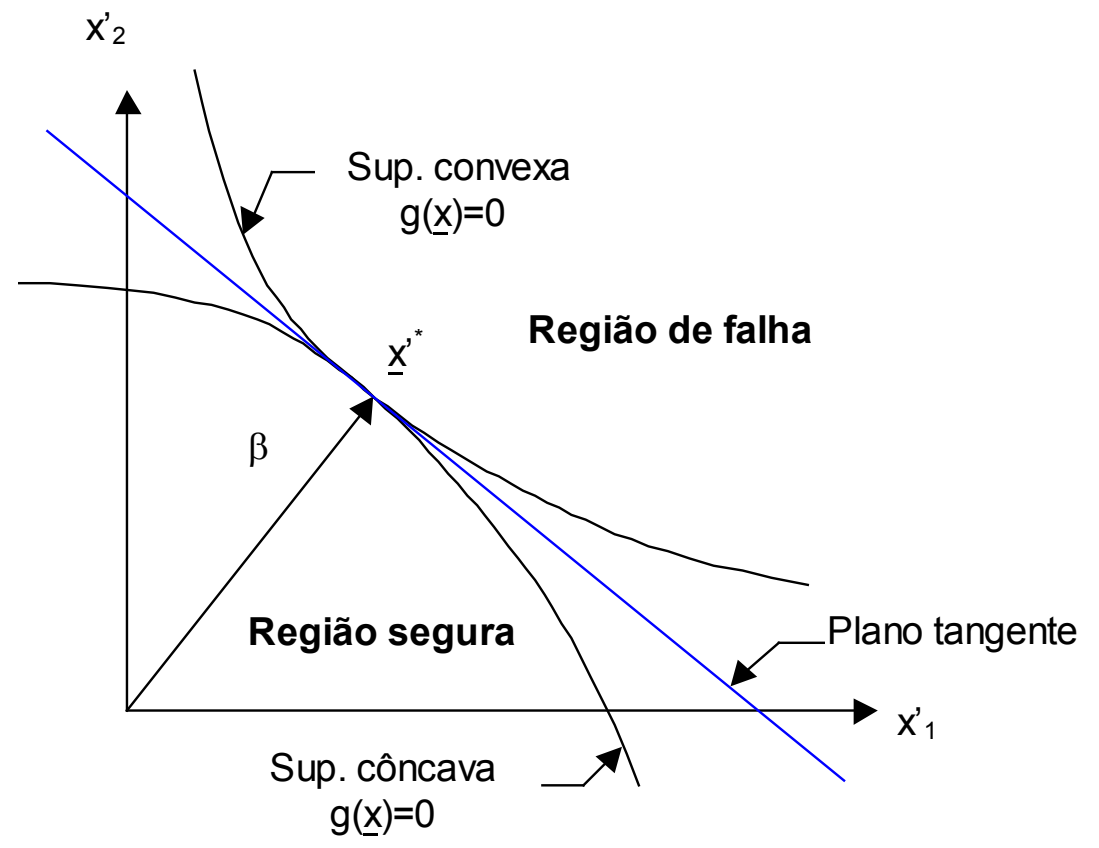

Figura 2.9: Plano tangente à $g(\mathbf{X})=0 \mathrm{em} \mathbf{x}^{\mathbf{\prime}^{*}}$.

Baseado no exposto, a distância do "mínimo" plano tangente (plano tangente correspondente à mínima distância), equação 2.42 , à origem das 
variáveis reduzidas é o índice de confiabilidade apropriado, que pode ser usado para representar a medida de confiabilidade.

No presente caso, o ponto de tangência na superfície de falha não é, a priori, conhecido. Consequentemente, a determinação do índice de confiabilidade requerido não será tão simples como no caso linear, mesmo que uma aproximação linear tenha sido feita. O ponto "mínimo" de tangência na superfície de falha pode ser determinado através do método de multiplicador de Lagrange como descrito no item 2.2.2. Os resultados relevantes deste item podem ser resumidos como segue.

O ponto mais provável de falha da equação 2.23a é:

$$
x_{i}^{\prime *}=-\alpha_{i}^{*} \beta
$$

em que $\alpha_{i}^{*}$ são os co-senos diretores da equação 2.23b:

$$
\alpha_{i}^{*}=\frac{\left(\frac{\partial g}{\partial X_{i}^{\prime}}\right)_{*}}{\sqrt{\sum_{i}\left(\frac{\partial g}{\partial X_{i}^{\prime}}\right)_{*}^{2}}}
$$

onde as derivadas parciais são calculadas em $\left(\mathbf{X}_{1}^{\prime^{*}}, \mathbf{X}_{2}^{\prime{ }^{*}}, \ldots, \mathbf{X}_{n}^{\mathbf{\prime}^{*}}\right)$. Tem-se que:

$$
x_{i}^{*}=\sigma_{x_{i}} x_{i}^{\prime *}+\mu_{x_{i}}=\mu_{x_{i}}-\alpha_{i}^{*} \sigma_{X_{i}} \beta
$$

A solução da equação estado limite $g\left(x_{1}^{*}, x_{2}^{*}, \ldots, x_{n}^{*}\right)=0$ conduz ao valor de $\beta$. Algoritmo numérico: os resultados resumidos anteriormente podem sugerir o seguinte algoritmo simples (ANG; TANG, 1984):

(1) Assume-se valores iniciais de $x_{i}^{*} ; i=1,2, \ldots, n$ e obtém-se:

$$
x_{i}^{\prime^{*}}=\frac{x_{i}^{*}-\mu_{x_{i}}}{\sigma_{x_{i}}}
$$

(2) Calcula-se $\left(\partial g / \partial X_{i}^{\prime}\right)_{*}$ e $\alpha_{i}^{*}$ em $x_{i}^{\prime *}$.

(3) Faz-se $x_{i}^{*}=\mu_{x_{i}}-\alpha_{i}^{*} \sigma_{x_{i}} \beta$.

(4) Substitui-se $x_{i}^{*}$ acima em $g\left(x_{1}^{*}, x_{2}^{*}, \ldots, x_{n}^{*}\right)=0$ e resolve-se para $\beta$. 
(5) Usando o $\beta$ obtido no passo (4), recalcula-se $x_{i}^{\prime *}=-\alpha_{i}^{*} \beta$.

(6) Repete-se os passos (2) a (5) até obter-se a convergência.

\subsubsection{1) Precisão da aproximação linear}

Como exposto anteriormente, a aproximação "linear" de funções não lineares de desempenho é equivalente a substituir uma superfície de falha ndimensional por um plano tangente a esta superfície de falha no "ponto mais provável de falha". Na realidade, isto muda o limite entre o estado seguro, $g(\mathbf{X})>0$, e o estado de falha, $\mathbf{g}(\mathbf{X})<0$, de uma superfície curvilínea geral para uma superfície plana; a probabilidade de falha, $p_{F}$, é então a integral no volume da função de distribuição de probabilidade conjunta sobre a região de falha $g(\mathbf{X})<0$. Como observado anteriormente da figura 2.9, a confiabilidade $\mathrm{p}_{\mathrm{S}}$ estimada baseada nesta superfície de falha plana aproximada será conservadora ou não conservadora, dependendo se a superfície de falha real é convexa ou côncava para a origem das variáveis reduzidas. A precisão pode ser melhorada através de aproximações quadráticas ou polinomiais com a desvantagem de complicações matemáticas e computacionais.

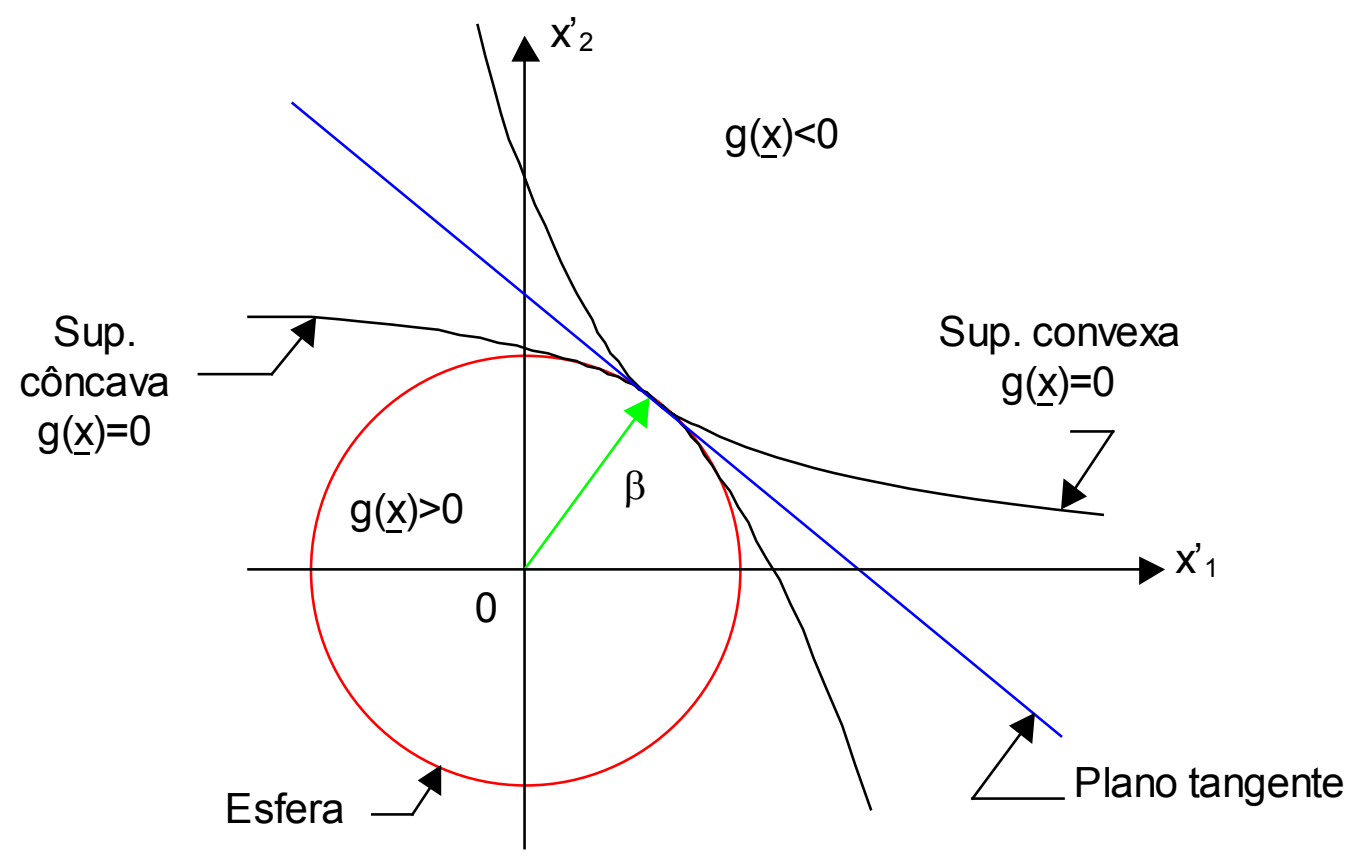

Figura 2.10: Implicações de várias superfícies de falha. 
Para uma superfície de falha côncava, o estado seguro, $g(\mathbf{X})>0$, é limitado entre o meio-espaço com o plano tangente (de distância $\beta$ ) e a esfera de raio $\beta$ (como ilustrado na figura 2.10 para duas dimensões). A equação correspondente de falha para a esfera é (HASOFER, 1974):

$$
\sum_{i=1}^{n} X_{i}^{\prime 2}-\beta^{2}=0
$$

Se as variáveis $X_{i}$ são variáveis normais padrão não correlacionadas, a soma dos quadrados $\sum_{i=1}^{n} X_{i}^{\prime 2}$ tem uma distribuição qui-quadrada com $n$ graus de liberdade. Portanto, a probabilidade de falha fica:

$$
p_{F}=1-\chi_{n}^{2}\left(\beta^{2}\right)
$$

onde $\chi_{n}^{2}(-)$ é a função de distribuição acumulada da distribuição quiquadrada com $n$ graus de liberdade.

Para superfícies de falha côncavas a probabilidade de falha é limitada como indicado a seguir:

$$
\Phi(-\beta)<\mathrm{p}_{\mathrm{F}}<1-\chi_{\mathrm{n}}^{2}\left(\beta^{2}\right)
$$

Em geral, a precisão da aproximação linear de segundo momento é de difícil acesso, o que dependerá do grau de não linearidade da função $\mathbf{g}(\mathbf{X})$, obviamente, o método é matematicamente exato se $\mathbf{g}(\mathbf{X})$ é linear. Para uma função $\mathbf{g}(\mathbf{X})$ não linear geral, a precisão somente pode ser avaliada numericamente para formas específicas de funções de desempenho não lineares, utilizando métodos como o Monte Carlo, por exemplo.

Para ilustrar o exposto acima considera-se que a capacidade plástica de resistência à flexão da seção de uma viga de aço pode ser dada por $\mathrm{X}_{1} . \mathrm{X}_{2}$, onde:

$$
\begin{aligned}
& X_{1}=\text { limite de escoamento do aço } \\
& X_{2}=\text { módulo plástico da seção }
\end{aligned}
$$


Então se o momento fletor aplicado à referida seção é $X_{3}$, a função de desempenho pode ser definida como:

$$
g(\mathbf{X})=X_{1} X_{2}-X_{3}
$$

Assumindo que as variáveis $\left(\mathrm{X}_{1}, \mathrm{X}_{2}\right.$ e $\left.\mathrm{X}_{3}\right)$ são normais e não correlacionadas os resultados apresentados por ANG; TANG (1984) estão listados a seguir para ilustração da precisão da aproximação linear apresentada:

Tabela 2.2: Comparação de probabilidades de falha calculadas.

\begin{tabular}{|c|c|c|c|c|}
\cline { 3 - 4 } \multicolumn{2}{c|}{} & \multicolumn{3}{c|}{ Monte Carlo } \\
\hline & $\begin{array}{c}\mathrm{p}_{\mathrm{F}} \text { calculado } \\
\text { por segundo } \\
\text { momento }\end{array}$ & $\mathrm{p}_{\mathrm{F}}$ esperado & $\begin{array}{c}\text { Intervalo de } \\
\text { confiança de } \\
95 \%\end{array}$ & $\begin{array}{c}\text { Tamanho da } \\
\text { amostra }\end{array}$ \\
\hline $\mathrm{X}_{1} \cdot \mathrm{X}_{2}-\mathrm{X}_{3}$ & 0,0031 & 0,0034 & $0,0029-0,0040$ & 50.000 \\
\hline
\end{tabular}




\section{CAPÍTULO 3 - CRITÉRIO dE CÁLCULO}

\section{BASEADO EM PROBABILIDADE}

\section{1) Critério de cálculo}

O principal objetivo de projetos e cálculos de engenharia é garantir o desempenho do sistema ou produto de cálculo. Como isto só pode ser alcançado sob condições de incertezas, a garantia de desempenho é realmente possível somente em termos de probabilidade, ou seja $\mathrm{p}_{\mathrm{s}}$. Em geral, análises probabilísticas serão necessárias para o desenvolvimento de tais cálculos baseados em probabilidade. Entretanto, pode-se também desenvolver cálculos satisfazendo tais condições de confiabilidade sem uma análise probabilística completa, isto é alcançado através da adoção de critérios de cálculos determinísticos apropriados (por exemplo, o uso de tradicionais "coeficientes de segurança"). De fato, bases probabilísticas para o cálculo serão mais efetivas se implementadas desta forma, isto pode ser conseguido se os "coeficientes de segurança" são pré-determinados por condições específicas baseadas em probabilidade. Em particular, para o propósito de cálculos mais rotineiros, os métodos de cálculo podem ser especificados em normas de cálculo de estruturas, onde tais métodos 
também deverão ser desenvolvidos para satisfazer confiabilidades especificadas.

Por razões óbvias, os métodos de cálculo deverão ser tão simples quanto possível, além disto, eles deverão ser desenvolvidos de uma forma familiar aos usuários ou calculistas. Não há uma forma única para um método de cálculo, ele pode ser desenvolvido em uma base probabilística, independentemente da forma.

Uma aproximação tradicional e comum para a introdução da segurança é através do uso de coeficientes de segurança. Estes coeficientes de segurança são utilizados na engenharia estrutural quando os cálculos são feitos em tensões admissíveis. Outra forma é a utilização de coeficientes de ponderação das ações e coeficientes de resistência, ou seja, as ações nominais são majoradas pelos coeficientes de ponderação apropriados e as resistências nominais são minoradas pelos correspondentes coeficientes de resistência, e a segurança é assegurada se a resistência "minorada" for maior ou igual às solicitações "majoradas".

Em um ou outro formato, os coeficientes de cálculo necessários podem ser desenvolvidos para obter projetos que alcancem um nível de confiabilidade prescrito, $p_{s}$. Os coeficientes de cálculo são, freqüentemente, destinados a cobrir incertezas ou compensar falta de informações.

\subsection{1) PROBLEMA BÁSICO DE CÁLCULO}

Com base na premissa de que um projeto de engenharia é destinado a garantir a segurança ou o bom desempenho com uma dada confiabilidade $\mathrm{p}_{\mathrm{s}}$, o problema básico de cálculo, portanto, envolve a determinação da posição da função de distribuição de probabilidade da resistência, como mostrado na figura 2.2.a, tal que esta esteja suficientemente separada da função de distribuição de probabilidade das 
solicitações para que a probabilidade de falha $p_{F}$ satisfaça a um valor aceitável ou um valor alvo. Novamente, além da separação entre $f_{\mathrm{X}}(\mathrm{x})$ e $f_{\mathrm{Y}}(\mathrm{y})$, a probabilidade de falha, $\mathrm{p}_{\mathrm{F}}$, é também uma função do grau de dispersão $\left(\sigma_{X}\right.$ e $\left.\sigma_{Y}\right)$. Uma quantidade que representa estas duas influências é o índice de confiabilidade ou índice de segurança $\beta$. Portanto, especificando um valor de $\beta$ é equivalente a prescrever uma confiabilidade alvo, $\mathrm{p}_{\mathrm{S}}$, ou uma probabilidade de falha aceitável, $\mathrm{p}_{\mathrm{F}}$.

Uma forma de alcançar a confiabilidade de um dado projeto é usar uma margem de segurança média suficientemente grande, $\mu_{M}=\mu_{X}-\mu_{Y}$. Da equação 2.7, vê-se que para garantir uma confiabilidade alvo, em termos de um dado índice de segurança $\beta$, a margem de segurança média requerida é:

$$
\mu_{M}=\beta \sqrt{\sigma_{X}^{2}+\sigma_{Y}^{2}}
$$

Assim, a resistência média requerida (representando o projeto requerido) será:

$$
\mu_{\mathrm{X}}=\mu_{\mathrm{Y}}+\mu_{\mathrm{M}}
$$

Para o propósito de cálculo normalizado, isto é, estabelecer previsões de cálculos em normas, a forma mais geral é a utilização de coeficientes múltiplos de ações e resistência, como representado pela seguinte condição;

$$
\phi R \geq \sum_{i=1}^{n} \gamma_{i} S_{i}
$$

onde:

$$
\begin{aligned}
& \phi=\text { coeficiente de resistência } \\
& \gamma_{i}=\text { coeficiente de ponderação das ações para ser aplicado à } \\
& \text { ação } Q_{i} \text { ou à solicitação } S_{i} \text {. }
\end{aligned}
$$

As vantagens da forma de múltiplos coeficientes da equação 3.1 são: 
- os coeficientes individuais, $\phi$ e $\gamma_{i}$, são relativamente insensíveis a mudanças nos parâmetros de cálculo (por exemplo, as relações de ações entre as várias ações) e assim um dado conjunto de coeficientes de resistência e de ponderação das ações se aplicam à uma larga extensão de condições de cálculo, o que é uma característica desejável para previsões em normas;

- com os coeficientes de resistência e de ponderação parciais das ações, qualquer outra forma de coeficientes de cálculo, tais como os coeficientes de segurança, podem ser facilmente calculados ou derivados.

\section{2) Métodos de segundo momento}

Mesmo que um cálculo específico baseado em confiabilidade possa ser alcançado usando a margem de segurança ou o coeficiente de segurança adequado, o cálculo de uma classe de sistemas pode requerer uma forma mais geral para o método de cálculo. A forma mais geral e versátil de métodos de cálculo é especificar um coeficiente de cálculo para cada variável de cálculo. Consistente com situações práticas, como descrito na item 2.2.2, os necessários critérios de cálculo baseados em probabilidade têm sempre que ser desenvolvidos com base em aproximações de segundo momento, ou seja, os métodos devem ser formulados com base em informações para os primeiros e segundos momentos das variáveis de cálculo.

No espaço das variáveis reduzidas, cálculos em diferentes níveis de segurança podem ser vistos como correspondentes para satisfazer a diferentes superfícies de falha representadas pelas várias distâncias à origem, $\beta$, como mostrado na figura 3.1. O desenvolvimento de um critério de cálculo é essencialmente equivalente à determinação dos coeficientes de cálculo que resultarão em projetos com superfícies de falha que cumpram com um índice de segurança exigido, isto é, a distância da superfície de falha à origem das variáveis reduzidas deve satisfazer a algum valor alvo 
previamente determinado. Como indicado anteriormente, a forma de cálculo mais geral é aplicar um coeficiente de cálculo em cada uma das variáveis básicas de cálculo, conhecido também como método dos "coeficientes parciais". Sem perda de generalidade, estes coeficientes podem ser aplicados aos respectivos valores médios das variáveis de cálculo, assim:

$$
g\left(\bar{\gamma}_{1} \mu_{x_{1}}, \bar{\gamma}_{2} \mu_{x_{2}}, \ldots, \bar{\gamma}_{n} \mu_{x_{n}}\right)=0
$$

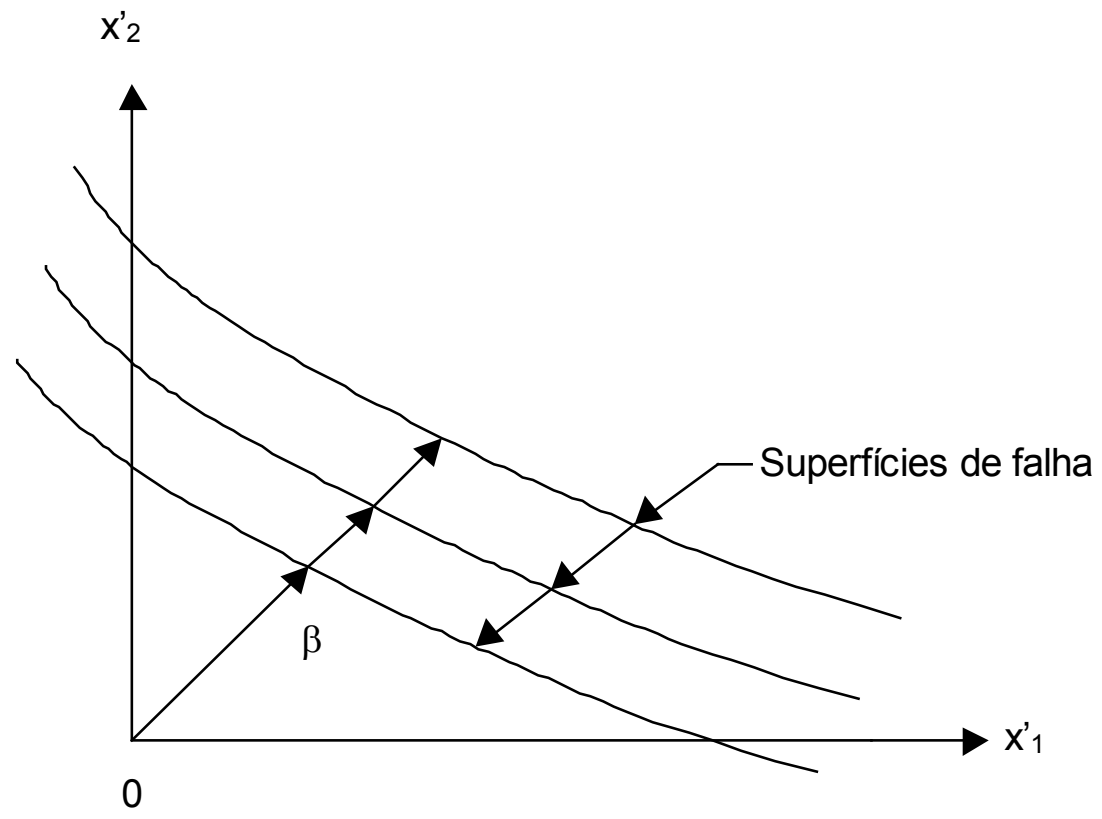

Figura 3.1: Projetos correspondentes a diferentes superfícies de falha.

Os valores $\bar{\gamma}_{\mathrm{i}} \mu_{\mathrm{x}_{\mathrm{i}}}$ da equação 3.2 deverão estar na superfície de falha, em particular, eles devem estar no ponto mais provável de falha. Assim, os coeficientes parciais de cálculo procurados são:

$$
\bar{\gamma}_{\mathrm{i}}=\frac{\mathrm{x}_{\mathrm{i}}^{*}}{\mu_{\mathrm{x}_{\mathrm{i}}}}
$$

Portanto, a determinação dos coeficientes de cálculo procurados é também um problema de determinar o ponto mais provável de falha, $x_{i}^{*}$.

No espaço das variáveis reduzidas, o ponto mais provável de falha, da equação 2.23a, é:

$$
X_{i}^{\prime^{*}}=-\alpha_{i}^{*} \beta
$$


onde:

$$
\alpha_{i}^{*}=\frac{\left(\frac{\partial g}{\partial \mathbf{X}_{i}^{\prime}}\right)_{*}}{\sqrt{\sum_{i}\left(\frac{\partial g}{\partial \mathbf{X}_{i}^{\prime}}\right)_{*}^{2}}}
$$

As variáveis originais podem ser obtidas de:

$$
x_{i}^{*}=\mu_{x_{i}}-\alpha_{i}^{*} \beta \sigma_{x_{i}}=\mu_{x_{i}}\left(1-\alpha_{i}^{*} \beta \delta_{x_{i}}\right)
$$

Portanto, os coeficientes de cálculo procurados são:

$$
\gamma_{i}=1-\alpha_{i}^{*} \beta \delta_{x_{i}}
$$

Na equação 3.4 , os co-senos diretores, $\alpha_{i}^{*}$, devem ser calculados no ponto mais provável de falha $x_{i}^{*}$. Em geral, a determinação de $x_{i}^{*}$ requer uma solução iterativa. Para este propósito, o algoritmo simples apresentado a seguir pode ser usado:

(1) Assume-se $x_{i}^{*}$ e obtém-se:

$$
x_{i}^{\prime *}=\frac{x_{i}^{*}-\mu_{x_{i}}}{\sigma_{x_{i}}}
$$

(2) Calcula-se $\left(\partial g / \partial X_{i}^{\prime}\right)$ * e $\alpha_{i}^{*}$.

(3) Obtém-se $x_{i}^{*}=\mu_{x_{i}}-\alpha_{i}^{*} \beta \sigma_{x_{i}}$.

(4) Repete-se os passos de (1) a (3) até atingir a convergência.

Os coeficientes de cálculo procurados são então obtidos com a equação 3.4. Para variáveis não normais, $\mu_{x_{i}}$ e $\sigma_{X_{i}}$ devem ser substituídos pelas médias e desvios padrão normais equivalentes $\mu_{x_{i}}^{N}$ e $\sigma_{x_{i}}^{N}$ no algoritmo acima. 


\subsection{1) FUNÇÃO DE DESEMPENHO LINEAR}

Para funções lineares de desempenho, os coeficientes de cálculo, $\gamma_{i}$, são tais que:

$$
a_{0}+\sum_{i} a_{i} \gamma_{i} \bar{x}_{i}=0
$$

Neste caso, as derivadas parciais são independentes de $\mathrm{x}_{\mathrm{i}}$, isto é:

$$
\frac{\partial g}{\partial X_{i}^{\prime}}=a_{i} \sigma_{X_{i}}
$$

e os correspondentes co-senos diretores resultam:

$$
\alpha_{i}=\frac{a_{i} \sigma_{x_{i}}}{\sqrt{\sum_{i}\left(a_{i} \sigma_{x_{i}}\right)^{2}}}
$$

Então, os coeficientes de cálculo procurados, equação 3.4, são:

$$
\gamma_{i}=1-\frac{a_{i} \sigma_{x_{i}}}{\sqrt{\sum_{i}\left(a_{i} \sigma_{X_{i}}\right)^{2}}} \beta \delta_{x_{i}}
$$

Portanto, tendo-se os valores médios, desvios padrão ou coeficientes de variação, relações entre os valores nominais e médios das variáveis pode-se então calcular os coeficientes a serem aplicados aos valores nominais das variáveis do problema em estudo. 


\section{CAPÍtulO 4 - COEFICIENTES DE}

\section{CÁlCULO PARA AS NORMAS EM ESTADOS LIMITES}

\section{1) Introdução}

Normas para cálculo estrutural devem conter condições para garantir que as estruturas se comportem satisfatoriamente sob o efeito de várias ações. Estas condições, que incluíam fatores de segurança, tensões admissíveis e limites de deslocamentos, eram desenvolvidas subjetivamente através da extensa experiência profissional bem ou mal sucedida, análise de dados experimentais disponíveis, teoria e juízo. Mas, se os critérios utilizados para garantir o bom desempenho das estruturas são desenvolvidos para diferentes materiais e métodos de construção, por grupos profissionais interessados e com diversas filosofias de cálculo, isto não garante níveis consistentes de segurança e desempenho para diferentes estruturas.

Esta diversidade considerável complica o processo de introdução da segurança no cálculo. O diferente tratamento dado às ações em cada especificação (norma de cálculo) tende a causar confusão e criar a necessidade de realização de análises separadas para a mesma estrutura, quando mais de um material estrutural for utilizado. Para simplificar estas 
análises tornou-se desejável o desenvolvimento de coeficientes de ponderação e regras de combinações das ações que estivessem incluídas em normas governando ações e cálculo geral para todos os materiais estruturais. Os grupos individuais de pesquisa e elaboração das normas técnicas do material selecionariam então critérios de resistência compatíveis com as condições gerais de ações.

A tendência contemporânea em desenvolvimento de normas é a utilização de conceitos probabilísticos como a base para selecionar critérios de cálculo. A maioria das ações variam com o tempo. Se o elemento estrutural estiver submetido a somente uma ação variável além da ação permanente, a confiabilidade pode ser determinada considerando a combinação da ação permanente com a máxima ação variável esperada durante algum período de referência "T", considerado apropriado para o projeto. Frequentemente, entretanto, mais de uma ação variável atua em uma estrutura. Quando isto ocorre, é extremamente improvável que cada ação alcance seu valor máximo ao mesmo tempo. Consequentemente, um elemento estrutural pode ser calculado sob uma ação total menor do que a soma das máximas ações individuais, isto é correntemente reconhecido e adotado pelas atuais normas de ações e segurança.

Conceitualmente, estas combinações de ações deveriam ser tratadas com a utilização da teoria de processos estocásticos que consideram a natureza estocástica e correlação das ações no espaço e no tempo. Para análises práticas de confiabilidade, entretanto, é preferível trabalhar com representações de variáveis aleatórias do que com representações de processos aleatórios. Talvez a aproximação mais simples para tratar combinações de ações é assumir que a máxima combinação das ações ocorrerá quando uma das ações estiver com o seu valor máximo, enquanto as outras ações assumem seus valores instantâneos ou arbitrados em um certo tempo. Em outras palavras, a máxima combinação "S" de uma soma de várias ações, $X_{i}$, durante o período de referência, $T$, é: 


$$
S=\max _{i}\left[\max _{T} X_{i}+\sum_{j \neq i} X_{j}\right]
$$

Segundo GALAMBOS (1982), a equação 4.1 é uma boa aproximação em muitos casos práticos, embora ela tenda a ser não conservadora em exemplos onde a probabilidade de ocorrência conjunta de mais de uma ação máxima não seja desprezível.

\section{2) Análise dos níveis de confiabilidade do cálculo em tensões admissíveis}

\subsection{1) ANÁLISE DE DADOS ESTATÍSTICOS}

Para o desenvolvimento dos critérios de cálculo baseados em probabilidade são requeridos dados das variáveis ação e resistência estrutural. A informação básica requerida é a distribuição de probabilidade de cada variável ação e resistência e estimativas de suas médias e desvios padrão ou coeficientes de variação. A média e o coeficiente de variação destas variáveis básicas deverão ser representativos dos valores esperados para as estruturas reais. Enquanto frequentemente há dados suficientes para obter uma estimativa razoável da distribuição de probabilidade, em muitos outros casos esta pode ser assumida com base em argumentos físicos ou por conveniência (GALAMBOS, 1982).

No contexto da aproximação FOSM (método de segundo momento de primeira ordem) para confiabilidade, o conceito de incerteza, exemplificado pela variabilidade ou dispersão de uma variável, é exprimido através da variância ou do coeficiente de variação (cov). As incertezas 
usadas nas análises de confiabilidade poderiam incluir variabilidade estatística dos parâmetros da resistência básica e das ações, fontes adicionais de incertezas que surgem devido aos erros de previsão e modelamento e informações incompletas. Incluídos nestas incertezas de modelamento estariam erros em estimativas dos parâmetros das funções de distribuição, idealizações matemáticas da capacidade estrutural e das ações reais, incertezas no processo de cálculo e variações nas aplicações das várias ações ou nas especificações dos materiais dos casos idealizados em seu desenvolvimento. Embora ocasionalmente possa haver alguns dados disponíveis com os quais estima-se estas últimas medidas de incertezas, frequentemente elas devem ser estimadas com base em juízo e experiência profissional.

\subsubsection{1) Resistência}

Valores médios, coeficientes de variação e distribuições de probabilidade para resistências estruturais têm sido determinadas através de dados de ensaios de resistência dos materiais, de testes de laboratório de elementos em escala real sob condições de solicitação idealizadas, e em alguns casos, onde um modelo analítico definido existe claramente, através da simulação Monte Carlo.

Uma amostra representativa destes dados é apresentada na tabela 4.1 que, segundo GALAMBOS (1982), resume resultados de numerosos programas de pesquisa conduzidos durante vários anos. Existe uma quantidade substancial de dados para elementos estruturais de aço e concreto armado. 
Tabela 4.1: Resumo dos dados estatísticos de resistência (GALAMBOS, 1982)

\begin{tabular}{|c|c|c|c|}
\hline $\begin{array}{c}\text { Descrição } \\
\text { (1) }\end{array}$ & $\begin{array}{c}\bar{R} / R_{n} \\
(2)\end{array}$ & $\begin{array}{l}\mathrm{V}_{\mathrm{R}} \\
(3)\end{array}$ & $\begin{array}{l}\text { Distribuição de } \\
\text { probabilidade } \\
\text { (4) }\end{array}$ \\
\hline Concreto armado, flexão & \multirow[b]{2}{*}{1,05} & \multirow[b]{2}{*}{0,11} & \multirow[b]{2}{*}{ Normal } \\
\hline grau $60\left(f_{y}=60 \mathrm{ksi}\right)$ & & & \\
\hline grau $40\left(f_{y}=40 \mathrm{ksi}\right)$ & 1,14 & 0,14 & Normal \\
\hline Colunas curtas de conc. arm. & 0,95 & 0,14 & Normal \\
\hline Vigas de conc. arm., cisalhamento & \multirow[b]{2}{*}{1,00} & \multirow[b]{2}{*}{0,19} & \multirow[b]{2}{*}{ Normal } \\
\hline estribos mínimos & & & \\
\hline Aço estrutural & \multirow[b]{2}{*}{1,05} & \multirow[b]{2}{*}{0,11} & \multirow[b]{2}{*}{ Lognormal } \\
\hline $\begin{array}{l}\text { Elementos. Tracionados, } \\
\text { escoamento }\end{array}$ & & & \\
\hline $\begin{array}{l}\text { viga compacta, momento } \\
\text { uniforme (cálculo plástico) }\end{array}$ & 1,07 & 0,13 & Lognormal \\
\hline Viga-coluna (cálculo plástico) & 1,07 & 0,15 & Lognormal \\
\hline $\begin{array}{l}\text { Aço conformado a frio (chapa } \\
\text { dobrada) }\end{array}$ & \multirow[b]{2}{*}{1,17} & \multirow[b]{2}{*}{0,17} & \multirow[b]{2}{*}{ Lognormal } \\
\hline Vigas travadas lateralmente & & & \\
\hline Alumínio & \multirow[b]{2}{*}{1,10} & \multirow[b]{2}{*}{0,08} & \multirow[b]{2}{*}{ Lognormal } \\
\hline Vigas travadas lateralmente & & & \\
\hline $\begin{array}{l}\text { Alvenaria estrutural não armada, } \\
\text { compressão }\end{array}$ & \multirow[b]{2}{*}{5,30} & \multirow[b]{2}{*}{0,18} & \multirow[b]{2}{*}{ Lognormal } \\
\hline Fabricação não inspecionada & & & \\
\hline \multicolumn{4}{|c|}{$\begin{array}{ll}\text { Nota: } & \bar{R}=\text { resistência média } \\
& R_{n}=\text { resistência nominal } \\
& V_{R}=\text { coeficiente de variação da resistência }\end{array}$} \\
\hline
\end{tabular}

\subsubsection{2) Ações}

Estão resumidos na tabela 4.2 os valores médios, coeficientes de variação e distribuições de probabilidade para efeitos das máximas ações em 50 anos e das ações reduzidas. De modo geral, estes estudos estatísticos são um resumo de valores relatados em vários estudos anteriores de ações e modelos de ações estruturais, comportamento de elementos estruturais e cálculo baseado em confiabilidade. Tanto quanto possível, as estatísticas das ações são baseadas em pesquisas "in loco", 
medidas de pressão do vento em edifícios e modelamento probabilístico da conversão de uma ação pesquisada em uma máxima ação usada para propósitos de análise e cálculo de confiabilidade.

Além da variabilidade básica da ação, incertezas surgem do modelo que transforma a ação real variável tanto no tempo quanto no espaço, em uma ação estática equivalente distribuída uniformemente que será usada no cálculo. Incertezas também surgem na análise que transforma a ação uniformemente distribuída em efeito desta ação, incluindo idealização bidimensional de estruturas tridimensionais, idealização de apoios, rigidez de conexões e continuidade (GALAMBOS, 1982). Estas incertezas são incluídas nos coeficientes de variação listados na tabela 4.2.

Segundo GALAMBOS, 1982, estatísticas das ações devidas a neve, vento e ação variável de ocupação (sobrecarga de utilização) foram determinadas através de distribuições de valores extremos usados na análise de confiabilidade usando as porcentagens superiores das distribuições obtidas através da simulação Monte Carlo ou integração numérica.

Tabela 4.2: Resumo de dados estatísticos das ações (GALAMBOS, 1982)

\begin{tabular}{|c|c|c|c|}
\hline $\begin{array}{c}\text { Ação } \\
\text { (1) }\end{array}$ & $\begin{array}{c}\bar{X} / X_{n} \\
(2)\end{array}$ & $\begin{array}{l}V_{x} \\
(3)\end{array}$ & $\begin{array}{c}\text { Distribuição de } \\
\text { probabilidade } \\
\text { (4) }\end{array}$ \\
\hline D (ação permanente) & 1,05 & 0,10 & Normal \\
\hline $\begin{array}{l}\text { L (sobrecarga de } \\
\text { utilização) }\end{array}$ & 1,00 & 0,25 & Valor extremo tipo I \\
\hline $\begin{array}{l}\text { LRED }_{\text {REsobrecarga }} \\
\text { reduzida) }\end{array}$ & $0,25-0,50$ & 0,60 & Gama \\
\hline W (ação do vento) & 0,78 & 0,37 & Valor extremo tipo I \\
\hline S (ação da neve) & 0,82 & 0,26 & Valor extremo tipo II \\
\hline
\end{tabular}

\subsection{2) CONFIABILIDADES NO CÁLCULO EM TENSÕES ADMISSÍVEIS}

Confiabilidades alvos (ou índices de segurança) podem ser estabelecidas através de revisão de níveis de confiabilidade pertencentes às 
normas já existentes que conduziram a resultados satisfatórios no passado. Enquanto confiança absoluta nestes valores pode admitir inconsistências e certas características indesejáveis da prática de cálculo passada, eles são úteis como guias para a seleção de confiabilidades alvos de um critério baseado em probabilidade.

Ações gravitacionais: As maiores combinações de ações envolvendo ações gravitacionais são as combinações de ação permanente com máximas ações variáveis de ocupação em pisos. Estes casos de ações gravitacionais governam os projetos em muitas situações práticas e eles são casos particularmente importantes, quando são acumuladas experiências bem sucedidas no passado. Cada situação de cálculo é definida por um conjunto de valores nominais de ações e resistência. Nas especificações em tensões admissíveis tinha-se:

$$
\frac{R_{n}}{F S}=D_{n}+L_{n}
$$

onde FS é o fator de segurança. No cálculo plástico de estruturas de aço segundo o AISC/78 tinha-se (GALAMBOS, 1982):

$$
R_{n}=1,7\left(D_{n}+L_{n}\right)
$$

Os índices de confiabilidade associados ao cálculo de vigas de aço submetidas a ações permanentes e variável, são mostrados na figura 4.1 como funções da relação $L_{0} / D_{n}$, numa análise feita por GALAMBOS, 1982. Na figura 4.1 percebe-se que $\beta$ tende a decrescer quando a relação $L_{0} / D_{n}$ aumenta. Deve ser lembrado que vigas de aço têm intervalo prático para $\mathrm{L}_{0} / \mathrm{D}_{\mathrm{n}}$ de 1 a 2 . Como mostrado na figura 4.1, valores representativos para $\beta$ são em torno de 2,5 para vigas de aço. A sobrecarga $L_{0}$ é a ação variável uniforme sem redução especificada pelo ANSI A58.1-1972 e sua relação com a sobrecarga nominal é dada pela seguinte expressão: 
$L_{n}=L_{0}\left\{1-\min \left[0,0008 A_{T} ; 0,23\left(1+\frac{D_{n}}{L_{0}}\right) ; 0,6\right]\right\}$, em que $A_{T}$ é a área de influência do elemento carregado em $\mathrm{ft}^{2}$.

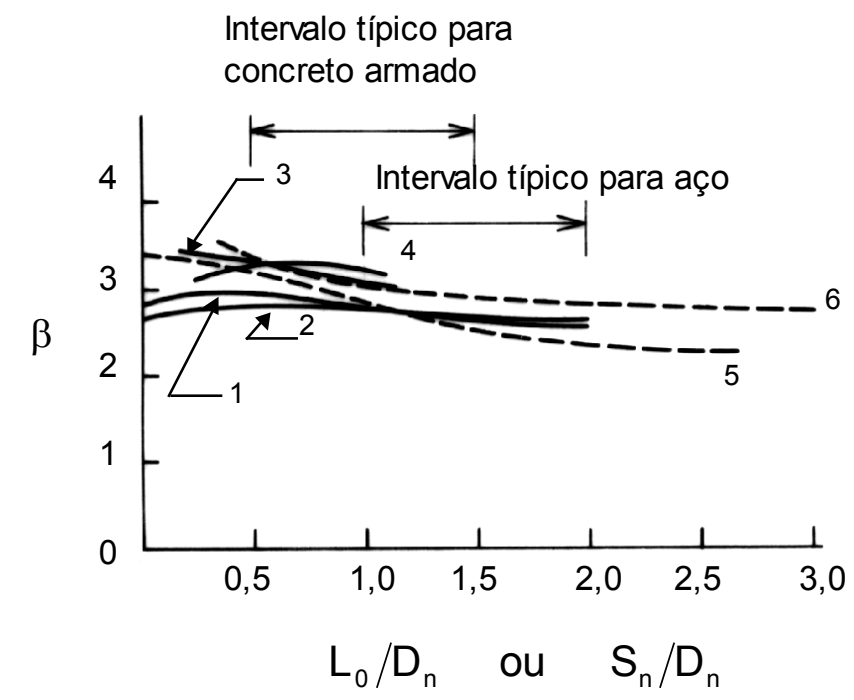

\begin{tabular}{|l|l|l|l|}
\hline Curva & \multicolumn{1}{|c|}{ Descrição } & $\bar{R} / R_{n}$ & $V_{n}$ \\
\hline 5 & aço $(D+L)$ & 1,07 & 0,13 \\
\hline 6 & aço $(D+S)$ & 1,07 & 0,13 \\
\hline \multicolumn{2}{|l|}{$A_{T}=37 m^{2}$ (área de influência do elemento) } \\
\hline
\end{tabular}

Figura 4.1: Índices de confiabilidade para vigas de aço calculadas em tensões admissíveis.

Outros valores típicos de $\beta$ para combinações $D+L$ para estruturas metálicas, de concreto, alvenaria e madeira são apresentados na tabela 4.3. As confiabilidades mostradas na tabela 4.3 dependem de $\bar{R} / R_{n}$, de $\delta_{R}$, da função de distribuição de probabilidade, das relações típicas da carga e das áreas de influência de cada elemento. Estes fatores contribuem para reduzir o intervalo das confiabilidades para elementos estruturais de concreto e aço. 
Tabela 4.3: Resumo de confiabilidades associadas às antigas normas de cálculo.

\begin{tabular}{|c|c|}
\hline $\begin{array}{c}\text { Elemento } \\
\text { (1) }\end{array}$ & $\begin{array}{c}\text { Confiabilidade } \beta \\
\text { (2) }\end{array}$ \\
\hline $\begin{array}{l}\text { Elemento tracionado de aço, escoamento como } \\
\text { estado limite a (ruptura) }\end{array}$ & $2,5(3,4)$ \\
\hline Viga de aço compacta $^{a}$ & 3,1 \\
\hline Pilar de aço, $\bar{\lambda}=0,5$ (esbeltez reduzida) & 3,1 \\
\hline Soldas de filete $^{a}$ & 3,9 \\
\hline Parafusos $A 325$, cisalhamento ${ }^{a}$ & 4,4 \\
\hline Pilares de alumínio $\left(L_{0} / D_{n}=5\right)$ & 2,8 \\
\hline \multicolumn{2}{|c|}{ Combinação das ações $(\mathrm{D}+\mathrm{L}), \mathrm{L}_{0} / \mathrm{D}_{\mathrm{n}}=1$ exceto quando anotado. } \\
\hline \multicolumn{2}{|l|}{${ }^{a} L_{0} / D_{n}=2$} \\
\hline
\end{tabular}

Ações gravitacionais e ambientais: As principais combinações destas ações são formadas por ação permanente, variável de ocupação e vento $(D+L+W)$. Atenção deve ser dada às combinações $\left(D+L_{R E D}+W\right)$ e $\left(\mathrm{D}+\mathrm{L}+\mathrm{W}_{\mathrm{RED}}\right)$, onde $\mathrm{L}$ e $\mathrm{W}$ são os máximos valores relacionados à vida útil da estrutura e, $L_{\text {RED }}$ e $W_{\text {RED }}$ são os valores reduzidos das ações variáveis de ocupação e do vento, respectivamente.

$A$ variação de $\beta$ com várias relações $L_{0} / D_{n}$ e $W_{n} / D_{n}$ é mostrada na figura 4.2 para vigas e pilares de aço. Na análise feita por GALAMBOS, 1982, $R_{n}$ é determinada para cada situação de cálculo de acordo com:

Para o cálculo em tensões admissíveis:

$$
1,33 \frac{R_{n}}{\text { F.S. }}=D_{n}+L_{n}+W_{n}
$$

Para o cálculo plástico de estrutura metálica:

$$
R_{n}=1,3\left(D_{n}+L_{n}+W_{n}\right)
$$

Em todos os casos, entretanto, $R_{n}$ não pode ser menor do que aquela requerida pela combinação $D+L$. 


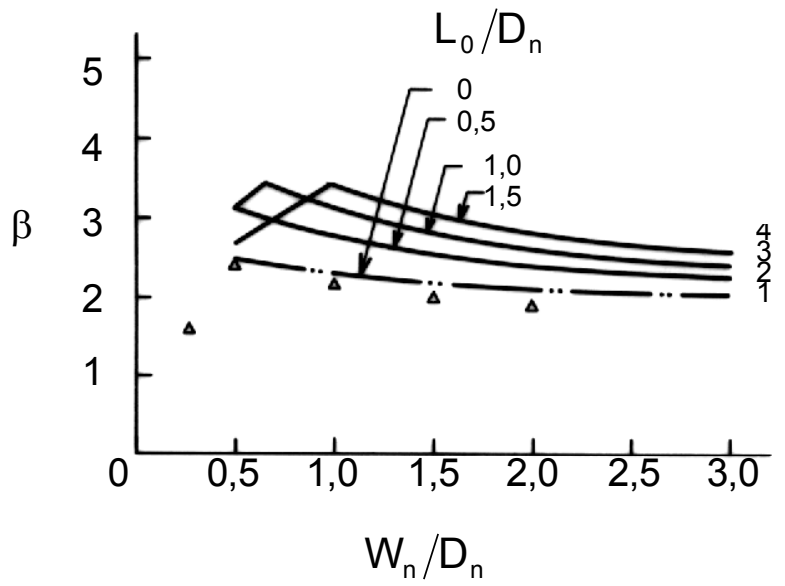

Vigas de aço
$A_{T}=37 \mathrm{~m}^{2}$
$\bar{R} / R_{n}=1,502 \quad V_{R}=0,13$

- pilares de aço

$\lambda=0,7 \quad \mathrm{~L}_{0} / \mathrm{D}=1,0$

$A_{T}=465 \mathrm{~m}^{2}$

$\bar{R} / R_{n}=1,28 \quad V_{R}=0,14$

Figura 4.2: Índice de confiabilidade para elementos de aço - ação gravitacional mais ação do vento.

Da figura 4.2 pode ser visto que $\beta$ decresce quando $W_{n} / D_{n}$ cresce. As curvas da figura 4.2 são de análises de vigas, mas segundo GALAMBOS, 1982, os resultados são semelhantes para outros tipos de elementos para os quais as estatísticas de resistência são semelhantes. Onde a ação do vento constitui a maior componente de ação, o valor de $\beta$ se aproxima do valor 2 . Com a predominância de ação permanente e variável de ocupação, o valor de $\beta$ cresce e tende para o caso de carregamento com $D+L$. Em geral, para a prática anterior, as combinações com ação do vento resultavam em confiabilidade aparentemente menor do que aquela das combinações somente com ações gravitacionais. Isto é devido ao aumento de 33\% na tensão admissível permitido na maioria das normas correntes que usavam esta avaliação. Não é claro desta análise se os critérios correntes para as ações gravitacionais são mais conservadores ou se os critérios para as ações do vento não são conservadores o suficiente, pelo menos de acordo com os métodos de verificação da segurança convencionais. É possível que a confiabilidade de estruturas sob a ação do vento seja somente aparentemente menor por causa de fatores tais como compartilhamento de ações por redistribuição destas e interação dos elementos. 
Analisando vigas de aço submetidas a diversos carregamentos como indicado na tabela 4.4, ROSOWSKY, 1994, determina os índices de confiabilidade destas vigas calculadas em tensões admissíveis, ou seja, com fator de segurança de 1,67 para combinações $D+L$ e variável de 1,25 a 1,67 para combinações envolvendo vento segundo o AISC-ASD, 1989, (para os casos 5, 6 e 7 os fatores de segurança são 1,67, 1,39 e 1,26, respectivamente, segundo HEGER, 1993).

Tabela 4.4: Casos analisados por ROSOWSKY, 1994:

\begin{tabular}{|c|c|c|c|}
\hline $\begin{array}{l}\text { Caso } \\
(1)\end{array}$ & $\begin{array}{c}\text { Tipo de ação no elemento fletido } \\
\text { (2) }\end{array}$ & $\begin{array}{c}\text { Ação permanente }\left(D_{n}\right) \\
\left(k N / m^{2}\right) \\
(3)\end{array}$ & $\begin{array}{l}\text { Sobrecarga } \\
\qquad\left(\mathrm{L}_{n}\right) \\
\left(\mathrm{kN} / \mathrm{m}^{2}\right) \\
(4)\end{array}$ \\
\hline 1 & gravidade - piso & 3,59 & 2,87 \\
\hline 2 & $\begin{array}{l}\text { gravidade - piso (elementos com } \\
\text { área de influência igual a } 335 \mathrm{~m}^{2} \text {, } \\
\text { sobrecarga reduzida }=0,5 \times \text { ação } \\
\text { básica) }\end{array}$ & 3,59 & 1,44 \\
\hline 3 & gravidade - viga de telhado & 0,96 & 1,44 \\
\hline 4 & $\begin{array}{l}\text { gravidade, com predominância da } \\
\text { ação permanente }\end{array}$ & 7,18 & 0,91 \\
\hline 5 & $\begin{array}{l}\text { gravidade mais vento (efeito do } \\
\text { vento }=33 \% \text { da ação gravitacional) }\end{array}$ & 3,59 & 2,87 \\
\hline 6 & $\begin{array}{l}\text { gravidade mais vento } \\
\text { vento }=33 \% \text { da } \text { ação } \\
\text { gravitacional) }\end{array}$ & 3,59 & 1,44 \\
\hline 7 & $\begin{array}{l}\text { permanente mais vento (efeito do } \\
\text { vento }=50 \% \text { da ação permanente) }\end{array}$ & 3,59 & 0 \\
\hline
\end{tabular}

Utilizando os dados estatísticos já listados anteriormente (tabelas 4.1 e 4.2) os índices de confiabilidade encontrados por ROSOWSKY, 1994, são apresentados na tabela 4.5 . 
Tabela 4.5:: Confiabilidades de vigas de aço em tensões admissíveis.

\begin{tabular}{|c|c|c|c|c|c|c|c|c|}
\hline $\begin{array}{c}\text { Caso } \\
(1)\end{array}$ & 1 & 2 & 3 & 4 & 5 & 6 & 7 & $7^{\mathrm{a}}$ \\
\hline $\begin{array}{c}\text { Índice de } \\
\text { confiabilidade } \beta \\
(2)\end{array}$ & 3,0 & 3,3 & 2,7 & 3,4 & 3,4 & 2,5 & 1,9 & 3,4 \\
\hline
\end{tabular}

Nos casos em que se tem a atuação do vento, o AISC-ASD, 1989 e outras especificações de cálculo em tensões admissíveis permitem a majoração de 1,33 na tensão admissível, mesmo quando não há outra ação variável na combinação (caso 7). Para os casos 5, 6 e 7 portanto, a tensão admissível foi multiplicada por 1,33. O caso 7a é simplesmente o caso 7 sem o fator de majoração da tensão admissível, por este não ser sempre utilizado por calculistas quando se tem somente a atuação de ação permanente e vento na combinação.

Os resultados mostrados na linha 2 da tabela 4.5 indicam a larga gama de confiabilidades associadas ao método das tensões admissíveis para vigas de aço. Segundo ROSOWSKY, 1994, gamas semelhantes são observadas quando outros estados limites são considerados. Isto sugere que uma confiabilidade alvo simples não existe e esta deverá ser determinada mediante análises detalhadas e decisões por juízo e bom senso, por exemplo, analisando as situações mais comuns de carregamento ou optar pelos níveis intermediários de confiabilidade e assim por diante. Se é feita a suposição de que níveis de confiabilidade associados aos cálculos anteriores são aceitáveis, um índice de confiabilidade alvo apropriado para se usar na calibração de um novo método de cálculo poderia, então, ser o valor mínimo obtido na tabela 4.5 (1,9 por exemplo. No entanto análises mais consistentes devem ser feitas para a seleção deste índice de confiabilidade alvo, como mencionado anteriormente.

Quando os efeitos do vento atuam em sentido contrário ao das ações gravitacionais, os índices de confiabilidade encerrados pela prática de cálculo anterior tendem a ser um tanto menores do que quando as ações 
são aditivas, como indicado na figura 4.3 para a combinação W-D. Nas formas em tensões admissíveis é difícil tratar as combinações em que ações são adicionadas e subtraídas de uma forma consistente, do ponto de vista de segurança.

Para cálculo em tensões admissíveis:

$$
R_{n}=\max \left\{\begin{array}{l}
F S\left(D_{n}+L_{n}\right) \\
0,75 F S\left(D_{n}-W_{n}\right)
\end{array}\right.
$$

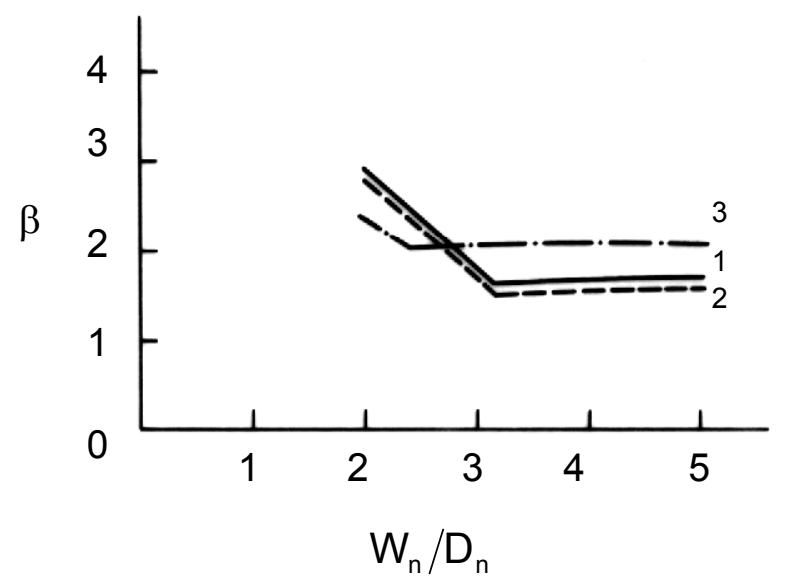

1 - viga de aço

2 - pilar de aço

3 - viga de concreto

Figura 4.3: Índice de confiabilidade para elementos de aço e concreto armado ações atuando em sentidos contrários.

\section{3) Calibração dos coeficientes de cálculo dos estados limites}

\subsection{1) SELEÇÃO DO FORMATO}

Cálculos em estados limites baseados em probabilidade empregam, tradicionalmente, ações ou efeitos de ações multiplicados pelos coeficientes 
de ponderação das ações e resistências multiplicadas pelos coeficientes de resistência, em um conjunto de equações que têm a forma geral:

$$
\text { resistência fatorada } \geq \text { efeitos das ações fatoradas }
$$

Vários formatos de equações de verificação da segurança são possíveis. A seleção do formato deverá ser guiada pela necessidade de simplicidade e continuidade em relação a formatos existentes, bem como pelas considerações teóricas.

Alguns formatos utilizados para o lado das ações da expressão (4.5) são listados a seguir, por exemplo, a forma usada pelo National Building Code of Canada (ELLINGWOOD, 1982) para seu novo critério de cálculo em estados limites, dá o efeito das ações fatoradas como:

$$
U_{1}=\gamma_{D} D_{n}+\psi\left(\gamma_{L} L_{n}+\gamma_{W} W_{n}+\gamma_{T} T_{n}\right)
$$

em que $D_{n}, L_{n}, W_{n}$ e $T_{n}$ correspondem a ação permanente nominal, ação variável (sobrecarga) nominal, ação nominal do vento e ação nominal devido a variação de temperatura ou deformação imposta; $\gamma_{D}, \gamma_{L}, \gamma_{W}$ e $\gamma_{T}$ são os coeficientes de ponderação das ações e $\psi$ é um "fator probabilidade" de combinação, calculado para refletir a pequena probabilidade de duas ou mais ações atingirem seus valores máximos de cálculo simultaneamente. Outro formato tem sido sugerido por vários grupos normativos europeus (ELLINGWOOD, 1982):

$$
U_{2}=\gamma_{D} D_{n}+\gamma_{Q}\left(Q_{n_{i}}+\sum \psi_{0_{j}} Q_{n_{j}}\right)
$$

em que $Q_{n_{i}}$ é a ação variável principal e $\psi_{0_{j}} Q_{n_{j}}$ são os valores freqüentes das demais ações variáveis $\left(\psi_{0_{j}}<1\right)$, que é o formato utilizado pela norma brasileira de ações e segurança nas estruturas - NBR 8681. Um terceiro formato, a forma LRFD, tem sido usado nos Estados Unidos, na $\mathrm{ACl}$ Standard 318 para concreto armado, desde 1963 (ELLINGWOOD, 1982). Na forma proposta para cálculo de estruturas metálicas (RAVINDRA, 1978), as ações freqüentes ou "arbitradas em um certo tempo", $Q_{\text {apt }}$, e o coeficiente 
de ponderação destas ações, $\gamma_{\text {apt }}$, aparecem na equação de cálculo diretamente:

$$
\mathrm{U}_{3}=\gamma_{\mathrm{D}} \mathrm{D}_{\mathrm{n}}+\gamma_{\mathrm{Q}} \mathrm{Q}_{\mathrm{n}}+\sum \psi_{\mathrm{apt}} \mathrm{Q}_{\mathrm{apt}}
$$

Finalmente, um coeficiente simples de ação pode ser aplicado ao efeito total das ações, como na parte 2 da especificação AISC de 1978 (cálculo plástico de estruturas de aço) (ELLINGWOOD, 1982):

$$
\mathrm{U}_{4}=\gamma\left(\mathrm{D}_{\mathrm{n}}+\mathrm{L}_{\mathrm{n}}+\ldots\right)
$$

O propósito dos coeficientes $\gamma$ nas equações 4.6a a 4.6d é considerar desvios desfavoráveis e imprevistos nos valores específicos das ações, $Q_{n}\left(\right.$ ou $\left.Q_{a p t}\right)$, e para variações nos efeitos das ações devidas a incertezas na análise.

A probabilidade de uma ocorrência conjunta de duas ou mais ações máximas é normalmente desprezível. Análises probabilísticas de combinações de ações (WEN, 1977) mostram que o efeito total máximo das ações é freqüentemente aproximado para o caso onde uma ação variável assume seu valor máximo, enquanto as outras ações variáveis da combinação estão com seus valores reduzidos ou freqüentes. As equações $4.6 b$ e $4.6 c$ representam uma afirmação desta observação. Nota-se que sob um rearranjo de termos, as equações $4.6 \mathrm{~b}$ e $4.6 \mathrm{c}$ são equivalentes, com $\psi_{\text {apt }} Q_{\text {apt }}=\gamma_{Q} \psi_{0} Q_{n}$. Na equação 4.6a, o coeficiente probabilidade é aplicado em todas as ações variáveis da combinação de ações e esta não é uma representação tão boa da combinação verdadeira das ações quanto a equação $4.6 \mathrm{~b}$ ou (4.6c). Os problemas associados com a utilização de um único coeficiente de ponderação das ações, como na equação $4.6 \mathrm{~d}$, são os mesmos daqueles resultantes dos cálculos em tensões admissíveis: é impossível manter confiabilidade uniforme sob diferentes combinações de ações com um único coeficiente de ponderação, visto que as diferenças nas variabilidades associadas às diferentes ações não são adequadamente consideradas com a aplicação deste mesmo coeficiente a todas as ações. 
Com base no exposto anteriormente, um formato que combina os melhores aspectos das equações $4.6 \mathrm{~b}$ e $4.6 \mathrm{c}$ pode ser analisado. Neste formato, coeficientes de ações são aplicados a cada ação individual na equação de verificação como feito na equação 4.6c, mas não há necessidade de especificar um valor da ação reduzida (arbitrada em um certo tempo) e um valor máximo, nem utilizar fatores de combinação $\psi_{0_{j}}$ separados como na equação 4.6b. O efeito último das ações fatoradas ficaria então:

$$
\mathrm{U}=\gamma_{\mathrm{D}} \mathrm{D}_{\mathrm{n}}+\gamma_{\mathrm{Q}} \mathrm{Q}_{\mathrm{n}}+\sum \gamma_{\mathrm{j}} \mathrm{Q}_{\mathrm{nj}}
$$

em que $\gamma_{Q} Q_{n}$ é a ação variável principal fatorada, e os termos $\gamma_{j} Q_{n j}$ são as ações nominais minoradas por um coeficiente $\gamma_{\mathrm{j}}<1$. As ações variáveis individuais consideradas devem ser alternadas na equação, cada ação tomando seu valor máximo, $Q_{n}$, para se obter a combinação crítica. Em geral, os coeficientes de ponderação das ações deverão ser aplicados às ações antes da análise que transforma as ações em seus efeitos. Se a relação entre ação e seu efeito é linear, não faz diferença onde o coeficiente de ponderação é aplicado. Entretanto, pode ser não conservador aplicar estes coeficientes nos efeitos das ações em certos problemas não lineares.

A resistência fatorada da expressão. (4.5) também pode ser expressa de diferentes formas, mas o método mais familiar é o uso do coeficiente de resistência aplicado à resistência característica ou nominal. A resistência fatorada é definida como o produto, $\phi R_{n}$, de uma resistência nominal calculada, $R_{n}$, por um coeficiente de resistência $\phi$. As principais vantagens desta forma são que erros do modelo de cálculo da resistência nominal e modo e conseqüência de falha do elemento estrutural podem ser facilmente refletidos na seleção de $\phi$. A desvantagem é que $\phi$ não é aplicado diretamente à fonte de incerteza (resistência do material, dimensões e modelos analíticos). E como uma conseqüência, é mais difícil manter confiabilidade constante sobre todas as situações de cálculo. A situação é análoga ao uso de um único coeficiente de ponderação das ações 
ao invés de um coeficiente para cada incerteza da variável ação (equações $4.6 \mathrm{~d}$ e 4.7 , respectivamente).

Um segundo método para calcular a resistência fatorada é através do uso de coeficientes de resistência parciais, onde cada uma das variáveis usadas para calcular a resistência é determinada dividindo o seu valor nominal por um coeficiente de segurança parcial antes de calcular a capacidade estrutural, por exemplo, $\mathrm{f}_{\mathrm{y}}=\mathrm{f}_{\mathrm{yn}} / \gamma_{\mathrm{y}}$ para a tensão de escoamento. A vantagem deste formato é que os coeficientes são aplicados diretamente às fontes de incertezas e assim é relativamente fácil manter constante a confiabilidade para muitas situações de cálculo. Isto é particularmente importante quando vários materiais contribuem para a resistência de um elemento, como em um elemento de concreto armado ou uma viga composta. A desvantagem é que a variabilidade devido a erro no modelamento, efeito do modo de falha e importância do elemento não são tão facilmente incluídos, porque os coeficientes parciais de resistência são tipicamente os mesmos para todos os elementos e estados limites.

Segundo ELLINGWOOD, 1982, estudos comparativos do efeito do formato de cálculo da resistência fatorada nos coeficientes de ponderação das ações mostram que estes coeficientes calculados são quase os mesmos em ambos os casos.

\subsection{2) CRITÉRIOS DE CARREGAMENTO BASEADOS EM PROBABILIDADE}

Confiabilidades alvos " $\beta_{0}$ " para selecionar coeficientes de ponderação das ações e de resistência podem ser determinados com base em análises das confiabilidades dos cálculos anteriores. GALAMBOS, 1982, estabeleceu confiabilidades alvos para determinadas situações de carregamento e para 50 anos de vida útil da estrutura. Para combinações de ações envolvendo somente ações gravitacionais, $\beta_{0}=3,0$; para aquelas 
combinações envolvendo ações do vento aditivas, $\beta_{0}=2,5$; para aquelas envolvendo ações do vento atuando em sentido contrário aos efeitos das ações gravitacionais, $\beta=2,0$. Deve ser enfatizado que confiabilidades alvos são escolhidas unicamente com o propósito de permitir que os coeficientes de ponderação das ações sejam calculados inteligentemente, isto é, para assegurar que com o conjunto de coeficientes de ponderação das ações desenvolvidos, será possível desenvolver critérios de resistência para alcançar projetos que são semelhantes, em um sentido global, àqueles obtidos usando a prática anterior.

O critério de cálculo prático é selecionar um conjunto de coeficientes de ponderação das ações para serem aplicados em todas as situações de cálculo, no entanto é interessante, sempre que possível, examinar como os coeficientes de ponderação das ações e de resistência variam para diferentes estados limites e combinações de ações. Este exame tornará possível uma melhor apreciação de algumas das considerações que guiaram a seleção do critério de cálculo dos coeficientes.

Exemplos de coeficientes de resistência e coeficientes de ponderação de ações permanentes, variáveis de ocupação e neve são mostrados na figura 4.4. Estes coeficientes foram calculados de acordo com o que foi exposto no capítulo 3 , com $\beta_{0}=3$, para a combinação de ação permanente mais sobrecarga máxima em vigas metálicas. Resultados semelhantes têm sido obtidos para outras combinações e para outros materiais de construção, segundo ELLINWOOD, 1982. Note que o coeficiente de resistência é relativamente indiferente à sobrecarga na combinação. Similarmente, os coeficientes de ponderação das ações não se apresentam sensíveis às estatísticas da resistência. O coeficiente de ponderação da ação permanente é muito menor do que os valores comumente recomendados pelas normas. Isto porque a variabilidade de D é muito pequena comparada com as variabilidades das outras ações. A magnitude de $\gamma_{D}$ aparece virtualmente independente da magnitude das sobrecargas, exceto para relações L/D muito pequenas. 
Estas observações indicam que escolher $\gamma_{D}$ e $\phi$ constantes e separar especificações de coeficientes de ponderação das ações e de resistência, não causa significativos desvios de $\beta_{0}$. Por outro lado, o coeficiente de ponderação da ação variável na combinação, aumenta quando a importância desta ação na combinação aumenta por causa de sua maior variabilidade. Se os coeficientes de ponderação $\gamma_{L}, \gamma_{S}, \gamma_{W}, \ldots$, para ações variáveis são especificados como constantes, como sempre foi feito, haverá algum desvio da confiabilidade alvo $\left(\beta_{0}\right)$ para certas situações de carregamento. Assim há uma necessidade de selecionar um conjunto de coeficientes de ponderação das ações e combinações que minimize a extensão deste desvio de $\beta_{0}$ sobre todas as situações possíveis de projeto.

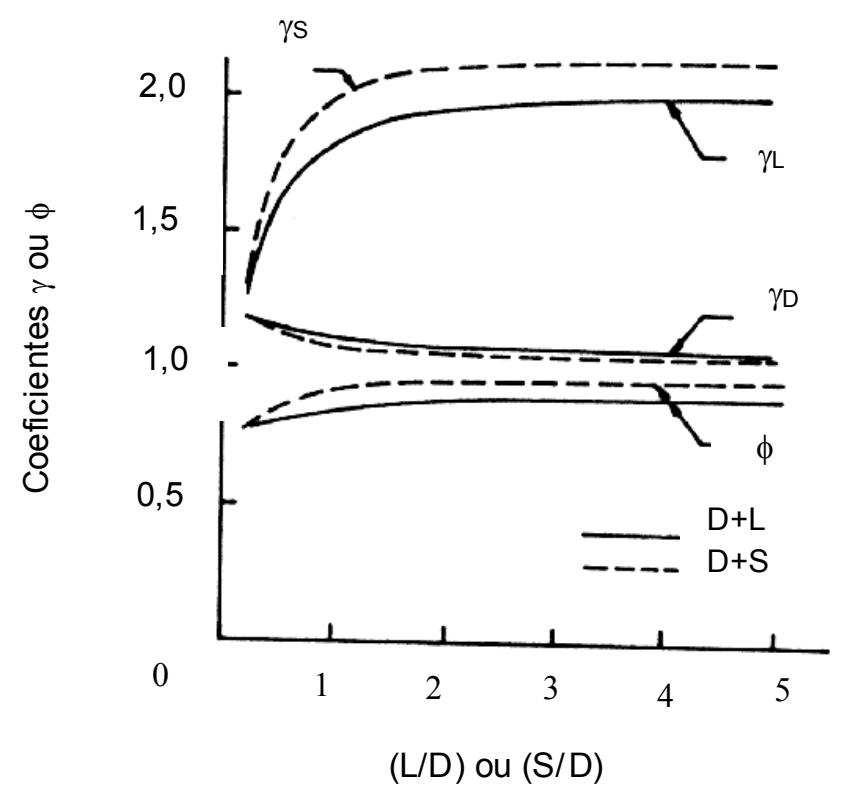

Figura 4.4: Coeficientes de ponderação das ações e de resistência para vigas de aço.

O processo para selecionar este conjunto de combinações de ações e coeficientes constantes não é único. Um método poderia ser determinar os coeficientes de ponderação das ações de forma que a probabilidade dos efeitos das ações majoradas serem excedidas seja a mesma, em média, para todas as situações possíveis de carregamento. Entretanto, esta 
aproximação ignora do problema o aspecto resistência e não dá garantia de que será possível selecionar critério de resistência viável compatível com os critérios das ações.

A seleção de coeficientes de ponderação das ações não pode ser feita completamente independente do lado da resistência. ELLINGWOOD, 1982, afirma que os coeficientes de resistência para elementos fletidos de concreto armado e aço deverão estar no intervalo de 0,80 a 0,90 . Quando $\phi$ é maior do que 0,90 para tais elementos, há pequena margem para ajustes adicionais para refletir melhoramentos na fabricação ou controle de qualidade que tenderiam a reduzir a variabilidade. $O$ coeficiente quase constante de ponderação da ação permanente, $\gamma_{D} \cong 1,1$, indicado pelos cálculos em várias situações de projeto, aparece mais baixo do que o meio técnico do cálculo estrutural "aceitaria", pelo menos agora.

Tabela 4.6: Coeficientes de ponderação das ações requeridos - uma ação atuando

\begin{tabular}{|c|c|c|c|c|c|c|c|c|}
\hline \multirow[b]{3}{*}{$\begin{array}{l}\text { Elemento } \\
\text { (1) }\end{array}$} & \multirow[b]{3}{*}{$\begin{array}{c}\phi \\
(2)\end{array}$} & \multicolumn{7}{|c|}{ AÇÕES } \\
\hline & & \multicolumn{2}{|c|}{$D$} & \multicolumn{2}{|c|}{$L$} & \multirow{2}{*}{$\begin{array}{c}S \\
\beta=3,0 \\
(7)\end{array}$} & \multirow{2}{*}{$\begin{array}{c}\mathrm{W} \\
\beta=2,5 \\
(8)\end{array}$} & \multirow{2}{*}{$\begin{array}{c}E \\
\beta=2,0 \\
(9)\end{array}$} \\
\hline & & $\begin{array}{c}\beta=2,5 \\
(3)\end{array}$ & $\begin{array}{c}\beta=3,0 \\
(4)\end{array}$ & $\begin{array}{c}\beta=2,5 \\
(5)\end{array}$ & $\begin{array}{c}\beta=3,0 \\
(6)\end{array}$ & & & \\
\hline \multirow{2}{*}{$\begin{array}{l}\text { Viga de aço } \\
\text { (perfil laminado) }\end{array}$} & 0,80 & 1,18 & 1,28 & 1,52 & 1,78 & 1,78 & 1,30 & 1,44 \\
\hline & 0,85 & 1,25 & 1,35 & 1,61 & 1,89 & 1,89 & 1,38 & 1,52 \\
\hline \multirow{2}{*}{$\begin{array}{l}\text { Viga de conc. } \\
\text { arm. aço grau } 40\end{array}$} & 0,80 & 1,18 & 1,33 & 1,44 & 1,70 & 1,66 & 1,28 & 1,39 \\
\hline & 0,85 & 1,26 & 1,41 & 1,53 & 1,81 & 1,77 & 1,36 & 1,48 \\
\hline \multirow{2}{*}{$\begin{array}{l}\text { Viga de conc. } \\
\text { arm. aço grau } 60\end{array}$} & 0,80 & 1,18 & 1,29 & 1,52 & 1,77 & 1,79 & 1,36 & 1,51 \\
\hline & 0,85 & 1,26 & 1,37 & 1,61 & 1,88 & 1,90 & 1,45 & 1,61 \\
\hline
\end{tabular}

Como uma indicação de coeficientes de ponderação das ações convenientes, pode ser primeiro considerado o caso simples onde somente uma ação esteja atuando. Isto, com efeito, representa o caso onde o efeito de uma ação domina a combinação das ações. Fixando $\phi=0,80$ ou 0,85 , o $\gamma_{Q}$ requerido para alcançar o $\beta_{0}$ prescrito são mostrados na tabela 4.6. Esta análise simples sugere valores razoáveis para os coeficientes de 
ponderação das ações, que poderiam ser aproximadamente $\gamma_{D}=1,2$ a 1,3 ; $\gamma_{S}, \gamma_{L}=1,6$ a 1,$7 ; \gamma_{W}=1,3$ a 1,$4 ; \gamma_{E}=1,4$ a 1,5

Para o próximo passo, considera-se o caso onde a ação permanente "D" é combinada com uma ação variável. Ao contrário do caso anterior, temse que determinar como distribuir os fatores de segurança para as ações individuais. Um conjunto ótimo de coeficientes pode ser selecionado, para isto define-se alguma função que meça a proximidade entre o nível de confiabilidade " $\beta_{0}$ " e a confiabilidade associada ao conjunto de coeficientes de resistência e de ponderação das ações proposto. Em seguida deve-se selecionar os coeficientes de ponderação que minimizem esta função. Várias medidas alternativas da proximidade têm sido propostas, algumas são bastante complexas. Segundo ELLINGWOOD, 1982, parece apropriado para um critério de confiabilidade de primeira geração usar uma função simples.

Pode-se observar que associado a um $\beta_{0}$ e a um dado conjunto de ações nominais, há uma resistência nominal requerida correspondente, $\mathrm{R}_{\mathrm{n}}\left(\beta_{0}\right)$, que poderia ser calculada. Por outro lado, uma equação de verificação que inclui um conjunto constante simples de coeficientes de ponderação, também levará a uma resistência nominal, $R_{n}^{\prime}$. Para o formato mais utilizado, isto seria dado pelo critério de ações, equação 4.7 e $\phi R_{n}$. Um conjunto de coeficientes de resistência e de ponderação das ações pode ser selecionado de tal forma que minimize a diferença quadrada ponderada entre estas duas resistências nominais, ou:

$$
I\left(\phi, \gamma_{i}\right)=\sum_{j}\left[R_{n j}\left(\beta_{0}\right)-R_{n j}^{\prime}\right]^{2} p_{j}
$$

sobre um conjunto pré-definido de ações permanente, vento, neve e terremoto, onde $p_{j}=$ peso relativo fixado para a j-ésima situação. Neste procedimento, desvios conservadores do nível de confiabilidade são penalizados igualmente àqueles não conservadores. 
As relações de ações nominais $L_{n} / D_{n}, W_{n} / D_{n}, \ldots$ e a freqüência relativa de diferentes situações comuns de ações, variam para materiais de construção diferentes. Os pesos " $p_{j}$ " fixados na tabela 4.7 para as combinações $D+L$ e $D+S$, representam as melhores estimativas, segundo ELLINGWOOD, 1982, para a probabilidade de diferentes situações de ações, mas deve ser lembrado que eles não são baseados em uma grande gama de dados experimentais. Estudos da sensibilidade dos coeficientes ótimos, para várias suposições, mostram que eles são consideravelmente mais sensíveis ao intervalo das relações de ações do que para a distribuição de $p_{j}$ dentro daquele intervalo. Nota-se que em estruturas de concreto armado e alvenaria, a ação permanente contribui com uma componente significativa para o efeito total das ações. Para combinações envolvendo vento e terremoto, os pesquisadores geralmente afirmam que valores de $W_{n} / D_{n}$ e $E_{n} / D_{n}$ iguais a $(0,5),(1,0),(3,0)$, e $(5,0)$ são igualmente prováveis. Para relações menores, as ações gravitacionais tenderiam a dominar.

Tabela 4.7: Pesos para combinações das ações $(D+L)$ e $(D+S)$

\begin{tabular}{|c|c|c|c|c|c|c|c|c|}
\hline \multirow[b]{2}{*}{$\begin{array}{l}\text { Material } \\
\text { (1) }\end{array}$} & \multirow[b]{2}{*}{$\begin{array}{c}\text { Combinação } \\
(2)\end{array}$} & \multicolumn{7}{|c|}{$L_{n} / D_{n}, S_{n} / D_{n}$} \\
\hline & & $\begin{array}{c}0,25 \\
(3)\end{array}$ & $\begin{array}{l}0,5 \\
(4)\end{array}$ & $\begin{array}{l}1,0 \\
(5)\end{array}$ & $\begin{array}{l}1,5 \\
(6)\end{array}$ & $\begin{array}{l}2,0 \\
(7)\end{array}$ & $\begin{array}{l}3,0 \\
(8)\end{array}$ & $\begin{array}{l}5,0 \\
(9)\end{array}$ \\
\hline Aço & $D+L, D+S$ & 0,00 & 0,10 & 0,20 & 0,25 & 0,35 & 0,07 & 0,03 \\
\hline \multirow{2}{*}{$\begin{array}{l}\text { Concreto } \\
\text { armado }\end{array}$} & $D+L$ & 0,10 & 0,45 & 0,30 & 0,10 & 0,05 & 0,00 & 0,00 \\
\hline & $\mathrm{D}+\mathrm{S}$ & 0,30 & 0,40 & 0,20 & 0,05 & 0,05 & 0,00 & 0,00 \\
\hline Alumínio & $D+L, D+S$ & 0,00 & 0,00 & 0,06 & 0,17 & 0,22 & 0,33 & 0,22 \\
\hline \multirow{2}{*}{$\begin{array}{l}\text { Madeira } \\
\text { lam. } \\
\text { colada }\end{array}$} & $\mathrm{D}+\mathrm{L}$ & 0,00 & 0,05 & 0,26 & 0,26 & 0,26 & 0,12 & 0,05 \\
\hline & $\mathrm{D}+\mathrm{S}$ & 0,00 & 0,02 & 0,16 & 0,32 & 0,32 & 0,18 & 0,00 \\
\hline Alvenaria & $D+L, D+S$ & 0,36 & 0,36 & 0,20 & 0,06 & 0,02 & 0,00 & 0,00 \\
\hline
\end{tabular}

Usando a análise de confiabilidade descrita anteriormente, $R_{n}$ pode então ser determinada para uma confiabilidade alvo inicial $\beta_{0}=3,0$, por exemplo, para combinações de ações gravitacionais (permanente e 
sobrecarga ou neve), e $\gamma_{S}, \gamma_{L}$ e $\phi$ ótimos são determinados minimizando a equação 4.8 com o valor de $\gamma_{D}$ fixado por exemplo em 1,2. Os coeficientes $\gamma_{S}, \gamma_{L}$ e $\phi$ ótimos dependem da combinação para cada material. A tabela 4.8 mostra os coeficientes ótimos encontrados por ELLINGWOOD em sua proposta para os coeficientes de ponderação das ações.

O $\gamma$ deverá ser tão próximo quanto possível dos coeficientes de ponderação das ações listados na coluna 4 da tabela 4.8, e ao mesmo tempo, $\phi$ deverá estar dentro do intervalo 0,8 a 0,9 para flexão em vigas de concreto e aço, como considerado anteriormente. Usando a tabela 4.8 como guia, pode então ser selecionados coeficientes $\gamma_{L}$ e $\gamma_{S}$ que satisfaçam estes requerimentos. $O \phi$ ótimo correspondente a $\gamma_{L}=\gamma_{S}=1,6$ é mostrado na coluna 5 da tabela 4.8 .

Tabela 4.8: Valores ótimos para os coeficientes de ponderação das ações e de resistência para ações gravitacionais

\begin{tabular}{|c|c|c|c|c|}
\hline \multirow[b]{2}{*}{$\begin{array}{l}\text { Material } \\
\text { (1) }\end{array}$} & \multirow[b]{2}{*}{$\begin{array}{c}\text { Combinação } \\
(2)\end{array}$} & \multicolumn{2}{|c|}{ Valores ótimos $\left(\gamma_{D}=1,2\right)$} & \multirow{2}{*}{$\begin{array}{c}\phi \text { ótimo para } \\
\gamma_{D}=1,2, \gamma_{L}=1,6 \\
(5)\end{array}$} \\
\hline & & $\begin{array}{c}\phi \\
(3)\end{array}$ & $\begin{array}{c}\gamma_{L}, \gamma_{S} \\
(4)\end{array}$ & \\
\hline \multirow{2}{*}{$\begin{array}{l}\text { Viga de aço } \\
\left(\beta_{0}=3\right)\end{array}$} & $\mathrm{D}+\mathrm{L}$ & 0,96 & 2,10 & 0,78 \\
\hline & $\mathrm{D}+\mathrm{S}$ & 1,05 & 2,32 & 0,79 \\
\hline \multirow{2}{*}{$\begin{array}{l}\text { Viga de conc. arm. } \\
\text { aço grau } 60\left(\beta_{0}=3\right)\end{array}$} & $\mathrm{D}+\mathrm{L}$ & 0,87 & 1,83 & 0,81 \\
\hline & $D+S$ & 0,93 & 1,93 & 0,84 \\
\hline \multirow{2}{*}{$\begin{array}{l}\text { Viga de conc. arm. } \\
\text { aço grau } 40\left(\beta_{0}=3\right)\end{array}$} & $\mathrm{D}+\mathrm{L}$ & 0,82 & 1,61 & 0,81 \\
\hline & $\mathrm{D}+\mathrm{S}$ & 0,85 & 1,56 & 0,86 \\
\hline \multirow{2}{*}{$\begin{array}{l}\text { Vigas de madeira } \\
\text { lam. Colada }{ }^{\mathrm{a}}\left(\beta_{0}=2,5\right)\end{array}$} & $\mathrm{D}+\mathrm{L}$ & 0,59 & 1,38 & 0,66 \\
\hline & $\mathrm{D}+\mathrm{S}$ & 0,59 & 1,08 & 0,77 \\
\hline $\begin{array}{l}\text { Alvenaria estrutural } \\
\text { de tijolo }{ }^{a}\left(\beta_{0}=7,5\right)\end{array}$ & $D+L$ & 0,38 & 4,10 & 0,22 \\
\hline $\begin{array}{l}\text { Alvenaria estrutural } \\
\text { de tijolo }\left(\beta_{0}=5\right)\end{array}$ & $D+L$ & 0,52 & 2,45 & 0,41 \\
\hline $\begin{array}{l}\text { Alvenaria estrutural } \\
\text { de concreto }^{a}\left(\beta_{0}=6,5\right)\end{array}$ & $D+L$ & 0,41 & 3,28 & 0,27 \\
\hline $\begin{array}{l}\text { Alvenaria estrutural } \\
\text { de concreto }{ }^{\text {a }}\left(\beta_{0}=5\right)\end{array}$ & $D+L$ & 0,49 & 2,38 & 0,40 \\
\hline
\end{tabular}


Esta análise pode ser feita para qualquer outra combinação utilizando o mesmo procedimento e buscando os índices de confiabilidade alvos para cada situação de carregamento. Para combinações com mais de uma ação variável deve ser feita a consideração de apenas uma ação variável atuar com seu valor máximo e as demais serem reduzidas por coeficientes de ponderação menores do que um.

ELLINGWOOD, 1982, verificou que fazendo $\gamma_{L}=1,6 ; \gamma_{L 1}=0,5$; $\gamma_{w}=1,3$ e $\gamma_{w 1}=0,1$, os coeficientes $\phi$ ótimos ficaram próximos do intervalo desejado. Estes são listados nas colunas finais da tabela 4.9. As combinações seriam então com ações permanentes, ações do vento e sobrecarga, da seguinte forma:

$$
\gamma_{D} D_{n}+\gamma_{L 1} L_{n}+\gamma_{w} W_{n}
$$

ou

$$
\gamma_{D} D_{n}+\gamma_{L} L_{n}+\gamma_{w 1} W_{n}
$$

devendo prevalecer em um projeto, a máxima combinação. Onde os coeficientes $\gamma_{L 1}$ e $\gamma_{w 1}$ são menores que a unidade para que $\gamma_{L_{1}} L_{n}$ e $\gamma_{w 1} W_{n}$ sejam os valores reduzidos da sobrecarga e ação do vento, respectivamente.

Tabela 4.9: Coeficientes de ponderação das ações e de resistência para ações gravitacionais atuando com ação do vento

\begin{tabular}{|c|c|c|c|c|c|c|}
\hline \multirow{2}{*}{$\begin{array}{c}\text { Material } \\
(1)\end{array}$} & \multicolumn{3}{|c|}{ Valores ótimos $\left(\gamma_{\mathrm{D}}=1,2\right)$} & \multicolumn{3}{c|}{$\phi$ ótimo quando $\gamma_{\mathrm{W}}=1,3$} \\
\cline { 2 - 7 } & $\phi$ & $\gamma_{\mathrm{L}}$ & $\gamma_{\mathrm{W}}$ & $\gamma_{\mathrm{L} 1}=0,3$ & $\gamma_{\mathrm{L} 1}=0,4$ & $\gamma_{\mathrm{L} 1}=0,5$ \\
$(2)$ & $(3)$ & $(4)$ & $(5)$ & $(6)$ & $(7)$ \\
\hline Vigas de aço & 1,11 & 0,61 & 1,71 & 0,85 & 0,87 & 0,89 \\
\cline { 2 - 7 } & 0,93 & 1,97 & 0,08 & - & 0,81 & - \\
\hline \multirow{2}{*}{$\begin{array}{l}\text { Vigas de concreto } \\
\text { armado }\end{array}$} & 1,06 & 0,49 & 1,76 & 0,82 & 0,83 & 0,84 \\
\cline { 2 - 7 } & 0,86 & 1,63 & 0,14 & - & 0,81 & - \\
\hline
\end{tabular}


Também em combinações com ações atuando em sentidos contrários, exemplos comuns incluem efeitos do vento que atuam em sentido contrário aos efeitos das ações gravitacionais $(U=D-W)$, deve ser admitida a possibilidade de ocorrência de valores menores do que os nominais para as cargas permanentes. Fazendo esta análise, ELLINGWOOD, 1982, selecionou $\gamma_{w}$ calculando primeiro $R_{n}$ para $\beta_{0}=2,0$ e então fixando $\gamma_{D}=0,9$ e $\phi=0,85$, e selecionando o $\gamma_{w}$ que minimize a equação 4.8. Esta análise levou a:

$$
\mathrm{U}=0,9 \mathrm{D}_{\mathrm{n}}-1,3 \mathrm{~W}_{\mathrm{n}}
$$

É interessante notar que se $\gamma_{w}$ é selecionado para alcançar $\beta_{0}=2,5$, confiabilidade alvo para a combinação aditiva $D+W$, então $\gamma_{w}$ seria igual a 1,5 e não 1,3. Isto resultaria em um conservadorismo adicional em contraste com a prática anterior.

\subsection{3) COEFICIENTES DE RESISTÊNCIA}

Com os coeficientes de ponderação das ações fixados, a confiabilidade $\beta$ pode ser ajustada variando o coeficiente $\phi$ e a especificação da resistência nominal para diferentes materiais e estados limites. A escolha de $\beta$ para selecionar o coeficiente de resistência $\phi$ deverá considerar, entre outros fatores, a ductilidade associada a cada modo de resistência, a freqüência relativa da ocorrência de diferentes situações de projeto e a conseqüência de falha. Para um determinado estado limite e material, o coeficiente $\phi$ não deverá depender da combinação das ações.

Embora referidos às vezes como coeficientes do material, os coeficientes $\phi$ também devem considerar outras contribuições para a variabilidade da resistência e não somente a variação da resistência mecânica do material. Quando aplicados à resistência de seções transversais de aço, estes coeficientes devem cobrir as variações nas dimensões dentro das tolerâncias de laminação, as diferenças entre os 
valores da resistência medida em um produto padrão e a resistência real dos perfis de um lote de laminação, e outros fatores como a possibilidade de correlação entre resistência do material e tolerâncias de laminação.

Tratando-se de um material e estado limite, por exemplo, em que a capacidade é descrita por $\bar{R} / R_{n}=1,10$ e $V_{R}=0,15$, os intervalos de $\beta$, correspondentes ao intervalo para $L / D_{n}$ de 0,25 a 5 e vários valores candidatos $\phi$, são dados na tabela 4.10. Tendo a relação $L / D_{n}$ prevalecente para cada situação ou a freqüência relativa de cada $L / D_{n}$, o valor de $\phi$ correspondente ao $\beta_{0}$ desejado então pode ser calculado.

Tabela 4.10: Variações de $\beta$ para valores típicos de $\phi\left(\bar{R} / R_{n}=1,10\right.$ e $\left.V_{R}=0,15\right)$

\begin{tabular}{|c|c|c|c|c|}
\hline$\phi$ & 0,70 & 0,75 & 0,80 & 0,85 \\
$(1)$ & $(2)$ & $(3)$ & $(4)$ & $(5)$ \\
\hline$\beta$ & $3,3-3,8$ & $3,0-3,4$ & $2,8-3,1$ & $2,6-2,8$ \\
\hline
\end{tabular}

A figura 4.5 mostra a variação de $\beta$ para várias combinações envolvendo ações gravitacionais e do vento para vigas de aço laminado com $\phi=0,85$. Os coeficientes de ponderação e as combinações das ações utilizadas são mostradas ao lado de cada gráfico. Em comparação com a prática anterior, mostrada nas figuras 4.1 a 4.3 , os valores de $\beta$ são muito mais uniformes.

Pode-se analisar os índices de confiabilidade associados às vigas de aço submetidas aos carregamentos indicados na tabela 4.4, sendo agora calculadas em estados limites e com os coeficientes de ponderação recomendados por ELLINGWOOD, 1982 e indicados na tabela 4.11. Os resultados obtidos estão listados na tabela 4.11 para valores de $\phi$ entre 0,6 e 1,0 e são também plotados como curvas $\beta-\phi$ nas figuras 4.6 e 4.7 . 

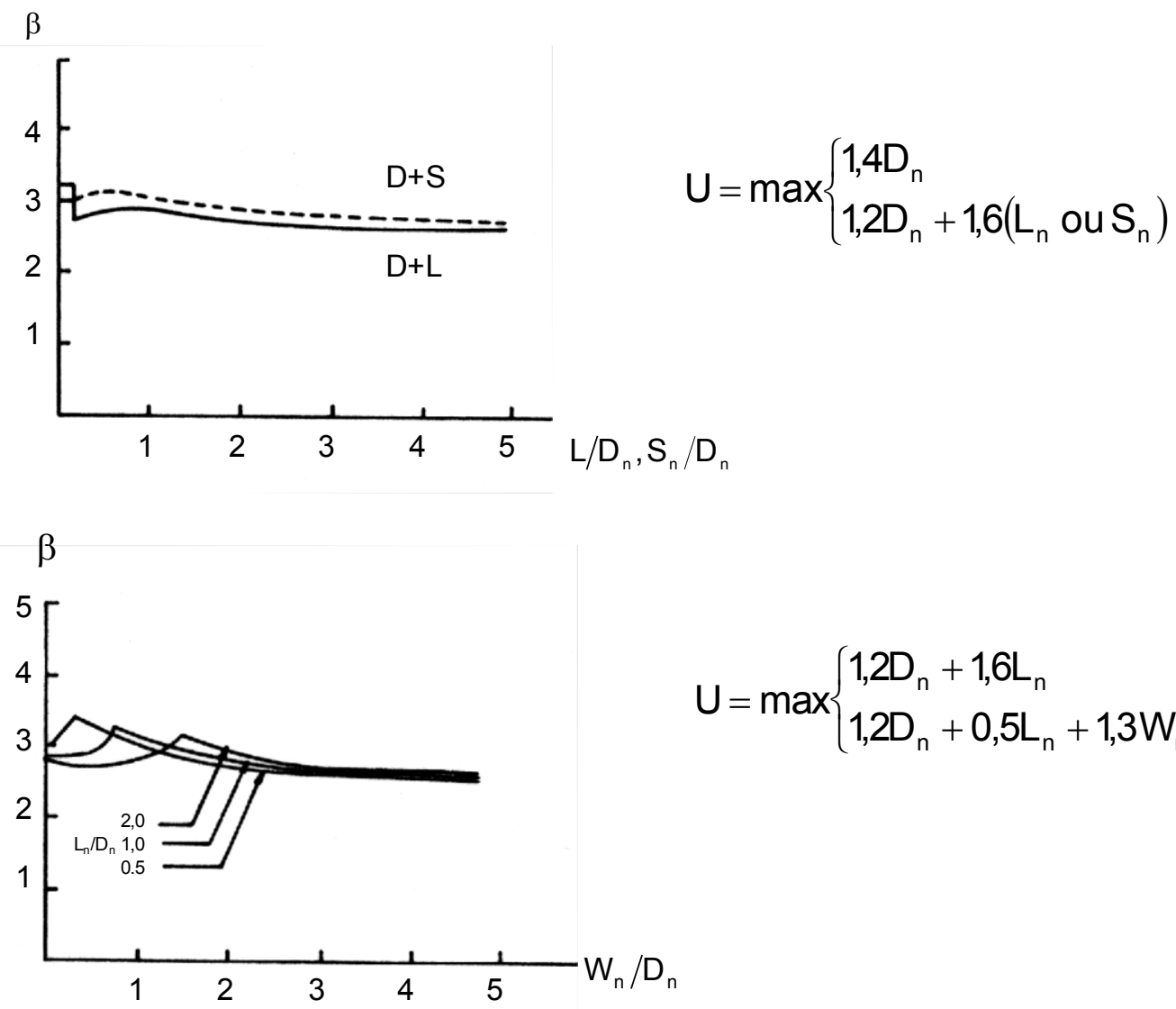

$$
U=\max \left\{\begin{array}{l}
1,2 D_{n}+1,6 L_{n} \\
1,2 D_{n}+0,5 L_{n}+1,3 W_{n}
\end{array}\right.
$$

Figura 4.5: Índice de confiabilidade para vigas de aço usando ações fatoradas individualmente.

Tabela 4.11: Índices de confiabilidade $\beta$ de vigas de aço para vários valores de $\phi$.

\begin{tabular}{|c|c|c|c|c|c|c|c|c|}
\hline $\begin{array}{c}\text { Caso } \\
(1)\end{array}$ & $\begin{array}{c}\gamma_{\mathrm{D}} \\
(2)\end{array}$ & $\begin{array}{c}\gamma_{\mathrm{L}} \\
(3)\end{array}$ & $\begin{array}{c}\gamma_{\mathrm{W}} \\
(4)\end{array}$ & $\begin{array}{c}\phi=0,6 \\
(5)\end{array}$ & $\begin{array}{c}\phi=0,7 \\
(6)\end{array}$ & $\begin{array}{c}\phi=0,8 \\
(7)\end{array}$ & $\begin{array}{c}\phi=0,9 \\
(8)\end{array}$ & $\begin{array}{c}\phi=1,0 \\
(9)\end{array}$ \\
\hline 1 & 1,2 & 1,6 & - & 4,41 & 3,73 & 3,12 & 2,56 & 2,03 \\
\hline 2 & 1,2 & 1,6 & - & 4,81 & 3,98 & 3,23 & 2,54 & 1,90 \\
\hline 3 & 1,2 & 1,6 & - & 4,09 & 3,49 & 2,97 & 2,49 & 2,04 \\
\hline 4 & 1,2 & 1,6 & - & 4,86 & 3,84 & 2,96 & 2,20 & 1,52 \\
\hline 5 & 1,2 & 0,5 & 1,3 & 4,61 & 3,91 & 3,28 & 2,71 & 2,19 \\
\hline 6 & 1,2 & 0,5 & 1,3 & 4,32 & 3,55 & 2,86 & 2,24 & 1,67 \\
\hline 7 & 1,2 & - & 1,3 & 4,31 & 3,60 & 2,96 & 2,37 & 1,82 \\
\hline
\end{tabular}


O figura 4.6 indica os valores $\phi$ para as confiabilidades alvo mais citadas pela literatura para vigas de aço $\beta=2,6$ e $\beta=3,0$. Nota-se que para o índice $\beta=3,0$ valores $\phi$ de aproximadamente 0,78 a 0,85 são requeridos. Para uma confiabilidade alvo de $\beta=2,6$ o intervalo de $\phi$ é cerca de 0,84 a 0,92 . $E$ finalmente, o figura 4.7 indica que para um coeficiente de resistência $\phi=0,9$, que é o valor recomendado pela maioria das normas, inclusive a NBR 8800 , os valores de $\beta$ estão contidos entre 2,2 e 2,7 . Ao não se considerar o caso com a atuação de somente ação do vento e permanente (caso 7) e os casos onde a ação permanente predomina (casos 4 e 6 ), o intervalo de $\beta$ reduz-se significativamente para 2,5 a 2,6.

Pode-se comparar ainda a variação nos valores de $\beta$ obtida com o cálculo em tensões admissíveis (tabela 4.5) de 1,9 a 3,4 que é consideravelmente maior do que a obtida em estados limites (2,2 a 2,7). Pode-se então perceber que o cálculo em estados limites fornece níveis mais consistentes de segurança e isto corresponde a uma das principais vantagens deste método.

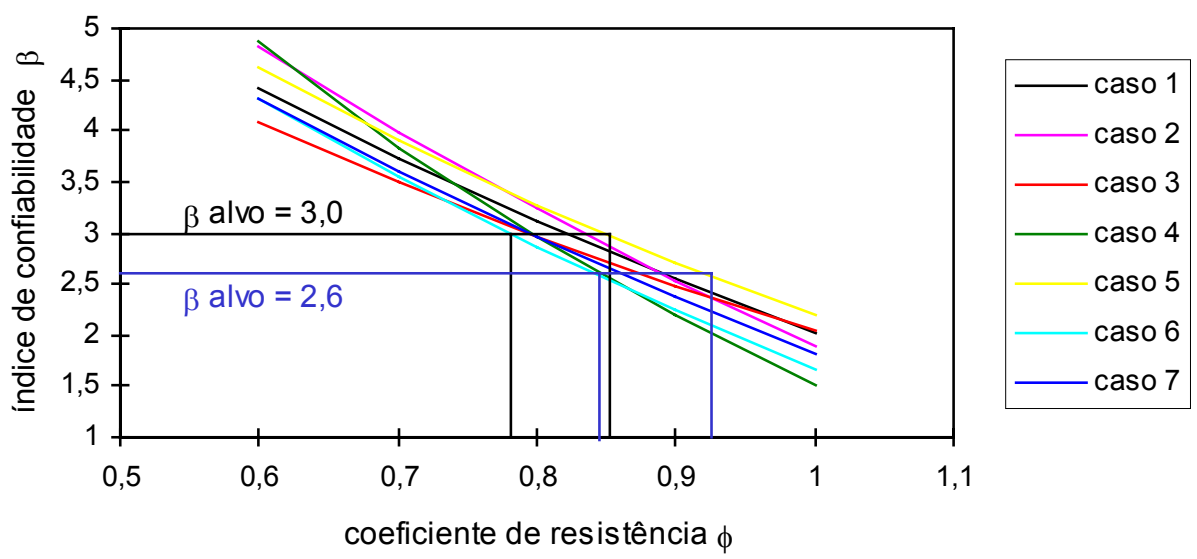

Figura 4.6: Valores de $\phi$ para valores alvos dos índices de confiabilidade. 


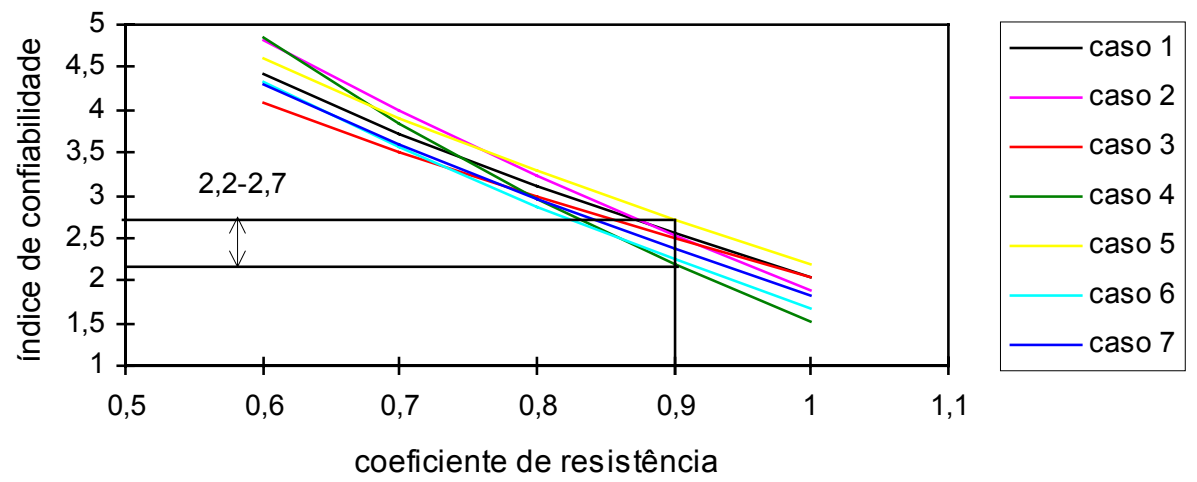

Figura 4.7: Gamas de valores $\beta$ para $\phi=0,9$.

\section{4) Conclusões}

O exame de confiabilidade de critérios de cálculo empregados anteriormente indica que o índice de confiabilidade varia de acordo com o material, tipo de elemento, modo de falha e combinação das ações. Parece que os níveis $\beta$ associados aos cálculos segundo normas anteriores eram menores para combinações de ações que incluíam efeitos de ação do vento do que para combinações envolvendo somente ações gravitacionais.

A razão para a diferença era o uso de $33 \%$ de aumento da tensão admissível quando uma das ações contribuintes fosse ação do vento. Aparentemente, este aumento sugeria um acréscimo maior do que a consideração da improbabilidade de ocorrência simultânea de duas ações máximas no período de vida útil da estrutura, já que este efeito estava incluído no modelo probabilístico usado na análise. Pode ser discutido que a menor confiabilidade das combinações de ações envolvendo vento é somente aparente. No caso de ações devido à ocupação, a ação consiste de várias fontes discretas que tendem a afetar a estrutura ou seus elementos individuais, enquanto os efeitos da ação do vento afetam o sistema inteiro do edifício, incluindo elementos estruturais e não estruturais. 
Normas de cálculo tratam explicitamente com elementos estruturais, e a análise probabilística feita por GALAMBOS, 1982 na determinação dos índices de confiabilidade seguiu a mesma aproximação, sendo que a confiabilidade real pode ser determinada somente por uma análise probabilística do sistema. Foi assumido que a mesma tolerância implícita para efeitos globais deveria ser a base da seleção de valores $\beta$ alvos para o desenvolvimento de coeficientes de ponderação probabilísticos. Assim, diferentes confiabilidades alvos foram escolhidas para combinações de ações gravitacionais e combinações com ações do vento, como indicado anteriormente. Esta decisão é baseada na suposição de que as diferenças de $\beta$ no cálculo anterior (tensões admissíveis) eram somente aparentes, como comprovado pelo fato de que cálculos realizados com base nas normas anteriores, para elementos principais sujeitos a ações gravitacionais e do vento, tenham mostrado desempenho satisfatório. Enquanto esta solução não é inteiramente satisfatória do ponto de vista analítico, ela permitiu o desenvolvimento de coeficientes de ponderação das ações, que não perturbassem e talvez distorcessem a prática anterior de uma forma indesejável.

Por outro lado, poderia também ser discutido que a prática anterior exigia estruturas superdimensionadas sob ações gravitacionais, ou pelo contrário, estruturas subdimensionadas sob combinações envolvendo ações do vento. Em ambos os casos, a seleção de um $\beta$ alvo simples, resultaria em coeficientes de ponderação das ações que mudariam drasticamente a prática anterior de cálculo. A base da análise desenvolvida até aqui, não justifica seguir esta alternativa especialmente frente ao desempenho satisfatório dos cálculos anteriores. Entretanto, o dilema causado pelas diferenças no valor de $\beta$ não está resolvido, e tanto os pesquisadores quanto os grupos revisores e elaboradores de normas estão desafiados a encarregar-se de sérios esforços para resolvê-lo. 


\section{CAPÍTULO 5 - EXEMPLOS}

Exemplo 5.1: Viga com função de desempenho linear, variáveis não correlacionadas com distribuição normal, log-normal e extremo tipo I.

Para a viga do caso 1 da tabela 4.4 (página 77) pode-se escrever uma equação linear de desempenho da seguinte forma:

$$
g(\mathbf{X})=R-D-L
$$

onde:

$R$ é a resistência do elemento à flexão.

$D$ e $L$ são as ações permanentes e variáveis respectivamente.

Utilizando os coeficientes de ponderação das ações e o coeficiente de resistência recomendados por ELLINGWOOD, 1982 e adotados pelo LRFD, 1986, a segurança do elemento fica expressa pela seguinte equação:

$$
0,9 R_{n} \geq 1,2 D_{n}+1,6 L_{n}
$$

onde:

$R_{n}, D_{n}$ e $L_{n}$ são os valores nominais da resistência e ações.

Estes valores nominais são geralmente diferentes dos valores médios das variáveis. Por exemplo, de acordo com GALAMBOS, 1982 
(tabela 4.2) as relações entre as médias e os valores nominais das ações são:

$$
\begin{aligned}
& \frac{\bar{D}}{D_{n}}=1,05 \\
& \frac{\bar{L}}{L_{n}}=1,00
\end{aligned}
$$

E para a resistência de vigas de aço a correspondente relação é:

$$
\frac{\overline{\mathrm{R}}}{\mathrm{R}_{\mathrm{n}}}=1,07
$$

Os coeficientes de variação e as distribuições de probabilidade das ações e resistência para o caso analisado também foram relacionados nas tabelas 4.1 e 4.2 :

$$
\begin{aligned}
& \delta_{\mathrm{D}}=0,10 \quad \Rightarrow \text { ação permanente tem distribuição normal } \\
& \delta_{\mathrm{L}}=0,25 \quad \Rightarrow \text { ação variável tem distribuição extremo tipo I } \\
& \delta_{\mathrm{R}}=0,13 \quad \Rightarrow \text { resistência à flexão tem distribuição log- } \\
& \text { normal }
\end{aligned}
$$

Para o caso em estudo tem-se:

$$
\frac{L_{n}}{D_{n}}=0,800
$$

Logo, pode-se fazer:

$$
\frac{\overline{\mathrm{L}}}{\overline{\mathrm{D}} / 1,05}=0,800 \Rightarrow \overline{\mathrm{L}}=0,762 \overline{\mathrm{D}}
$$

Portanto:

$$
0,9 \frac{\bar{R}}{1,07} \geq 1,2 \frac{\bar{D}}{1,05}+1,6 \frac{0,762 \overline{\mathrm{D}}}{1,00}
$$




$$
\bar{R} \geq 2,808 \bar{D} \rightarrow \text { no estado limite } \quad \bar{R}=2,808 \bar{D}
$$

Como as variáveis resistência e ação variável (sobrecarga) não têm distribuição de probabilidade normal, distribuições normais equivalentes poderão ser utilizadas para calcular $o$ índice de confiabilidade e a correspondente probabilidade de falha da viga em estudo de acordo com o que foi exposto nos capítulos 2 e 3 . Assumindo que as variáveis não são correlacionadas, tem-se que:

$$
\begin{aligned}
& \zeta_{R} \cong \delta=0,13 \text { em que } \zeta_{R} \text { é o desvio padrão de } \ln (R) \\
& \lambda_{R}=\ln \bar{R}-\frac{1}{2} \zeta_{R}^{2} \cong \ln \bar{R}=\ln 2,808 \bar{D}
\end{aligned}
$$

e

$$
\begin{aligned}
& F_{R}(r)=\Phi\left(\frac{\ln r-\lambda_{R}}{\zeta_{R}}\right) \\
& f_{R}(r)=\frac{1}{r \zeta_{R}} \phi\left(\frac{\ln r-\lambda_{R}}{\zeta_{R}}\right)
\end{aligned}
$$

Então as equações 2.32 e 2.31 , respectivamente ficam:

$$
\begin{aligned}
& \sigma_{R}^{N}=\frac{1}{f_{R}\left(r^{*}\right)} \phi\left\{\Phi^{-1}\left[\Phi\left(\frac{\ln r^{*}-\lambda_{R}}{\zeta_{R}}\right)\right]\right\} \\
& \sigma_{R}^{N}=\frac{1}{f_{R}\left(r^{*}\right)} \phi\left(\frac{\ln r^{*}-\lambda_{R}}{\zeta_{R}}\right) \\
& \sigma_{R}^{N}=r^{*} \zeta_{R}
\end{aligned}
$$

e

$$
\begin{aligned}
& \mu_{R}^{N}=r^{*}-\sigma_{R}^{N} \Phi^{-1}\left[\Phi\left(\frac{\ln r^{*}-\lambda_{R}}{\zeta_{R}}\right)\right] \\
& \mu_{R}^{N}=r^{*}-r^{*} \zeta_{R}\left(\frac{\ln r^{*}-\lambda_{R}}{\zeta_{R}}\right)
\end{aligned}
$$




$$
\mu_{\mathrm{R}}^{\mathrm{N}}=\mathrm{r}^{*}\left(1-\ln \mathrm{r}^{*}+\lambda_{\mathrm{R}}\right)
$$

Para a variável $L$ as funções $F_{L}(I)$ e $f_{L}(I)$ são:

$$
\begin{aligned}
& F_{L}(I)=\exp \left[-e^{-\alpha(I-u)}\right] \\
& f_{L}(I)=\alpha \exp \left[-\alpha(I-u)-e^{-\alpha(I-u)}\right]
\end{aligned}
$$

Com parâmetros:

$$
\begin{aligned}
& \alpha=\frac{\pi}{\sqrt{6}} \frac{1}{\sigma_{L}}=\frac{\pi}{\sqrt{6}} \frac{1}{0,191 \bar{D}}=\frac{6,733}{\bar{D}} \\
& u=\mu-\frac{\gamma}{\alpha}=\bar{L}-\frac{0,577}{\alpha}=0,762 \bar{D}-\frac{0,577}{6,733} \bar{D}=0,676 \bar{D}
\end{aligned}
$$

Neste caso, isto é, envolvendo distribuições não normais, embora a função de desempenho seja linear, os valores médios e desvios padrão requeridos na equação 2.33 são desconhecidos por estes serem agora funções dos respectivos valores no ponto de falha. Uma solução iterativa , usando as equações 2.31 e 2.32 será, portanto, necessária.

Para a primeira iteração, assume-se:

$$
\begin{aligned}
& r^{*}=\bar{R}=2,808 \bar{D} \\
& I^{*}=\bar{L}=0,762 \bar{D}
\end{aligned}
$$

Então;

$$
\sigma_{R}^{N}=2,808 \bar{D}(0,13)=0,365 \bar{D}
$$

e

$$
\mu_{R}^{N}=2,808 \bar{D}(1-\ln (2,808 \overline{\mathrm{D}})+\ln (2,808 \overline{\mathrm{D}}))=2,808 \overline{\mathrm{D}}
$$

Para a distribuição extremo tipo I de L:

$$
F_{L}\left(I^{*}\right)=0,571
$$




$$
\mathrm{f}_{\mathrm{L}}\left(\mathrm{I}^{*}\right)=\frac{2,154}{\overline{\mathrm{D}}}
$$

E assim as equações 2.32 e 2.31 ficam:

$$
\begin{aligned}
& \sigma_{\llcorner}^{N}=\frac{\frac{1}{\sqrt{2 \pi}} \exp \left[-\frac{1}{2}\left\{\Phi^{-1}(0,571)^{2}\right\}\right]}{\frac{2,154}{\bar{D}}} \\
& \sigma_{L}^{N}=\frac{1}{\sqrt{2 \pi}} \frac{\bar{D}}{2,154} \exp \left[-\frac{1}{2}(0,176)^{2}\right]=0,182 \bar{D}
\end{aligned}
$$

e

$$
\mu_{\llcorner}^{N}=0,762 \bar{D}-0,182 \bar{D} \cdot 0,176=0,730 \bar{D}
$$

Sendo $D$ uma variável normal:

$$
\begin{aligned}
& \sigma_{\mathrm{D}}^{\mathrm{N}}=\sigma_{\mathrm{D}}=0,10 \overline{\mathrm{D}} \\
& \mu_{\mathrm{D}}^{\mathrm{N}}=\overline{\mathrm{D}}
\end{aligned}
$$

Portanto a equação 2.33 fica:

$$
\begin{aligned}
& \beta=\frac{\mu_{R}^{N}-\mu_{D}^{N}-\mu_{L}^{N}}{\sqrt{\left(\sigma_{R}^{N}\right)^{2}+\left(\sigma_{D}^{N}\right)^{2}+\left(\sigma_{L}^{N}\right)^{2}}}=\frac{2,808 \bar{D}-\bar{D}-0,730 \bar{D}}{\sqrt{(0,365 \bar{D})^{2}+(0,100 \bar{D})^{2}+(0,182 \bar{D})^{2}}} \\
& \beta=2,567
\end{aligned}
$$

Mas o ponto de falha é:

$$
r^{*}=\mu_{R}^{N}-\alpha_{R}^{*} \beta \sigma_{R}^{N}
$$

onde:

$$
\begin{aligned}
& \alpha_{R}^{*}=\frac{\sigma_{R}^{N}}{\sqrt{\left(\sigma_{R}^{N}\right)^{2}+\sigma_{D}^{2}+\left(\sigma_{L}^{N}\right)^{2}}}=\frac{0,365 \bar{D}}{\sqrt{(0,365 \bar{D})^{2}+(0,100 \bar{D})^{2}+(0,182 \bar{D})^{2}}} \\
& \therefore \alpha_{R}^{*}=0,869
\end{aligned}
$$


logo:

$$
r^{*}=2,808 \bar{D}-0,869 \cdot 2,567 \cdot 0,365 \bar{D}=1,944 \bar{D}
$$

Similarmente:

$$
\begin{aligned}
& \alpha_{\mathrm{L}}^{*}=-0,433 \\
& \mathrm{I}^{*}=0,730 \overline{\mathrm{D}}+0,433 \cdot 2,567 \cdot 0,182 \overline{\mathrm{D}}=0,932 \overline{\mathrm{D}}
\end{aligned}
$$

A segunda e subsequentes iterações podem ser resumidas como segue:

Tabela 5.1: Resultados das iterações necessárias para o cálculo de $\beta$.

\begin{tabular}{|c|c|c|c|c|}
\hline Iteração & Ponto de falha assumido & $\sigma^{N}$ & $\mu^{N}$ & $\beta$ \\
\hline \multirow{2}{*}{2} & $r^{*}=1,944 \bar{D}$ & $0,259 \bar{D}$ & $2,677 \bar{D}$ & 2,657 \\
\cline { 2 - 4 } & $I^{*}=0,932 \bar{D}$ & $0,246 \bar{D}$ & $0,691 \bar{D}$ & \\
\hline \multirow{2}{*}{3} & $r^{*}=2,195 \bar{D}$ & $0,285 \bar{D}$ & $2,736 \bar{D}$ & 2,602 \\
\cline { 2 - 4 } & $I^{*}=1,124 \bar{D}$ & $0,317 \bar{D}$ & $0,596 \bar{D}$ & \\
\hline \multirow{2}{*}{4} & $r^{*}=2,252 \bar{D}$ & $0,293 \bar{D}$ & $2,749 \bar{D}$ & \multirow{2}{*}{2,597} \\
\cline { 2 - 4 } & $l^{*}=1,192 \bar{D}$ & $0,341 \bar{D}$ & $0,553 \bar{D}$ & \\
\hline \multirow{2}{*}{5} & $r^{*}=2,265 \bar{D}$ & $0,295 \bar{D}$ & $2,752 \bar{D}$ & 2,597 \\
\cline { 2 - 4 } & $I^{*}=1,209 \bar{D}$ & $0,347 \bar{D}$ & $0,541 \bar{D}$ & \\
\hline
\end{tabular}

Portanto, o índice de confiabilidade da viga calculada com os coeficientes de ponderação das ações de 1,2 para a ação permanente, 1,6 para a sobrecarga e ainda coeficiente de resistência igual a 0,9 é 2,597. A correspondente probabilidade de falha é:

$$
p_{F}=1-\Phi(2,597)=0,00466
$$

Exemplo 5.2: Função de desempenho linear, variáveis não correlacionadas e com distribuição normal. 
A forma mais comum das normas atuais para o cálculo de elementos estruturais é a desigualdade linear abaixo:

$$
\phi R_{n} \geq \gamma_{D} D_{n}+\gamma_{L} L_{n}
$$

Onde o subscrito " $\mathrm{n}$ " indica os valores nominais da resistência e das ações. As relações destes valores nominais para os seus respectivos valores médios podem ser consideradas como os correspondentes fatores:

$$
v_{R}=\frac{R_{n}}{\bar{R}} ; \quad v_{D}=\frac{D_{n}}{\bar{D}} ; \quad v_{L}=\frac{L_{n}}{\bar{L}}
$$

Seja por exemplo, determinar o coeficiente de resistência $(\phi)$ e os coeficientes de ponderação das ações $\left(\gamma_{D}\right.$ e $\left.\gamma_{L}\right)$ para alcançar projetos com uma confiabilidade de $\beta=2,50$. Considera-se uma relação da ação variável para a ação permanente de $\bar{L} / \bar{D}=2,0$ e que as variáveis têm distribuição de probabilidade normal e são não correlacionadas. Admite-se também:

$$
\delta_{\mathrm{R}}=0,11 ; \quad \delta_{\mathrm{D}}=0,10 ; \quad \delta_{\mathrm{L}}=0,25
$$

e

$$
v_{R}=0,95 ; \quad v_{D}=0,95 ; \quad v_{L}=1,18
$$

A equação. de cálculo anterior é uma função de desempenho linear, isto é:

$$
g(\mathbf{X})=R-D-L
$$

com derivadas parciais:

$$
\begin{aligned}
& \frac{\partial g}{\partial R^{\prime}}=\sigma_{R} \\
& \frac{\partial g}{\partial D^{\prime}}=-\sigma_{D} \\
& \frac{\partial g}{\partial L^{\prime}}=-\sigma_{L}
\end{aligned}
$$


Então:

$$
\frac{\bar{R}-\bar{D}-\bar{L}}{\sqrt{\sigma_{R}^{2}+\sigma_{D}^{2}+\sigma_{L}^{2}}}=\beta=2,50
$$

Onde

$$
\overline{\mathrm{L}}=2 \overline{\mathrm{D}}
$$

e

$$
\begin{aligned}
& \sigma_{D}=0,1 \bar{D} \\
& \sigma_{L}=\delta_{L} \bar{L}=\delta_{L}(2 \bar{D})=0,5 \bar{D} \\
& \sigma_{R}=0,11 \bar{R}
\end{aligned}
$$

Donde:

$$
\frac{\bar{R}-\bar{D}-2 \bar{D}}{\sqrt{(0,11 \bar{R})^{2}+(0,10 \bar{D})^{2}+(0,50 \bar{D})^{2}}}=2,50
$$

resultando na seguinte equação. quadrática:

$$
\bar{R}^{2}-6,491 \bar{R} \bar{D}+7,978=0
$$

A solução de interesse para $\bar{R}$ é:

$$
\bar{R}=4,844 \bar{D}
$$

e

$$
\sigma_{R}=4,844 \bar{D} \times 0,11=0,533 \bar{D}
$$

Os co-senos diretores são: 


$$
\begin{aligned}
& \alpha_{R}=\frac{\sigma_{R}}{\sqrt{\sigma_{R}^{2}+\sigma_{D}^{2}+\sigma_{L}^{2}}}=\frac{0,533 \bar{D}}{\sqrt{(0,533 \bar{D})^{2}+(0,100 \bar{D})^{2}+(0,500 \bar{D})^{2}}}=0,722 \\
& \alpha_{D}=\frac{-\sigma_{D}}{\sqrt{\sigma_{R}^{2}+\sigma_{D}^{2}+\sigma_{L}^{2}}}=\frac{-0,100 \bar{D}}{0,738 \bar{D}}=-0,136 \\
& \alpha_{L}=\frac{-\sigma_{L}}{\sqrt{\sigma_{R}^{2}+\sigma_{D}^{2}+\sigma_{L}^{2}}}=\frac{-0,500 \bar{D}}{0,738 \bar{D}}=-0,678
\end{aligned}
$$

Donde, de acordo com a equação 3.4, os coeficientes médios de resistência e de ponderação das ações apropriados são:

$$
\begin{aligned}
& \bar{\phi}=(1-0,722 \times 2,5 \times 0,11)=0,80 \\
& \bar{\gamma}_{D}=(1+0,136 \times 2,5 \times 0,10)=1,03 \\
& \bar{\gamma}_{L}=(1+0,678 \times 2,5 \times 0,25)=1,42
\end{aligned}
$$

Estes coeficientes médios deverão ser usados com as correspondentes resistências e ações médias, isto é, a exigência de segurança será:

$$
0,80 \bar{R} \geq 1,03 \overline{\mathrm{D}}+1,42 \overline{\mathrm{L}}
$$

Observe que neste caso (linear), não é necessário processo iterativo para se obter os coeficientes de cálculo.

Para determinar os correspondentes coeficientes nominais de resistência e de ponderação das ações, observa-se que:

$$
v_{\mathrm{R}}=\frac{\mathrm{R}_{\mathrm{n}}}{\overline{\mathrm{R}}}=0,95
$$

ou

$$
\overline{\mathrm{R}}=\frac{\mathrm{R}_{\mathrm{n}}}{0,95}
$$

Similarmente,

$$
\overline{\mathrm{D}}=\frac{\mathrm{D}_{\mathrm{n}}}{0,95} \quad \text { e } \quad \overline{\mathrm{L}}=\frac{\mathrm{L}_{\mathrm{n}}}{1,18}
$$


Portanto, em termos dos valores nominais, a segurança exigida anteriormente fica:

$$
0,80\left(\frac{R_{n}}{0,95}\right) \geq 1,03\left(\frac{D_{n}}{0,95}\right)+1,42\left(\frac{L_{n}}{1,18}\right)
$$

ou

$$
0,84 R_{n} \geq 1,08 D_{n}+1,20 L_{n}
$$

O correspondente coeficiente total das ações e o coeficiente de segurança podem ser calculados como segue:

$$
1,08 D_{n}+1,20 L_{n}=\gamma_{n}\left(D_{n}+L_{n}\right)
$$

ou

$$
\gamma_{n}=\frac{1,08 D_{n}+1,20 L_{n}}{D_{n}+L_{n}}
$$

Para a relação de ações, $\bar{L} / \overline{\mathrm{D}}=2,0$ :

$$
\frac{L_{n}}{D_{n}}=2\left(\frac{1,18}{0,95}\right)=2,48
$$

Assim, o coeficiente total das ações é:

$$
\gamma_{\mathrm{n}}=\frac{1,08+1,20 \times 2,48}{1+2,48}=1,17
$$

Ao passo que o correspondente coeficiente de segurança é:

$$
\theta_{\mathrm{n}}=\frac{1,17}{0,84}=1,39
$$

Exemplo 5.3: Função de desempenho não linear, variáveis não correlacionadas com distribuição normal.

A resistência à flexão de uma viga de aço de seção compacta pode ser escrita como $R=Y Z$, em que $Y$ é a tensão de escoamento do material e 
Z é o módulo plástico da seção. A função de desempenho é não linear da forma $g(\mathbf{X})=Y Z-M$, sendo $M$ o momento aplicado à seção.

Pode-se determinar os coeficientes de cálculo a serem aplicados aos valores médios das variáveis para se alcançar um índice de confiabilidade igual a 2,5. Assumindo que as variáveis do problema apresentam distribuição normal de probabilidade, não são correlacionadas e que $\bar{Y}=40 \mathrm{kN} / \mathrm{cm}^{2}$ e ainda:

$$
\begin{aligned}
& \delta_{Y}=0,125 \\
& \delta_{Z}=0,050 \\
& \delta_{M}=0,200
\end{aligned}
$$

No estado limite:

$$
\mathrm{y}^{*} \mathrm{z}^{*}-\mathrm{m}^{*}=0
$$

e

$$
\left(\frac{\partial g}{\partial Y^{\prime}}\right)_{*}=z^{*} \sigma_{Y} ; \quad\left(\frac{\partial g}{\partial Z^{\prime}}\right)_{*}=y^{*} \sigma_{Z} ; \quad\left(\frac{\partial g}{\partial M^{\prime}}\right)_{*}=-\sigma_{M}
$$

Para a primeira iteração, assume-se:

$$
\begin{aligned}
& \mathrm{y}^{*}=\overline{\mathrm{Y}}=40 \mathrm{kN} / \mathrm{cm}^{2} \\
& \mathrm{z}^{*}=\overline{\mathrm{Z}} \\
& \mathrm{m}^{*}=\overline{\mathrm{M}}
\end{aligned}
$$

Então:

$$
\begin{aligned}
& \left(\frac{\partial \mathrm{g}}{\partial \mathrm{Y}^{\prime}}\right)_{*}=\overline{\mathrm{Z}}(40.0,125)=5 \overline{\mathrm{Z}} \\
& \left(\frac{\partial \mathrm{g}}{\partial \mathrm{Z}^{\prime}}\right)_{*}=40(0,05 \overline{\mathrm{Z}})=2 \overline{\mathrm{Z}}
\end{aligned}
$$




$$
\left(\frac{\partial \mathrm{g}}{\partial \mathrm{M}^{\prime}}\right)_{*}=-0,20 \overline{\mathrm{M}}=-0,20(40 \overline{\mathrm{Z}})=-8 \overline{\mathrm{Z}}
$$

E

$$
\begin{aligned}
& \alpha_{Y}^{*}=\frac{5}{9,644}=0,5185 \\
& \alpha_{Z}^{*}=\frac{2}{9,644}=0,2074 \\
& \alpha_{M}^{*}=\frac{-8}{9,644}=-0,8296
\end{aligned}
$$

Portanto o novo ponto é:

$$
\begin{aligned}
& \mathrm{y}^{*}=40(1-0,5185 \cdot 2,5 \cdot 0,125)=33,52 \\
& \mathrm{z}^{*}=\overline{\mathrm{Z}}(1-0,2074 \cdot 2,5 \cdot 0,05)=0,9741 \overline{\mathrm{Z}} \\
& \mathrm{m}^{*}=\overline{\mathrm{M}}(1+0,8296 \cdot 2,5 \cdot 0,20)=1,4148 \overline{\mathrm{M}}
\end{aligned}
$$

Os resultados das demais iterações são apresentados na tabela 5.2

Tabela 5.2: Resultados das iterações para o cálculo dos coeficientes de cálculo.

\begin{tabular}{|c|c|l|l|l|l|}
\hline Iteração & Variável & $\mathrm{X}^{*}{ }_{\mathrm{i}}$ assumido & $\left(\frac{\partial \mathrm{g}}{\partial \mathrm{X}_{\mathrm{i}}}\right)_{*}$ & $\alpha_{\mathrm{x}_{\mathrm{i}}}$ & Novo $\mathrm{X}^{{ }^{*}}{ }_{\mathrm{i}}$ \\
\hline \multirow{2}{*}{2} & $\mathrm{Y}$ & 33,52 & $4,871 \overline{\mathrm{Z}}$ & 0,7052 & 31,19 \\
\cline { 2 - 6 } & $\mathrm{Z}$ & $0,9741 \overline{\mathrm{Z}}$ & $1,633 \overline{\mathrm{Z}}$ & 0,2374 & $0,9705 \overline{\mathrm{Z}}$ \\
\cline { 2 - 6 } & $\mathrm{M}$ & $1,4148 \overline{\mathrm{M}}$ & $-4,616 \overline{\mathrm{Z}}$ & $-0,6683$ & $1,3342 \overline{\mathrm{M}}$ \\
\hline \multirow{2}{*}{3} & $\mathrm{Y}$ & 31,19 & $4,853 \overline{\mathrm{Z}}$ & 0,7122 & 31,09 \\
\cline { 2 - 6 } & $\mathrm{Z}$ & $0,9705 \overline{\mathrm{Z}}$ & $1,513 \overline{\mathrm{Z}}$ & 0,2220 & $0,9723 \overline{\mathrm{Z}}$ \\
\cline { 2 - 6 } & $\mathrm{M}$ & $1,334 \overline{\mathrm{M}}$ & $4,538 \overline{\mathrm{Z}}$ & $-0,6660$ & $1,333 \overline{\mathrm{M}}$ \\
\hline \multirow{2}{*}{4} & $\mathrm{Y}$ & 31,09 & $4,862 \overline{\mathrm{Z}}$ & 0,7130 & 31,09 \\
\cline { 2 - 6 } & $\mathrm{Z}$ & $0,9723 \overline{\mathrm{Z}}$ & $1,511 \overline{\mathrm{Z}}$ & 0,2216 & $0,9723 \overline{\mathrm{Z}}$ \\
\cline { 2 - 6 } & $\mathrm{M}$ & $1,333 \overline{\mathrm{M}}$ & $-4,536 \overline{\mathrm{Z}}$ & $-0,6652$ & $1,333 \overline{\mathrm{M}}$ \\
\hline
\end{tabular}


Os coeficientes de cálculo requeridos são, portanto:

$$
\begin{aligned}
& \bar{\gamma}_{Y}=1-0,7130 \cdot 2,5 \cdot 0,125=0,78 \\
& \bar{\gamma}_{Z}=1-0,2216 \cdot 2,5 \cdot 0,05=0,97 \\
& \bar{\gamma}_{M}=1+0,6652 \cdot 2,5 \cdot 0,20=1,33
\end{aligned}
$$

A equação de cálculo com os coeficientes a serem aplicados aos valores médios das variáveis fica:

$$
(0,78 \bar{Y})(0,97 \bar{Z})-1,33 \bar{M} \geq 0
$$

ou

$$
0,76 \overline{\mathrm{YZ}}-1,33 \overline{\mathrm{M}} \geq 0
$$

e para $\bar{Y}=40 \mathrm{kN} / \mathrm{cm}^{2}$, tem se o módulo plástico médio requerido para resistir a um momento médio $\overline{\mathrm{M}}$ com um índice de confiabilidade igual a 2,5.

$$
\overline{\mathrm{Z}} \geq 0,044 \overline{\mathrm{M}}
$$




\section{CAPÍTULO 6 - CONCLUSÕES E}

\section{COMENTÁRIOS FINAIS}

A afirmação de que é possível separar coeficientes de segurança afirmando que cada coeficiente é dependente somente da incerteza no parâmetro a que ele é aplicado e é independente da incerteza em todas as outras variáveis tem alguma carência de rigor probabilístico, mas isto não condena o processo como inútil, já que praticamente nenhum processo usado em projeto pode ser justificado rigorosamente. Algumas aproximações são sempre necessárias até mesmo para assegurar outra característica também importante em um processo de cálculo, que é a transparência de lógica ou facilidade com que os princípios básicos do modelo podem ser entendidos.

Um dos principais fatores que atraiu a comunidade acadêmica para a aproximação dos coeficientes parciais foi a clareza lógica do sistema: incerteza na ação permanente é coberta por um coeficiente aplicado à ação permanente, incerteza na sobrecarga por um coeficiente aplicado à sobrecarga e assim por diante. Isto não poderia ser sustentado pelo método das tensões admissíveis. Esta aproximação também permite ao engenheiro julgar e tomar decisões sobre o que poderia ser feito em situações atípicas onde a variabilidade de um parâmetro de cálculo não for padrão. 
Uma outra característica importante de um processo de cálculo é a simplicidade com que ele pode ser aplicado. Inicialmente o método dos estados limites foi criticado por introduzir uma complexidade adicional no cálculo, argumento que foi perdendo força com o passar do tempo, à medida que os calculistas foram se familiarizando com o processo.

O método dos estados limites tem sido aplicado a uma vasta gama de situações, por apresentar também flexibilidade e universalidade de aplicação, ou seja, pode ser adaptado com comodidade para a utilização em diferentes áreas.

Entretanto, vale comentar que métodos probabilísticos podem ser aplicados somente onde a informação estatística existe e, reconhecimento devido tem que ser dado à forma real das curvas de densidade de probabilidade. A princípio a idéia é simples: as incertezas que afetam o projeto estrutural são identificadas e suas variações potenciais quantificadas estatisticamente, admitindo coeficientes de segurança parciais apropriados a serem calculados. Isto então é reunido para gerar projetos com uma probabilidade de falha aceitável, previamente especificada.

Portanto para que esta idéia seja realmente efetivada, os dados utilizados para a determinação destes coeficientes de cálculo devem ser resultados de pesquisas científicas e não valores arbitrados convenientemente para conduzir a projetos sobretudo mais econômicos, promovendo assim o uso das novas normas. O objetivo de escapar dos problemas do passado e obter resultados claramente mais racionais deve ser sempre mantido.

No entanto, ressalta-se que o método dos estados limites é mais racional do que o das tensões admissíveis, mesmo em se tratando de arbitrar valores

A maioria das normas em estados limites adotam valores menores de $\gamma_{f}$ para as ações permanentes do que para as sobrecargas afirmando que o peso próprio da estrutura pode ser determinado com maior precisão do 
que as sobrecargas. Entretanto muitos estudiosos do assunto contestam esta posição afirmando que o termo ação permanente inclui itens como acabamentos, divisórias, utilidades penduradas e forros que podem ocasionar uma variabilidade maior do que a prevista pelas atuais normas de cálculo. Nas normas de hoje o menor $\gamma_{f}$ cobre quase todas as ações permanentes ou de longa duração, incluindo itens como pressão de terra que são as ações com menos precisão dentre as que atuam nas estruturas. HEGER, 1993, afirma que existe significativamente mais incerteza nas ações permanentes do que é assumido na escolha do corrente coeficiente de ponderação da ação permanente do LRFD, 1986, $\gamma_{\mathrm{f}}=1,2$.

Segundo BEAL, 1994, estudos de falhas reais mostram que, exceto em casos evidentes de erros, estas são quase sempre causadas por resistência inadequada ao invés de variabilidade das ações normais. Normas correntes recomendam $\gamma_{\mathrm{f}}$ da ordem de 1,4 a 1,6 para as ações e $\gamma_{\mathrm{m}}$ da ordem de 1,0 a 1,15 para o aço. Isto sugere que as margens de segurança dos materiais estão insuficientes, o que pode ser corrigido pela alteração dos dados estatísticos utilizados na análise (relação resistência média pela nominal e/ou coeficiente de variabilidade da resistência).

Pode-se concluir disto que o problema de introdução da segurança nas estruturas não estará resolvido apenas com boas formulações probabilísticas, mas sobretudo, é necessário que se tenha dados confiáveis das variáveis envolvidas no cálculo.

De certa forma a revolução tem ainda que começar, pois as primeiras normas em estados limites não apresentaram diferenças significativas em relação às normas em tensões admissíveis, o que foi desejado realmente em um estágio inicial, para não introduzir mudanças muito bruscas em relação ao produto final, ou seja, os elementos estruturais projetados. Sabe-se que o que foi feito inicialmente foi uma calibração, entretanto, espera-se naturalmente que isto mude com a evolução das normas e com a obtenção de mais dados experimentais. 
Esta obtenção de dados constitui um amplo campo para pesquisas futuras, proporcionando assim bases para se desenvolver métodos consistentes com nossas situações de projetos e de materiais. Pois sabe-se que a maioria dos processos e coeficientes de cálculo recomendados pelas normas brasileiras são "importados" sem muita modificação ou adaptação às nossas condições específicas de recursos materiais, humanos e também ambientais. 


\section{BIBLIOGRAFIA}

AMERICAN INSTITUTE OF STEEL CONSTRUCTION. (1986). Load and resistance factor design - LRFD. Chicago.

AMERICAN INSTITUTE OF STEEL CONSTRUCTION. (1989). Allowable stresses design - ASD. Chicago.

AMERICAN IRON AND STEEL INSTITUTE. (1991). Load and resistance factor design for cold-formed steel structural members. Washington, DC.

ANG, A.H-S.; CORNELL, C.A. (1974). Reliability bases of structural safety and design. Journal of the Structural Division, ASCE, v.100, n.ST9, p.1755-1769, September.

ANG, A.H-S.; TANG, W.H. (1975). Probability concepts in engineering planning and design: basic principles. New York, John wiley \& Sons, Inc. v1.

ANG, A.H-S.; TANG, W.H. (1984). Probability concepts in engineering planning and design: decision, risk, and reliability. New York, John wiley \& Sons, Inc. v2.

ASSOCIAÇÃO BRASILEIRA DE NORMAS TÉCNICAS. (1984). NBR 8681 Ações e segurança nas estruturas. Rio de Janeiro.

ASSOCIAÇÃO BRASILEIRA DE NORMAS TÉCNICAS. (1986). NBR 8800 Projeto e execução de estruturas de aço de edifícios. Rio de Janeiro. 
ASSOCIAÇÃO BRASILEIRA DE NORMAS TÉCNICAS. (1978). NBR 6118 -

Projeto e execução de obras de concreto armado. Rio de Janeiro.

BEAL, A.N. (1994). Limit state at 40: new beginning or midlife crisis? The Structural Engineer, v.72, n.2, p.22-23.

BEEBY, A.W. (1994). Partial safety factors: an overview. The Structural Engineer, v.72, n.2, p.19-21.

BIGNOLI, A. J. (1995). Auditorias tecnicas en ingenieria estructural. In: JORNADAS SUDAMERICANAS DE INGENIERIA ESTRUCTURAL, 27., Tucumán, Argentina. Conferencia plenaria.

CALAVERA, J. (1983). Concepto de seguridad. IN CURSO DE REHABILITACION, v.5 - La Estructura. Madrid, Colégio Oficial de Arquitectos de Madrid.

CAROTIS, R.B.; DOSHI, V.A. (1977). Probability models for live-load: survey results. Journal of the Structural Division, ASCE, v.103, n.ST6, p.12571174 , June.

DITLEVSEN, O. (1979). Generalized second moment reliability index. Journal Structural Mechanics, v.7, n.4, p.435-451.

DITLEVSEN, O. (1979). Narrow reliability bounds for structural systems. Journal Structural Mechanics, v.7, n.4, p.453-472.

ELLIFRITT, D.S. (1977). The mysterious 1/3 Stress increase. Engineering Journal, AISC, v.14, p.138-140.

ELLINGWOOD, B. (1982). Safety checking formats for limits states design. Journal of the Structural Division, ASCE, v.108, n.ST7, p.1481-1493, July. 
ELLINGWOOD, B.; MACGREGOR, J.G.; GALAMBOS, T.V.; CORNELL, C.A. (1982). Probability based load criteria: load factors and load combinations. Journal of the Structural Division, ASCE, v.108, n.ST5, p.978-997, May.

ESSENTIALS of LRFD: An overview of LRFD as found in Part 2 of the Manual of the Steel Construction: first of three parts (1995). Modern Steel Construction, p.38-44, June.

ESSENTIALS of LRFD: An overview of LRFD as found in Part 2 of the Manual of the Steel Construction: second of three parts (1995). Modern Steel Construction, p.38-44, July.

ESSENTIALS of LRFD: An overview of LRFD as found in Part 2 of the Manual of the Steel Construction: third of three parts (1995). Modern Steel Construction, p.38-44, August.

EUROCODE 1 (1994). Basis of design and actions on structures - Part 1: Basis of design. Brussels, CEN. 85p.

FREUDENTHAL, A.M. (1947). The safety of structures. ASCE Transactions, v.121, p.125-159.

FREUDENTHAL, A.M. (1956). Safety and the Probability of structural failure. ASCE Transactions, v.121, p.1337-1397.

FREUDENTHAL, A.M.; GARRELT, J.M.; SHINOZUKA, M. (1966). The analysis of structural safety. Journal of the Structural Division, ASCE, v.92, n.ST1, February, p.125-159.

FUSCO, P.B. (1974). Contribuição ao estudo da verificação da segurança das estruturas de concreto. São Paulo, 137 p. Tese (livre-docência) Escola Politécnica, Universidade de São Paulo. 
FUSCO, P.B. (1976). Fundamentos estatísticos da segurança das estruturas. São Paulo, EDUSP/McGraw-Hill.

FUSCO, P.B. (1993). Comentários sobre a normalização das ações e segurança nas estruturas. São Paulo, EPUSP. 59p. (BT/PEF/9312).

FUSCO, P.B. (1995). A calibração da segurança na nova norma de projeto de estruturas de madeira. São Paulo, EPUSP. 28p. (BT/PEF/9507).

GALAMBOS, T.V. (1990). Developments in modern steel design standarts. Journal of Construction Steel Research, v.17, n.1 e 2, p. 141-162.

GALAMBOS, T.V.; RAVINDRA, M.K. (1978). Properties of steel for use in LRFD. Journal of the Strctural Division, v.104, n.ST9, p. 1459-1468.

GALAMBOS, T.V.; ELLINGWOOD, B.R.; MACGREGOR, J.G.; CORNELL, C.A. (1982). Probability based load criteria: assessment of current design practice. Journal of the Structural Division, ASCE, v.108, n.ST5, p.959977, May.

GESCHWINDNER, L.F.;DISQUE, R.O.; BJORHOVDE, R. (1994). Load and resistance factor design of steel structures. New Jersey, Englewood Cliffs,Prentice Hall.

HASOFER, A.M. (1974). Reliability index and failure probability. Journal of Structural Mechanics, v.3, n.1, p.25-27.

HASOFER, A.M.; LIND, N. (1974). An exact and invariant first order reliability format. Journal of Engineering Mechanics, ASCE, v.100, n.EM1, p.111-121, February.

HEGER, F.J. (1993). Public safety: is it compromised by new LRFD design standarts? Journal of Structural Engineering, ASCE, v.119, n.4, p.12511264, April. 
HEGER, F.J. (1996). Calibration of current factors in LRFD for stell. Journal of Structural Engineering, ASCE, v.122, n.3, p.346-347, March.

INSTITUTO BRASILEIRO DA MADEIRA E DAS ESTRUTURAS DE MADEIRA. (1995). Projeto da nova norma brasileira NBR 7190 - Projeto de estruturas de madeira. São Paulo.

KIUREGHIEN, A.D. (1989). Measures of structural safety under imperfect states of knowledge. Journal of Structural Engineering, ASCE, v.115, n.5, p.1119-1140, May.

MALITE, M.; SÁLES, J.J.; GONÇALVES, R.M. (1993). Sistemas estruturais: segurança nas estruturas. São Carlos, Apostila/EESC-USP.

MELCHERS, R.E. (1989). Human error in structural design tasks. Journal of Structural Engineering, ASCE, v.115, n.7, p.1495-1807, July.

PORTUGAL. Conselho de Ministros. (1985). Regulamento de segurança e acções para estruturas de edifícios e pontes. Decreto-Lei n.235/83 de 31/05/85. Lisboa, Imprensa Nacional-Casa da Moeda, 114 p.

QUEIROZ, G. (1993). Elementos das estruturas de aço. 4a . edição. Belo Horizonte, editado pelo autor.

RAVINDRA, M.K.; GALAMBOS, T.V. (1978). Load and resistance factor design for steel. Journal of the Structural Division, ASCE, v.104, n.ST9, p.1337-1353, September.

ROSOWSKY, D.V.; HASSAN, A.F.; KUMAR, N.V.V.P. (1994). Calibration of current factors in LRFD for steel. Journal of the Structural Engineering, ASCE, v.120, n.9, p.2737-2746, September.

SALMON, C.G.; JOHNSON, J.E. (1990). Steel structures: design and behavior. $3^{\text {a }}$.edição. Harper \& Row. 
SHINOZUKA, M. (1983). Basic analysis of structural safety. Journal of the Structural Division, ASCE, v.109, n.3, p.721-740, March.

SILVA LEME, R.A. (1970). Curso de estatística: elementos. Ao livro técnico. Rio de Janeiro.

TAYLOR, J.C. (1994). A new approach?. The Structural Engineer, v.72, n.2, p.23-24.

WEN, Y.K. (1977). Statistical combination of extreme loads. Journal of the Structural Division, ASCE, v.103, n.ST5, p.1079-1095, May.

ZAGOTIS, D.L. (1978). Pontes e grandes estruturas - introdução ao projeto estrutural. São Paulo, Apostila/EPUSP, v.14. 